Illinois State University

ISU ReD: Research and eData

Theses and Dissertations

10-19-2017

\title{
The Growth Mindset School Community
}

Christina A. Hild

Illinois State University, hildc@mattoon.k12.il.us

Follow this and additional works at: https://ir.library.illinoisstate.edu/etd

Part of the Educational Administration and Supervision Commons

\section{Recommended Citation}

Hild, Christina A., "The Growth Mindset School Community" (2017). Theses and Dissertations. 828.

https://ir.library.illinoisstate.edu/etd/828

This Dissertation is brought to you for free and open access by ISU ReD: Research and eData. It has been accepted for inclusion in Theses and Dissertations by an authorized administrator of ISU ReD: Research and eData. For more information, please contact ISUReD@ilstu.edu. 


\title{
THE GROWTH MINDSET SCHOOL COMMUNITY
}

\author{
Christina A. Hild
}

\section{Pages}

Traditional school models perpetuate limited notions of ability. Established in systems designed to label and sort, educators must examine their beliefs about ability and the ways culture and power structures impact expectations and student achievement. By adopting a growth mindset lens and applying distributed leadership to systems within a school, educational leaders can enhance opportunities for all children. The Growth Mindset School Community is an organization committed to growth and reflective processes intended to monitor thinking and procedures impacting learning and growth. Teacher expectations, feedback, assessment, and grading practices, behavior management, special education, teacher evaluation, and leadership models are all systems that can encourage or limit. This text examines each component through a growth mindset frame and makes recommendations to current or aspiring educators.

KEYWORDS: growth mindset; distributed leadership; ability; leadership; school culture; expectations 


\title{
THE GROWTH MINDSET SCHOOL COMMUNITY
}

\author{
CHRISTINA A. HILD
}

A Dissertation Submitted in Partial

Fulfillment of the Requirements

for the Degree of

DOCTOR OF EDUCATION

Department of Educational Administration and Foundations

ILLINOIS STATE UNIVERSITY 
CC 2018 Christina A. Hild 


\title{
THE GROWTH MINDSET SCHOOL COMMUNITY
}

\author{
CHRISTINA A. HILD
}

COMMITTEE MEMBERS:

Dianne Renn, Chair

Beth Hatt

Guy Banicki

Larry Lilly 


\section{ACKNOWLEDGMENTS}

I first want to acknowledge my wonderful and loving husband, Shonn Hild, who believes in me and the important work of building capacity in others. He has cheered me on and encouraged my continued growth as an educator and person. I am lucky to have you. I also want to thank my children, Beckett and Harper, who are not only the lights of my life, but also the best things I will ever create. Thank you for sharing me with hundreds of other children, and for reminding me why this work matters. My parents set an example of educators who not only valued learning, but also service to others. I also think their books-as-allowance encouraged my love of reading. Thank you.

This work is a culmination of growth made possible through mentoring by many much wiser than me. The gift of time and talents given by each of my committee members was an incredible investment which has not only impacted my writing, but also molded me into who I am as an educator and person. Thank you, Dianne, Guy, Larry, and Beth. I want to offer a special thank you to Dr. Beth Hatt, whose incredible work on smartness and her suggestion to read Mindset (Dweck, 2006) connected many dots in my professional and personal lives. The practical and ongoing mentoring by Larry Lilly has helped solidify my thoughts, values, and actions as an administrator, and his coaching made growth in the school tangible and real. As

I've told you before, thank you doesn't seem like enough. Finally, Dianne, whose perseverance and attention to detail greatly improved my writing and expanded my thinking. I am very appreciative of your influence on my life.

Mentors I will likely never meet, but who made an indelible mark on my mind, include Jonathan Kozol, whose work makes me simultaneously cry and feel like I must act; Linda Darling-Hammond, whose thinking should be guiding educational policy everywhere; Angela 
Duckworth and Carol Dweck, who lit a match of possibility within my mind and our hallways; and Roald Dahl, who reminds me humor can be a powerful way to send an important message. Thank you to my teachers, who inspire me daily, and my students, who I love. You are the reason for all of this. May each of you grow in a school who believes in you and not only wants you to succeed, but will do whatever it takes to make it happen.

C.A.H. 


\section{CONTENTS}

Page

ACKNOWLEDGMENTS

$\begin{array}{ll}\text { CONTENTS } & \text { iii }\end{array}$

TABLES vii

FIGURES viii

CHAPTER I: INTRODUCTION 1

Let's Talk 1

What Kids Deserve $\quad 2$

Who am I? $\quad 4$

$\begin{array}{ll}\text { What Do I Believe? } & 6\end{array}$

$\begin{array}{ll}\text { Regarding Ability } & 8\end{array}$

Problem One: Equity 99

Problem Two: Label for Life 9

$\begin{array}{ll}\text { What is Mindset? } & 10\end{array}$

Regarding Leadership $\quad 13$

$\begin{array}{ll}\text { Adventures in Our School } & 15\end{array}$

Systemic Foundations: How was this Possible? 16

$\begin{array}{ll}\text { District-level contributions } & 17\end{array}$

$\begin{array}{ll}\text { Building-level contributions } & 22\end{array}$

$\begin{array}{ll}\text { Team-based contributions } & 24\end{array}$

$\begin{array}{ll}\text { Why We Need You } & 26\end{array}$

What You Can Expect from this Book 27 
Mindset and Grit: An Alternative

What is Mindset?

What is Grit?

Traditional Beliefs

Inequality, Perception, and Ability

Constructs of Class

The Danger of Deficit Thinking

Mindset: A Developing Alternative for Framing Ability

Teacher Expectations

Pygmalion, Galatea, and Golem

Galatea and the Self-Fulfilling Prophecy

What Great Teachers Do Differently

How Can Mindset Help Guide Expectations?

Classroom Culture and Peer Influence

Your Story: What Steps Can You Take to Grow in this Area?

Variance and Miscommunication

How Do I Earn an "A"? 
$\begin{array}{ll}\text { Fairness in Schools } & 93\end{array}$

The Case for Growth Mindset in Discipline $\quad 94$

What Do Effective Teachers and Schools Do? 96

Positive Behavior Supports and Interventions $\quad 98$

$\begin{array}{ll}\text { Restorative Practices } & 101\end{array}$

Growth-Oriented Behavior Management 103

$\begin{array}{ll}\text { When Behaviors Occur } & 109\end{array}$

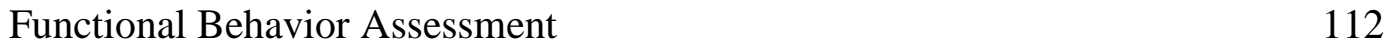

Growth-Oriented Behavioral Intervention Plan 113

$\begin{array}{ll}\text { Scenarios } & 115\end{array}$

Planning Checklist for Effective and Growth-Oriented Behavior Management 117

$\begin{array}{ll}\text { Other Steps for Success } & 117\end{array}$

CHAPTER VI: SPECIAL EDUCATION 119

My Kids, Your Kids, Our Kids 121

$\begin{array}{lr}\text { Special Education } & 122\end{array}$

$\begin{array}{ll}\text { Ability as Perception Rather than Biology } & 125\end{array}$

What Can You Do? 135

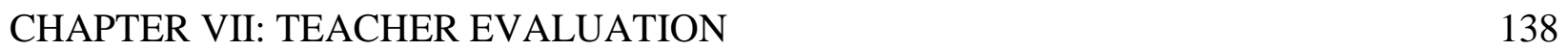

Principal's Role in Evaluation: Traditional vs. Growth-Oriented 143

Teacher's Role in Evaluation: Traditional vs. Growth-Oriented 145

$\begin{array}{ll}\text { Procedures and Practices } & 147\end{array}$

$\begin{array}{ll}\text { Systemic Shifts } & 147\end{array}$ 
$\begin{array}{ll}\text { Giving and Receiving Feedback } & 148\end{array}$

$\begin{array}{ll}\text { Giving Effective Feedback } & 149\end{array}$

$\begin{array}{ll}\text { Receiving Feedback Effectively } & 154\end{array}$

What Can You Do? 158

$\begin{array}{ll}\text { For Further Consideration } & 160\end{array}$

CHAPTER VIII: LEADERSHIP FOR A GROWTH-ORIENTED CULTURE 161

$\begin{array}{lr}\text { CHAPTER IX: CHRONOLOGY } & 180\end{array}$

$\begin{array}{ll}\text { CHAPTER X: CONCLUSION } & 187\end{array}$

$\begin{array}{ll}\text { End Note } & 188\end{array}$

$\begin{array}{lr}\text { REFERENCES } & 190\end{array}$

APPENDIX A: ASPIRING ADMINSTRATOR BELIEFS \& VALUES ASSESSMENT 204

APPENDIX B: ACADEMIC BEHAVIORS CHECKLIST 206

$\begin{array}{ll}\text { APPENDIX C: GROWTH NOTE } & 207\end{array}$

$\begin{array}{ll}\text { APPENDIX D: DISCIPLINE REFLECTION FORMS } & 208\end{array}$

APPENDIX E: RESTORATIVE QUESTIONS 212

APPENDIX F: GROWTH-ORIENTED FUNCTIONAL BEHAVIOR ASSESSMENT 214

$\begin{array}{ll}\text { APPENDIX G: FEEDBACK TRIGGER ANAYLSIS } & 215\end{array}$ 


\section{TABLES}

Table

Page

1. Growth-Mindset Traits 49

2. Decision Analysis Tool 67

3. Gradebook Comparison 79

4. Impact of Extra Credit $\quad 81$

5. Behavior Analysis Tool 113

6. Growth-Oriented Behavior Intervention Plan 115

7. Behavior Intervention Planning Practice 116

8. Tool for Improving Feedback 153

9. Feedback Trigger Analysis 157

10. Leadership Frames and Applications 174

11. Chronology of Shift 182 


\section{FIGURES}

Figure $\quad$ Page

$\begin{array}{ll}\text { 1. Components of the Shift } & 8\end{array}$

2. Social Construction of Ability 34

3. Cycle of Beliefs, Expectations, and Behaviors 60

4. Academic and Personal Growth Tool 108

5. Teacher and Administrator Continuum of Evaluation Approaches 142

6. Developing Targeted Feedback 160

7. Guiding Principles of Leadership for Change 167 


\section{CHAPTER I: INTRODUCTION}

\section{Let's Talk}

Hey! Grab some coffee and pull up a chair. I'm Christy - a principal and school leader who fell in love with those roles, even after many wide-eyed disclaimers of "I don't want to be a principal!" Yet, here I sit, loving every minute of my overly-scheduled days, from collaborative meetings each morning to ketchup and mustard refills at lunch; from administering medicine in the absence of a nurse to subbing in fourth grade when a teacher's own child is sick at home; from comforting teachers through loss to celebrating the births of their children; from boisterous hugs and high-fives to watching a teacher facilitate a light-bulb moment after months of perseverance and planning. You've been there, right? Don't you also love those quiet evenings when only you and the custodian are left in the building, where you can think about long-range planning, do some reading, or engage in some personal reflection for growth? It's also those quiet times you might worry about the teacher who is carrying a heavy burden, or make a call to a family you've been concerned about, or maybe drive by a student's home to make sure he isn't alone. If you're anything like me, it's also right about then you realize you didn't put anything in the crock pot and your own children are going to be hungry.

Is it any wonder we are tired? I mean, I'm exhausted from writing that. In a weird way, though, isn't it also invigorating? I mean, really - the reasons underpinning what we do are so important they energize us, don't they? (Even more so than that coffee you are drinking, which is likely now cold.)

Being a principal is the best. I unequivocally love my job, my school, and the people in it. I wholly believe in the power of education and the possibility of learning, and I believe that 
all kids deserve the best shot at it. Those passions are what drive me to become better, to learn more, teach more, and do more. Our kids deserve it, don't they?

Coincidentally, that exact thought is what led me to the principal's office. Not as a rowdy fifth grader, although fifth grade arguably could have led me there. I'm talking about choosing to take the path out of my beloved classroom where I helped students find their personal voices as writers and thinkers, into the principal's office. I mean, my students were my people, and I gave them everything I had. How could I have left the classroom? What's more, how could I enjoy any job more than that?

As a teacher, I had strong beliefs about what my students needed from me, from their school. All students deserve mentors who believe in their potential, coaches who offer targeted feedback for growth. In my classroom, I could offer that. But my beliefs extended beyond the walls of my classroom, and occasionally out of my sphere of influence. You see, I also believe all students deserve schools built upon the promise of potential, schools whose schedules, curricula, and practices unequivocally communicate "We believe you can grow, and we are going to help you do it!" My career path wasn't really out of the classroom, it was expanding the classroom. I wanted to help teachers help kids, and that's what a good principal does.

\section{What Kids Deserve}

Throughout this book, we will examine traditional practices that are in conflict with the beliefs I espoused. Schools have not always been havens for improvement, but more frequently systems of sorting - which kids are smart? Which kids are slow? Which kids are athletes? Which kids are math geniuses? This must change. Kids deserve better. This book will examine why, and apply the why to traditions within school buildings, from grading and assessment to discipline procedures through a growth mindset lens (Dweck, 2006). Throughout this book, 
school leaders will be challenged to use a distributed leadership model to truly transform a school community into one that creates a culture founded on growth.

With that in mind, this book is written for two specific purposes: First, to help educators frame their day-to-day, practical work through a growth mindset. This will be done in relation to expectations, assessment, behavior, special education and evaluation. Secondly, this book is intended to help school leaders harness the power of distributed leadership in order to create a growth mindset school learning community. In order for that to happen, three essentials must be in place:

1. The school community has to believe everyone has limitless potential to grow. That growth is dependent upon our beliefs, our passions, and the amount of focused work we put toward the growth (Dweck, 2006; Duckworth, 2016).

2. The school community has to be passionate about making growth real. The passion is what makes the work happen (Duckworth, 2016).

3. The school community has to provide appropriate coaching through focused feedback in order for work to be meaningful and productive (Hattie, 2011).

4. The school community must engage all of its leadership capacity through distribution, which creates opportunities for meaningful contributions from all stakeholders - teachers, families, students, and community partners.

As such, each chapter will provide an opportunity to reflect along the first three points. The fourth point references distributed leadership, which began with shared learning. That shared learning empowered and compelled all members of the school community to shift toward a growth-oriented culture. The lessons within each section are only effective when the work of change is distributed; therefore, the fourth point is a thread that pulls throughout the applications. 


\section{Who am I?}

Have you ever been to a workshop and wondered, "Yeah. When was the last time she taught a class like mine?" I think that's natural. We want to know that ideas aren't too pie-inthe-sky before we invest ourselves in them. The concepts in this book may seem pie-in-the-sky for some of your contexts, so I want to let you know a little about me and where this all began. I am the daughter of two teachers, so I can tell you I was literally raised in school. My mom, Janet, taught fifth and sixth graders in a little school in a little rural community, and by little, I mean there were about fifty kids per grade level. I have fond memories of helping her create bulletin boards in the upstairs of that old school, which was blazing hot in the summertime. I remember helping her set up science projects, especially the owl pellets her students would dissect each year. I can distinctly recall the effort she put into prepping for her students' learning, and then the care she took in providing them feedback on the work they turned into her. Many nights, Mom would sit upstairs with my sister and me, grading papers in our room until we fell asleep. Little did I know, those hours of grading would stretch on long after we drifted off to dreamland. She was doing more than grading. She was giving her students her time, her energy, her thoughts. She was loving them through her teaching.

My dad was a high school teacher for thirty years. He did a short stint in junior high, where he delighted students with an edible chalk trick, but his heart was with high schoolers, where he made an indelible mark on many of them. His course assignments were US History, Civics, and Service Learning, and through all, he taught young adults the importance of thinking, as well as the importance of serving in their communities. Dad's great sense of humor drew kids to him. There isn't a visit to my hometown today that doesn't include at least one mention of, “Oh, hey! Are you Mr. Kracht's daughter? He was my high school teacher. How’s he doing?” 
Let me tell you - I love this now, but as an awkward thirteen-year old, when all the cute high school boys were coming over to see him, I perpetually wanted to die. More than that, though, I remember he always had time to talk, to encourage, and yes, to tease.

My parents' dedication to their careers has been imprinted in my memory not as dedication to their role as a teacher, but rather as dedication to their students. They were serving them, helping them, loving them. I never once got the sense they were "going to work." I'm certainly lucky for that, because as a result, I have never felt like working at a school was working. There are times even today I tell my co-workers, "I can’t believe I get paid for this!" (Now, there are other days it feels like we should be paid double; am I right?) In all seriousness, I also never felt like I should be doing something else, so it wasn't a surprise, really, when I graduated from Eastern Illinois University with a degree in Elementary Education.

Thanks to an artsy study abroad semester, which I adamantly do not regret, I was one of those weird mid-year graduates. I figured I would sub for a semester and then find a job in the fall. Thankfully, things worked out differently, and I landed My Dream Job! I was hired to teach third graders in January, taking over for a teacher who may or may not have suffered a mental breakdown. From day one, I loved my students. I spent hours at school and even more hours thinking about school.

The next fall, my superintendent encouraged me to start a Master's program. I am so thankful for mentors like him, because at that point, I really wasn't thinking too far beyond the next set of student papers I needed to return. He could see a path for me more clearly than I could, and he introduced me to the Educational Leadership Program he completed through the University of Illinois, where my thinking about educational service to others began to broaden. 
As I began taking classes, people would ask me what I was studying. When I told them Educational Leadership, their natural next question was, "Do you want to be a principal?" Of course, I would quickly say, "No!," not wanting to betray my students to whom I was devoted and loyal. At that time, I also had a misperception of the role - or the potential of the role - of principal. My school improvement course changed all of that. Through that class, I learned about change and systems. I began to see that a principal was really someone who could impact many, many, many classrooms, and through those classrooms, many, many kids. The key seemed to be that the principal had to be willing to learn, and more importantly, had to have great relationships with the teachers. I started to see the school as a learning organization and started to think beyond the walls of my own classroom. My understanding of school leadership was growing.

Over the next eight years, I would teach students in grades three through eight, and each year, I would find a new way to learn about school leadership and the systems that supported organizational growth. I decided I wanted to be an administrator to impact more students, and ideally in a place whose concept of a school leader was focused on students, not tasks or management. Thankfully, in 2010, I was hired as an Assistant Principal in a district that has raised me as a school leader. I have been growing through serving students and teachers here ever since. I love it.

\section{What Do I Believe?}

Since that program back in 2003 , I have continued my learning, reading, and thinking. Paired with authentic classroom and school experiences, as well as molding by various educational experts and mentors, my beliefs about education, equity, service, and leadership have grown. For our school's journey, which is portrayed in this text, these beliefs will be framed by 
three major influencers: relationships, notions of ability, and shared leadership. These tenants, illustrated in Figure 1, created my leadership style and grounded our school's shared journey toward an important shift in our school culture, which is what this text is about. It is important to note, however, that while this text will specifically discuss beliefs about ability and shared leadership, the thread of relationships will implicitly run throughout. I firmly believe nothing lasting can be accomplished without the foundation of authentic, caring relationships, but this isn't a text specifically designed to teach you how to build relationships. You will find examples of how we strengthened our school by strengthening relationships. You will read how we did that through discussions about ability and through distribution of leadership, but this isn't a stepby-step guide on how to build relationships with your staff. There are many other excellent sources of learning focused solely on that. This story is about how relationships facilitated a cultural change in our school. The change was a result of distributed leadership and shared experiences, which this book will discuss. Those shared experiences hinged primarily on creating a set of shared beliefs regarding ability; the resulting systemic changes could not have been executed without the relationships required for trusting, expanded leadership. 
Figure 1. Components of the Shift

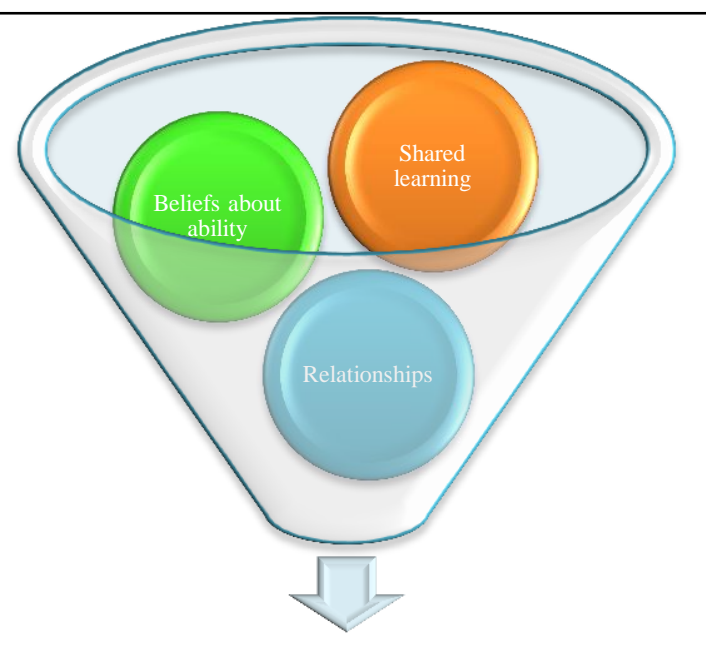

Distributed Growth Leadership

\section{Regarding Ability}

How do you define ability? Do you believe we are born with a set amount of talent or intelligence? Do you believe our talents and intelligence can be developed to a level dependent upon our will? If you are like most of the teachers with whom I talk, you are probably somewhere in the middle, with a lot of qualifiers thrown in to explain your position. This book will mention mindset a lot, and that term is really just a label for your answers to the previous questions. Growth mindset describes the belief that individuals can develop talents and intelligence and fixed mindset describes just that - a more "fixed" or set amount of talents and intelligence, based largely on factors beyond our control, like genetics (Dweck, 2006).

When it comes to ability, I believe many of us are limited by social constructions. By that, I mean society has identified skills that are of value, and we sort people based on their present levels of mastery related to that skill. In schools, we have traditionally sorted or labeled people based on things like reading level, or math aptitude, compliant behavior, or conforming to 
social norms. There are several problems with this approach, and those problems become especially sticky when we are talking about children. Specifically, we will address issues of equity and labels for life.

\section{Problem One: Equity}

Who determined what skills were important? How does that balance of power affect various groups of people? Let's use language as an example. Many IQ tests are language-based. If two children of varying linguistic backgrounds take the same IQ test, would we compare their scores equally? Would those scores result in one child being labeled more intelligent than the other? Your initial reaction may be an emphatic "no", but this is something that happens daily. Now broaden the context of linguistic background beyond speaking different languages. Consider exposure to language. Consider emotional control over language. Are children of varying capacities because of those differences? I believe no, but a standardized test built upon language would send the message yes. I think they are at two different starting lines, which leads to the second systemic issue of schools, a label for life.

\section{Problem Two: Label for Life}

The second major issue with notions of ability in schools today is a reluctance to view achievement information as a present level. Instead, educators tend to use it as a predictor or sorter. For example, IQ scores are frequently used in schools, but instead of being offered as information from which to grow, more often the IQ score provides rationale for a special education label. I have seen this throughout my career. In fact, I recently sat in on an evaluation meeting for a student in another district. During that meeting, the psychologist who conducted the cognitive testing portion reported that the student's full scale IQ was 55. The reaction was collective head-nodding, almost like an acceptance of life with inferior skills. This kid was 
eight! Yet it was as though the one test, that one score, predicted the child's future. There is so much wrong with this picture. At a surface level, the IQ test was not designed to determine fate; in fact, it was designed to describe the present level of performance of the subject (Binet, 1916). Yet schools don't typically use IQ tests that way, do they? I believe a traditional desire to sort children into homogenous groups perpetuated the school's need to have a sorting mechanism. Quantifiable scores make that process much easier, and as a result, we have children being sorted into programs based on a number that wasn't intended to become fate, but ultimately does.

You see, even if we approach the IQ as an indicator of present performance only, when we place children in classrooms where expectations are low and peer models have similar present levels, we are limiting their growth. In Keeping Track, Jeannie Oakes (1985) clearly and unequivocally illustrated how tracking, or grouping students by "ability," results in inequity related to opportunities to learn and actually perpetuates the gap between "high" and "low" achieving students. Sadly, her work was initially published in 1985, yet these practices persist. Why? When we know something is not good for students, why do we continue to implement such a practice? This type of question is exactly what compelled me to become a school leader. If we intend to serve all students, then a new mental model is needed. This book provides an option for a new mental model: The Growth Mindset School Community. Based initially on a book by Carol Dweck (2006) called Mindset, and paired with practical application over a fouryear period in an elementary school, this approach lends itself to more equitable, growth-oriented approach to framing ability.

\section{What is Mindset?}

Psychologist Carol Dweck and a team of researchers at Stanford have been developing a theory of mind related to the ways in which some people thrive in challenges while others avoid 
them. Her curiosity was piqued by the question of why some see failure as an opportunity to learn, while others see failure as a defining moment. Grouping the patterns of choices and responses into two categories of thinking created the terms growth mindset and fixed mindset. Her 2006 book, Mindset, presents a compelling theory sure to begin a journey of introspection for anyone who reads it.

As a new principal, I was fortunate to have a professor suggest the text. Dr. Beth Hatt, whose own research (Hatt, 2008, 2011) looks at notions of smartness in classrooms, thought it might align with some of the questions I was voicing about practices. I wondered why we grouped students the way we did in school. I was curious about the efficacy of special education systems. I was also interested in how some students overcame challenges while others seemed to accept a destiny aligned with what grown-ups believed about them. The most interesting thing to me at the time, however, was how our espoused beliefs, or what we said mattered most to us, did not always match up with what we did. This was one of those nagging thoughts that bugged me in almost every context, like a mosquito that wouldn't stop buzzing near my ear. In IEP meetings, during teacher evaluation conversations, while in the lounge... I was blatantly faced with mental models related to ability and the use of labels that contradicted my beliefs. At Hatt's recommendation, I read Dweck's book in 2014, and it created a proverbial lightbulb moment.

Dweck proposes that thinking can be fixed or growth-oriented. As you would imagine, a fixed mindset adheres to the belief that people are given a certain amount of ability. This ability, whether cognitive, athletic, artistic, social-emotional, or really any skill set, is genetic. The most anyone can do, according to fixed-mindset thinkers, is fulfill their potential. Conversely, growth-minded thinkers see ability as a starting point. These people approach life with the belief 
they can improve any aspect of their being with reflection, plans for improvement, and intentional action.

This theory illuminated the dichotomy I had been feeling, both as a teacher and administrator. During my years as a classroom teacher, the schools I served in espoused growthoriented thinking with mission statements like "All students can learn" or "We believe in the growth of all children." Yet many relied heavily on tests and labels to categorize students, set schedules, and form groups that tended to remain fixed. Often, those groups were stagnant. In short, our espoused academic beliefs were growth-oriented, but our traditional, factory-model academic practices had a fixed-orientation.

This realization led me to look at other aspects of our educational practice. Schools are institutions of much more than academics. Through popular programs that teach socialemotional skills, regulation, and socially-accepted behavioral norms, we also form beliefs about students related to their behaviors. I wondered if the same concepts held true about children's ability to grow and change socially. What about behaviorally? The same potential problems arise. I began to see our collective mindset as the common thread connecting our ability to help children grow.

From there, my thinking broadened to the lens of school administrator. I reflected on my thoughts and various conversations I had been privy to related to teachers. I believe my role is an instructional coach. I want to support teacher growth and promote the ongoing development of teacher leaders. How did this reconcile with my additional job of evaluating, or judging, teacher performance? My beliefs about my role were growth-oriented, as I would contend are those of many principals, but the practical, traditional model of the school administrator has a 
fixed-mindset flavor. Through evaluation, we label teachers. You are satisfactory. You are excellent. It's easy to see the conflict; not as easy to reconcile it.

So I read Mindset. I reread Mindset, which led me to other research about labels, notions of ability, grit, self-fulfilling prophecies, and the Pygmalion effect. After about two years' worth of reading, reflecting, journaling, discussing, and analyzing practices, I identified the areas most responsible for the conflict between our espoused beliefs about ability and our actual practices limiting growth. Areas like special education and gifted education, the labeling associated with discipline and traditional disciplinary practices, and teacher evaluation. Further, our systems perpetuated some of these categorical practices. Our visual messaging throughout the school, our schedules and service delivery models, and our interactions with families all pointed toward a fixed belief system. Ironically, rather than feeling better at narrowing my thinking and targeting these areas, I now had a very clear sense of hypocrisy. I knew we said all kids could learn and grow, so why didn't our actions match? Thinking about our practices that could be stifling student and teacher growth made me itchy. What could we do about it? How on Earth could we possibly tackle so much? Those questions led to the work featured in this book.

\section{Regarding Leadership}

I remember my elementary school principal, but vaguely. What I can recall was a busy woman who wore skirts and sensible shoes and rarely smiled. I also remember a school assembly where we all got called into the gymnasium/cafeteria and it was announced she was now a Dr. instead of a Mrs. As everyone clapped, I vaguely wondered if now she could fix my friend's arm which she had broken on the monkey bars. I don't remember seeing Dr. Principal again. This recollection is exactly why I responded with an emphatic "No!" anytime someone asked me if I wanted to be a principal. I wanted to connect with kids and help them, not seem 
busy and mad. Basically, I didn't see the role of school principal for all it could be; I didn't see her as a school leader.

There are a million and one books written on school leadership. There are probably an equal amount of terms to describe types of school leaders - the school manager, instructional leader, coach, facilitator, constructivist leader, adaptive leader, culturally responsive leader, transformational leader, chaos leader, servant leader - if you are reading this book, you have likely read or at least heard of some of these terms. My goal is not to teach you different leadership types or even to tout one as the best. Clearly, that has been done comprehensively and effectively by people who have spent their entire lives studying just that. Instead, I hope this story shows you a practical application of distributed and cultural leadership, because like I said at the beginning, I'm a regular school leader, just like you. I have read a lot, just like you, and I have tried a lot, just like you. Some of it has worked well, and some of it has bombed terrifically. This story is about applying our school's learning; it is written to share our experience and offer one path, not the only path. It is written simply as an example. I'm sure you will learn from the good things we did, and I'm equally sure you can learn from the portions of our work that weren't as successful. The lessons have to inform the leader. The leader guides the learning and distributes shared experiences so lasting change can occur for the benefit of all kids.

When I left my classroom in the hopes to reach more students as an administrator, I was taking a risk. Now, I am taking another risk in sharing our journey with you. I hope you can use our story to help your school grow, and as a result, your teachers and students will benefit. Certainly, you will do it your own way, but isn't it nice to have a conversation with someone else whose been there? That's what this book is for. I love learning from my colleagues, and I hope 
you enjoy learning from our team's adventure in distributed growth leadership. (Hey, why not add one more school leadership term to the mix?)

\section{Adventures in Our School}

In 2015, a team of staff members and I formed a professional development committee. I wanted to replicate my experience reading Mindset with a team of leaders in our school building, and my hope was that the dialogue between us would be rich as we read Mindset together. I further believed that the ideas of many would be better than the ideas of individuals, so I wanted to create a situation that allowed us to talk in an ongoing way. Our school's existing committee structure was designed for monthly meetings and bound by contract language that limited committee time, and to be honest, I knew that the thirty minutes between arrival and students entering classrooms would not be sufficient for the lofty goals I had in mind. It's barely enough to make copies for the day.

As a result, I wrote a grant that allowed me to offer a $\$ 100$ stipend and $\$ 100$ classroom allotment to team members for their participation on a private online discussion board. All of the staff members were on Facebook, and I figured if we created a group on that existing platform, their interaction with the discussion questions and with each other could occur whenever they squeezed in a few social media minutes. While I don't think Facebook is the only way something like this could exist, I believe part of why it worked so well for us is because it was already part of our team members' daily routines. Some checked Facebook while waiting for their son or daughter's practice to end. Others scrolled at 8:30 p.m., while lying in bed before falling asleep. Because the notifications popped up when they logged in, it wasn't something extra to do, but something embedded in what they already did. We soon found that everyone was contributing as it best fit their schedule, and the site was an ongoing dialogue between leaders 
and learners, and everyone was both. Facebook also easily lent itself to sharing related material; soon, members were adding TED Talks, links to EdWeek articles, and YouTube lectures, all related to research on mindset and notions of ability. We were learning together, and as a result, we were growing together, both in relational trust and understanding of how to better serve students.

In addition to our ongoing online conversation, we met in person once per month to discuss classroom and schoolwide applications of our learning., In this way, the thirty minute face-to-face meeting was less of the personal discovery and shared learning that had to occur, and more brainstorming applications to make our learning matter for our students. Once we finished reading and discussing Mindset, we moved on to other texts, articles, research studies. Our learning continued, as you will find out in this text, and it was prerequisite to the cultural shift that happened as a natural response to our shared discoveries.

\section{Systemic Foundations: How was this Possible?}

Sometimes I read books and think, This would be amazing for our kids! Or, our staff would love this! I have also thought, This would be so good for our community! This book is intended to make you feel all three, and I really think it will. But I would be remiss in failing to acknowledge the other question I occasionally ask when reading about other schools' experiences. How on Earth could we make this happen? It goes without saying (but I will say it anyway), it would be nearly impossible to identically replicate programs other schools or universities have implemented, but when your culture and climate closely match those described in the texts, it is closer to possible. Even in cases where our culture and climate seems miles away from the featured organization's, there are often components we can incorporate similarly, and there are certainly ideas we can use to jumpstart our own initiatives. In order to help you 
frame your thinking as you work through this text, I want to describe the systemic foundations that allowed us to find success in establishing a growth mindset school community.

\section{District-level contributions}

Can I just start by saying: I am one lucky lady? I happened to be hired into a district whose purpose, values, and beliefs closely matched mine. Truly, that good fortune cut out a lot of the drudgery many school administrators feel. My district proclaims "Helping students learn and grow" as their mission. Dream motto, right? Even better is that it is reality. I can attest to the fact that the work within the district is well-aligned to that vision. Certainly, we deal with nuts and bolts of budgets, personnel, and policies, but in each context, we are collectively committed to considering what decisions will help kids learn and grow. We discuss doing what is best for students, even if it isn't what's easiest or most convenient for adults. In many districts, similar concepts are plastered on websites, across gymnasium walls, and framed in offices, but practices may not fully align. After all, it is easy to write mottos like "Helping students learn and grow", but it is much harder to ensure systemic integrity. So, what's the difference? How do you maintain visions that match reality? What makes our district different from other places? To prevent those important words from becoming simple bumper sticker slogans, their meaning must be maintained by the people who make up the organizations. That type of maintenance happens most effectively when there is sustained, focused leadership. We have been fortunate to have that. Alignment becomes easier still when leadership devises hiring protocol aligned to the vision. Who are we bringing into the organization? Do their beliefs match this vision? We have that, too.

I say I am lucky, and I am. But ten years in, I have a feeling there was more than simple luck involved in my hiring. Our district looks for individuals whose beliefs match their motto. 
Simple, but brilliant. What better way to perpetuate your vision than to find people who will work to help you achieve it?

Often, when I talk with aspiring administrators enrolled in leadership courses, I encourage them not to look for a job. Now, let me say that again, slightly differently so you don't think I'm crazy and stop reading. I want aspiring leaders to find a job, but I encourage them not to look for A job, but to look for the RIGHT job. Early in my career, I had a great mentor encourage me to pursue a degree in Educational Administration, so I was relatively young when I finished. I had my degree for five years before I got the itch to begin applying for administrative positions. Like many people, and even in accordance with some advice I received, I just wanted to get A job, so I applied for the first one close enough to our home that it would work for our family. During the interview, I knew it wasn't a good fit. The panel asked me questions that made me have to restrain my facial expressions. (Cheap advice: If you ever feel like you are going to laugh or ask "Are you serious?" during an interview, it probably is not going to be a good fit.) But I was young, I really wanted to be an administrator, I happen to be occasionally stubborn, and this was an opportunity to not only gain experience, but bring my ideas and thoughts to the district. After all, I believe experience can be the best teacher! All of these thoughts stayed with me for a week after the interview, a reassuring mantra anytime I started to incredulously recall the questions I was asked.

I didn't get the job.

Naively, but also naturally, I was disappointed. But in case I needed more evidence that it wouldn't have been a great fit, I got some. After receiving a letter indicating I had not received the position, I called the Superintendent and asked what I could learn from the interview. Was there something I could learn or a specific area I could improve so I could be 
considered for the next opportunity that came my way? Her response: No, thank you, dear. Huh? Truth be told, I had already learned so much, but it would take time and reflection to see those lessons clearly.

Over ten years later, I can see those lessons now, and I love sharing this experience with aspiring administrators for those reasons. Number one, my values, purpose, and beliefs did not match the district's, and I now know that is important to me. Even though their espoused vision and mission statements aligned with mine, their actual beliefs, evidenced by practice, did not match. I knew it from the interview. I could tell from the questions. And I certainly knew it when I asked for feedback to help me grow and got none. It was not a place I would have been professionally satisfied, especially as a new administrator. To others, that may not be important. To me, I now know myself well enough to know it would have been. I may not have been able to make an impact because it wasn't a match. And guess what? That's okay! That's why sites like match.com exist! We just need something for school administrators. (Next million dollar idea!) In all seriousness, it takes all kinds of people and personalities to make the world go 'round; however, had I gotten that job, I probably would have felt like I was banging my head against a wall. That's why I advise aspiring administrators to give themselves permission to interview the district. If you find what you believe about education and your purpose for being an educator does not match the vision and mission of the district leadership, allow yourself to consider it may not be a good fit for either of you. In this instance, that was true. Sometimes the best news is that you did not get the job. In this instance, that was also true.

So that's why I tell you it may be less important to get a job than it is to get the right job. Depending on your motivation for becoming a school leader, this advice may hold more or less truth. If your purpose is to move up the ladder, increase your pay, and just get experience, it's 
fair to say that advice may not matter much, and please disregard. If, however, like me, your purpose in being a school leader is to make improvements, help more people learn and grow, and do the same alongside them, this is important. Find the right place. Find the right job. How you define "right job" may not be the same for you as it was for me. For me, it was a place where who I am matches who the district is. For you, maybe it's the opposite. Maybe you love a challenge and want to revolutionize a place, in which case, you may be looking for a district that is opposite from you. If that's you, if you can convince the district they need that, and if you have the tenacity to shake it up, go for it! Here's the big takeaway: Whatever it is that gives your professional life meaning and purpose, be sure you can fulfill that in the place you are seeking a job. Otherwise, it will just be a job... and maybe not a long-lasting one. You can use the tool in Appendix A to uncover your personal route to leadership with an Aspiring Administrator Beliefs \& Values Assessment.

You might be thinking, what was all that bragging about luck? So far, it sounds like rejection! You would be right, but that rejection is what led to my luck. Fast forward a couple of years, and an opening occurred in my current district. I hadn't applied for any other jobs since The Great Mismatch, but when I researched the district, it seemed like a student-focused, supportive place to learn and grow. I applied. Talk about a different interview experience. The questions were more like conversation starters, and the feeling was of old friends, even though I had never met any of the people in the room. More importantly, I left feeling and thinking, "I really showed them who I am, and hopefully they see who I can become. Either I will be a fit, or I won't." What a good feeling! Authenticity in an interview means if you are offered the position, you can be confident that who you are is who they want. I had seen that proven true the last time I was authentic in the interview, but this time, I felt more aligned. There is nothing 
more affirming or freeing than being offered a position aligned to your purpose and mission! And that's just what happened.

Here is why the district-level match is important to the story you are reading. Because I was in a place whose vision matched mine, I had the luxury and freedom to explore growth mindset and apply it to our building-level work. If I had district administration who was concerned only with budget lines or test scores, talking with my superintendent about growth mindset may have felt a little like talking with him about the tooth fairy. In my case, that could not be further from the truth. You can imagine that a district whose tenants are student learning and growth would be led by a superintendent whose beliefs, mission, and purpose were also learning and growth. You would be right.

My superintendent is the guru of growth. He doesn’t go around quoting Dweck (2006) or Duckworth (2016), but he could probably tell you about the greatest baseball coaches of all time. He is the ultimate coach, and because of that, Dweck's and Duckworth's work resonated. Perhaps even more importantly, he believes in the people he hires, and if one of his crazy principals tells him growth mindset can impact students learning and growth, he will listen, ask good questions, offer some guidance, and then get out of the way. Having a superintendent who can see that the big picture of relationships and growth are what most impact the details has been instrumental in this work. Now, please don't misunderstand - he is also interested in the details of student growth and budget-focused and detail-oriented. In fact, he guided our district through one of the largest financial crisis known to public education, including a two-year period of no state budget, and he kept us in the black while he did it. There are probably many superintendents who could do that, but there are not many who could also preserve relationships and a laser-like focus on what is best for students throughout. He realizes that the details of 
budgets and numbers are meaningless if we aren't making choices that will help children learn and grow, because that is the reason we have budgets and tests to begin with! If we get the big picture of our mission and vision right, then the details will fall in line with them. His leadership and understanding of the higher purpose of educators is really why this book is possible; he allows people to lead in alignment with the district's mission and vision. It's important for you to know that support for this type of work was at the very top level of our organization's leadership. My superintendent allowed me to lead. (If you are a superintendent, there may be a lesson in there somewhere for you.)

\section{Building-level contributions}

My superintendent wasn't alone in that endeavor. Have I mentioned I'm pretty lucky? I mean, truly, it's kind of amazing I haven't won the lottery. Because if I was lucky to get a job in a district with the right climate and culture for this type of work, I was doubly lucky to be hired as the Principal of my specific school. Our school is a beautiful facility that opened in 2003. On average, about 760 students in Kindergarten through fifth grade attend annually, divided into six sections of Kindergarten and first grades, and five sections in second through fifth. We have support staff in the way of a part-time psychologist, part-time social worker, two Speech and Language Pathologists, and five special education teachers.

Now there are some things you just can't "big picture" around. If your building is chaotic, it will not do to ignore that in order to focus on student growth. Just as children have foundational needs for appropriate development, I think there are foundational needs for building development. If you don't have a master schedule, it probably is not in your best interest to spend all of your time encouraging growth. Now, I do believe that a focused study of growth and grit can occur simultaneous to other pressing culture and climate issues. Often, I talk to 
principals whose buildings are heavily focused on student discipline. I fully encourage a focused study of growth mindset through the development or revision of student behavior supports and strategies. As you will see in subsequent chapters, this work should not be isolated to academics. In fact, I hope you will agree that expanding notions of ability in schools does not pertain just to academics, but to the whole child, and that includes behavior. Further, I hope you will begin to see that this expansion of how we view ability does not pertain only to students, either. How we think about ability of students is of utmost importance to schooling because they are our purpose. But expanding our ideas about ability has implications for how we view our families, teachers, and leaders, too. Because of that interconnectedness, I believe this work can be very effective when there are topical issues like student discipline, family involvement, or teacher evaluation that can be used as a vehicle to discuss notions of ability.

Let me tell you - I hit the jackpot. My dear friend and Assistant Principal would have been one of the best principals I could ever write about, but she decided to put in a letter for retirement rather than apply, which meant I got to work alongside her and learn from her during her last five years. All in all, the conditions were right for our building to grow, and I was at the right place at the right time.

I'm going to pause right there to clearly state: We are not perfect. Our building is growing and learning, even as I write this. We have issues like every other school. February may be the shortest month, but it's still the longest, and our third quarter still grinds the same way I'm guessing it does in your school. We never have enough time, we go home worried about kids and families, we obsess over our effectiveness, and sometimes we are just plain tired. That said, when it comes to the big stuff, we are on the same page, and we will talk more about that in the second section of the book. 


\section{Team-based contributions}

Growing up, I loved watching John Wayne movies. The Duke was everything - strong, smart, and he always had a great closing line. We watched El Dorado on repeat (although it was VHS, so we had to Be Kind: Rewind!), and when he died in The Alamo, I cried for hours. It was The Alamo. I should have known. Although John Wayne is still a favorite when it comes to movies, that style of leadership was never really my thing. I don't really believe in the school leader who is everything - sure, it's helpful to be strong, smart, and always having a closing line, but school isn't like a wonderfully choreographed Western, for many obvious reasons, but in this case, mostly because there is never one singular hero. The real leaders are those who can bring people together to accomplish things greater than what they could have done alone. I believe the in the power of the teacher. I believe that power is exponentially multiplied when they work together, so when it comes to leadership, I think John Wayne types are best in the movies. In schools, no one has to save the day all alone.

With that background, you can imagine my initial response to reading Mindset. I was moved, and I knew we needed to address notions of ability and how we view students. At the same time, I knew I couldn't charge in and lay out a plan, because I understood how the experience of personal reflection and application helped me deeply understand the concept Dweck was trying to explain through her theory. Although a PowerPoint Presentation or set of handouts would have been easier, I knew that without reading the book and replicating that experience, teachers might only gain a superficial understanding and we could end up with the bumper sticker version of Dweck's theory, and I would be a sad excuse for a John Wayne, trying to do it all on my own. I needed teachers to not only understand the theory's significance, but 
personally reflect and fully apply it to their lives in order for there to be any impact on students, which meant that we would need an effective approach to professional learning.

Because I have seen and been a part of great things happening when teachers work and learn together, I wanted to create a situation where that could occur. With that in mind, the first step was to form a team of educators who were open to the learning process. Through a brief explanation of the book study concept, I asked for volunteers who would be interested in pursuing topics relevant to our practice through reading, discussion, and application. From those individuals, we formed a team and called it the professional development team.

So far, so good, right? But do you know any teachers who have time for one more thing? I certainly don't. All of our teachers are busy. During the school day, we want them in class with their students. After the school day, we want them to live a balanced life with their friends, family members, and hobbies. At the time of this project's infancy, we were entering the summer months, which is typically a time of vacation and renewal for most of our teaching staff. Still, we really wanted to have this shared experience and learning under our belts prior to beginning our work with kids in the fall. So how could we balance these demands with the need to get our learning process going?

As I previously mentioned, we decided to harness the power of social media. This was the novel approach to professional learning; it was leveraging social media to construct meaning socially. Even better, every educator on our team already had a personal Facebook account. Often times, scrolling through newsfeeds was a quick respite between making dinner, reading books with the kids, training for $5 \mathrm{Ks}$, lesson planning, or grading. For many, it was a selfproclaimed winding down strategy before they went to bed, or a ritual before starting their day. The bottom line was that in Facebook existed a platform woven into the fabric of everyone's 
current lives, situated within their uniquely demanding schedules. Everyone agreed this might actually work. It did.

Before we left for the four corners of the earth for summer vacations that first year, we met with the team and explained the goal for the summer, which was to read, discuss, and create a shared understanding of Mindset through online collaboration. Intentionally, there were no other materials or explanations offered, because we were afraid we would plant ideas before the

reading, and that personal discovery was the key to our shared experience. Team members were given a reading schedule, a copy of the book, and we created some shared expectations for participation. Because this was on their time, we offered $\$ 100$ in classroom materials upon successfully meeting the group's expectations.

That was it. The setup was simple. Off we went, and it continued with three separate teams as of this writing. As a result... Well, you will see the results framed in various contexts throughout this book, but I will tell you, the process has been powerful.

\section{Why We Need You}

Just because I've shown you my four-leaf clover, my horseshoe, and my rabbit's foot doesn't mean you should be able to list reasons why you can't do this. If you don't have a superintendent like mine or a predecessor like mine, all that means is you don't work in our district. (Shameless plug: We are always looking for good people!) If you don't have a beautiful new school building, all that means is you are like the majority of schools in America. If you don't have a staff that has been hired along the principles of your mission and vision, consider yourself fortunate to have a hand in future hiring! The things that make us different do not exclude you from this work; those facts are just part of our journey, relevant only for context. Yes, the specific people, the specific place, and their specific contributions facilitated my 
introduction of growth mindset, but that doesn't mean in their absence it would have been impossible to create a Growth Mindset School Community. I told you I was stubborn, so you know I would have tried it anyway!

Here's what I'm trying to say: Please don't read this contextual framework and think "My school is so different from hers! I can never make this happen." That type of reaction would not be very growth-oriented, and more importantly - and please read this carefully - If you are in a place without these door-openers, it means it is even more imperative that you find a way to do this work, because all children deserve a leader and school community committed to their growth. Maybe that person is you. Maybe you are your district's future. Maybe your community's new chapter will begin with you. Maybe you will be the leader someone else writes about. Creating a Growth Mindset School Community can start with you, and you're here already. So, let's get going. Look for what you can learn from our journey that could inspire the next generation of school leaders.

\section{What You Can Expect from this Book}

This book is written in four parts: The Opening, The Classroom-Level Contributions, System-Level Contributions, and Resources. The book is written so you can select a certain chapter your team is most interested in tackling, or you can read it cover-to-cover, using the questions for team discussion and application as a guide for growth.

This chapter and the next form Part I, intended to develop an understanding of the research underpinning this work as well as the systems and steps we took to make change. In Part II of this book, you will read about the ways we learned mindset and notions of ability are manifested in the school. Specifically, there is a chapter on each of the following contexts where mindset plays an important role in schools. These are labeled in terms of traditional school 
terminology, and they are: 1) teacher beliefs, 2) feedback and assessment, and 3) behavior management. In Part III, you will read about school-wide systems that reflect a growth minded school community's mindsets as procedures and practices, again labeled traditionally, including: 1) special education, 2) teacher evaluation, and 3) leadership. The leadership chapter will focus specifically on creating a shared culture, on ways to distribute your leadership.

In my conversations with colleagues, a recurrent theme is that school administrators and other educational leaders can get easily lost in the sea of change. There are so many initiatives! Is it ESEA or ESSA? Is it PARCC or SAT? Are we counting student growth in teacher evaluations or not? It's no wonder many of us don't last beyond five years. Even if we do, it is really easy to lose sight of what matters most, simply by the distraction compliancy demands place upon us. This is exactly why school leadership cannot exist in just one person. No one can do it all. No one should do it all. Beliefs about student ability and relationships will always matter in schools, and they should matter to everyone, not just The Principal. As a result, the leadership chapter of this book was written to help you create a shared culture to distribute the important work of staying focused on a shared set of beliefs. This chapter is written so no matter if we are NCLBing or ESSAing, our schools - and all the people in them - are foundationally focused on creating a culture designed for all students to succeed.

Finally, Part IV is dedicated to resources, including tools, chronology, and an end note. Here you will find very practical tools for teachers, teams, or leaders to implement or modify. There are also suggestions for further reading and exploration, dependent upon the direction your learning takes you. With that in mind, I want to caution the reader that while there are many practical, immediate take-aways and applicable concepts, this text is not Growth Mindset in a Box. By its very definition, that cannot exist. The growth (pun intended) is in the thinking, both 
for you as an individual and for your school as a team. While it is an investment of time and energy, the discussion and subsequent growth (sorry) will be richly worth it to your students, their families, and your staff.

Take a moment to reflect on your purpose for reading this text. Your purpose will help you know where to begin. Are you personally reflecting? Leading a team? Developing your own vision for a future leadership role? Understanding your purpose for reading will help you determine how to read the text, either from beginning to end, or with certain chapters to drive important discussions. Regardless of your purpose, take time to think, discuss, and apply as you read. The learning happens in the thinking and it is multiplied when discussed with others. Your Growth Mindset School Community awaits, so here we grow! 


\section{CHAPTER II: FOUNDATIONS FOR EXPANDING NOTIONS OF ABILITY}

This book is about expanding notions of ability within schools. Anchored by theories of Mindset by Carol Dweck (2006) and Grit by Angela Duckworth (2016), and underlined by research about notions of ability presented in this chapter, this text asks educators to carefully consider the view they adopt for themselves and their students. Once educators can clearly articulate their view, they can begin to develop a broadened view of ability within schools. Implications for educators' beliefs about student ability, as well as beliefs about their own abilities, can have dramatic effects on student achievement and equity of opportunity.

There is a lot of research in the field to support the argument that our notions of ability are far too limiting (Oakes, 1985; McDermott, 2007; Hatt, 2011). There is a lot of research suggesting our concepts of ability are culturally-constructed and misinformed (Carlone et al, 2011; Rowe \& O'Brien, 2002; LaReau, 2006). There are also a lot of reasons why that should matter to school leaders. This chapter's purpose is to help reveal why. In fact, the information presented in this chapter is what formed the foundation for the practical application and functional suggestions that most likely encouraged you to buy the book. Now, while I love rolling up my sleeves and getting my hands dirty as much as the next passionate school leader, it is imperative you take the time to develop at least a cursory understanding of the research supporting a broadened view of ability. If you are going to encourage your school community to expand their notions of ability, you need to understand why. If you are going to lead the horses to water, please be sure you have something for them to drink! People will ask you why this work matters. Even better, people might also become very interested in one of the topics in the following chapters, and this brief dip into what's out there can fuel their passion for learning more. So, it's important. You don't have to be an expert on every research study related to 
ability, but consider this the Cliff Notes version. You can utilize the reference section at the back of the book to follow leads on the specific topics that interest or apply to you most.

It is time to expand our notions about how we think of kids' abilities in schools, because our ideas and beliefs about ability matter. We know this, because as a profession, while we have learned ability is not absolute, our practices treat students as if it were. Here, we will examine the current notion of ability as a cultural construction (McDermott, 2006; Hatt, 2011), influenced by ideas about class (LaReau, 2003; Hart \& Risley, 1995) and race (Artiles, 2011; Harry \& Klingner, 2014; Hatt, 2016). Intelligence testing and ideas of smartness further impact our beliefs about ability (Gardner, 2006; Sternberg, 2007). Notions of ability are racialized, and they can be greatly impacted through deficit thinking (Artiles, 2011; Garcia \& Guerra, 2004; Nieto, 1996; Valencia, 2010). A solid understanding of these cultural constructions helps us understand why our ideas are flawed. These flawed ideas matter, because they form our expectations. Our expectations create realities for students, and those realities impact their future. Due to that significance, we cannot afford for our ideology to be flawed.

? Talk About It: How does your school use the term "ability"? Consider student groupings, classroom placements, special education structures and conversations about intelligence or personality.

\section{Mindset and Grit: An Alternative}

This text will suggest schools use growth mindset and grit as an alternative approach to considering ability because our traditional notions are flawed.

\section{What is Mindset?}

In her 2006 book, Mindset: The New Psychology of Success, Carol Dweck presents the theory of mindset as the view you adopt for yourself. She offers two mindsets, fixed and growth, 
and explains characterizations for each as well as limitations and opportunities for each. Fixed Mindset is based on the belief that you have a set amount of ability. Growth Mindset is "based on the belief that your basic qualities are things you can cultivate through your efforts," (Dweck, 2006, p.7).

\section{What is Grit?}

In her 2016 book, Grit, Angela Duckworth presents a theory about success that provides additional considerations to Dweck's work. Through various anecdotes, case studies, and analysis, Duckworth argues a long-term combination of passion and perseverance is what creates greatness, not innate talent. She presents the theory that natural talent multiplied by effort results in a certain level of skill. That skill, multiplied by effort, results in achievement. In this way, effort counts twice (Duckworth, 2016). You can likely see the connection to growth mindset. Why would I put in double effort if my abilities are fixed? Conversely, if I can control how successful I am, why wouldn't I try to grow? Duckworth explains this further, suggesting four attributes that contribute to someone's sustained effort that results in achievement: interest, practice, purpose, and hope. Along the lines of growth mindset, she writes, "the four psychological assets of interest, practice, purpose, and hope are not you have it or you don't commodities. You can learn to discover, develop, and deepen your interests. You can acquire the habit of discipline. You can cultivate a sense of purpose and meaning. And you can teach yourself to hope" (Duckworth, 2016, p. 92) 


\section{Traditional Beliefs}

\section{Inequality, Perception, and Ability}

What a person values is determined by a wide variety of influences. Race, class, religion, political beliefs - all may have an impact on what a teacher values. As such, they all may have an impact on what the classroom culture values (Carlone et al, 2011; Hatt, 2012). It stands to reason, then, that those same contributors may determine what the classroom, or teacher, believes about a child's ability. These may not be ideas we talk about frequently or frankly, especially because an educated society knows it should value its members equally. An educated society is not always an open, introspective one, however, and actions reveal beliefs more accurately than words.

Tracking, special education, smartness: these are all actionable concepts, based on the perception of those making the decisions related to children's education. Sometimes those decisions are classroom-level, related to assignments or texts, and sometimes they are larger systemic decisions that result in tracking or categorization (Finn, 2009; Oakes, 1985). Other times, decisions are individualized and involve labels or administration of discipline (Artiles, 2011; Harry \& Klingner, 2014). The variety of influences impacting the construction of ability is conceptualized in Figure 2. As illustrated, ability is a culminating product of context. When the abstract values or concrete realities of any nested circle changes, so does the construct of the individual's ability. 
Figure 2. Social Construction of Ability

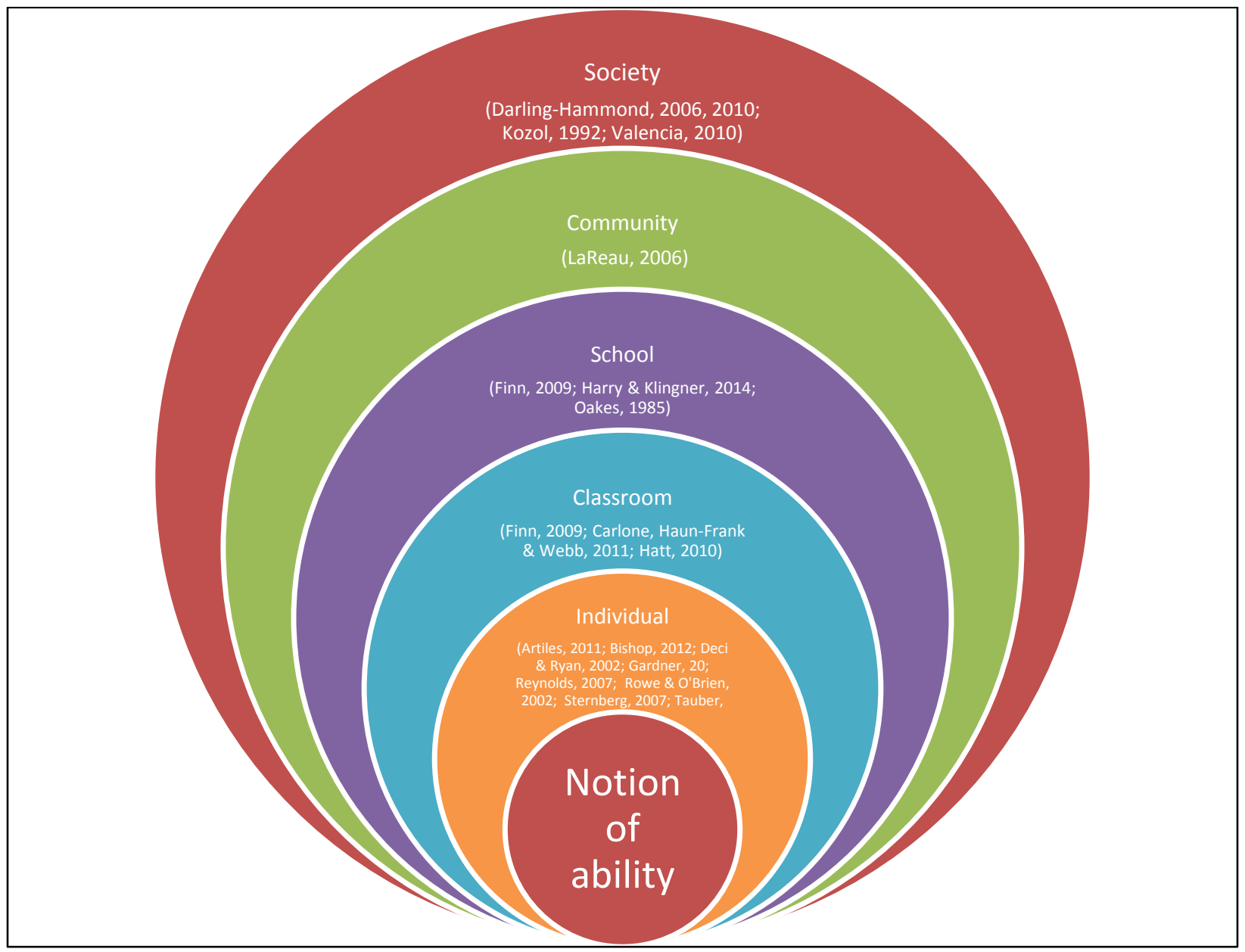

For example, when situated in democratic society, there are notions of equality and opportunity. Within that society, the differences in communities are wide. Communities could be described as affluent or poor, religious or non-religious, open or closed, large or small, and the list goes on. Those differences impact choices made in the schools related to tracking, pedagogy, material, purpose (Finn, 2009). The determinations of the school greatly impact the choices made in the classroom (Carlone et al, 2011; Rowe \& O’Brien, 2002). What does the teacher value? How does he or she present learning? What are the expectations for student participation? Within those expectations, realities and identities are developed for and by 
children regarding their abilities, their purpose, their role (Bishop, 2012; Hatt, 2010). Decisions are made about children related to sorting or labeling, and often, those decisions are made in the context of local norms, furthering the divide started at the split in the path at community (Oakes, 1985).

If the same child were placed on a different path at one of the outer circles, it is arguable that the differences in the inner circle of notions of ability would be stark. By this illustration and the subsequent descriptions of research to support each circle of choices, ability is clearly a social construct, not an absolute defined by biology. Through understanding of the various ways society and power impact notions of ability, educators can make more informed and deliberate decisions with students to avoid predetermination of ability resulting in negative self-concepts with disastrous results (Hatt, 2007). In essence, educators need to see the impact of each concentric circle on the development of beliefs about a child as well as a child's present levels of performance. The fact that each circle bears influence on a child's "ability" indicated ability is not fixed, but malleable. If the constructs in the circle can bear weight, can't the school? Hopefully, you want the school to believe in growth of all, rather than limited potential for all.

\section{Constructs of Class}

Are our ideas about an individual's ability impacted by class? It is first through families that children begin to learn the social rules expected in formalized schooling, and the family structure's system of values may or may not align with that of the dominant culture or socialized structure of school. LaReau (2006) used a large scale sociological study of life in various classes to make a compelling case for thinking about how socio-economic levels impact societal views of ability. After extensive "naturalistic" observations of nine- and ten-year old children from twelve families, child-rearing practices were categorized into two major camps, calling them 
"concerted cultivation" and "accomplishment of natural growth" and importantly noting that the patterns of parenting fall along lines of class (LaReau, 2006, pp. 2-3). In middle- to upper-class settings, parents adopt a style of raising children described as "developing" their talents in a "concerted fashion" (LaReau, 2006, p. 1). In the descriptions of the children, this resulted in over-scheduling of events, extra-curricular activities, and an overall harried sense of business. It also resulted in children from this class interacting with a wide variety of people in institutional settings, which developed an early awareness of how societal systems work and the linguistic prowess to navigate them effectively (LaReau, 2006).

In working class families, children's basic needs were cared for while they learned about the world naturally. Most of the case studies included described children playing with neighbors or siblings. Interactions with adults were more incidental and transactional, and interactions with institutions were rare. When presented, those interactions were categorized as recipients of institutions, or dependent upon institutions (LaReau, 2006).

These differences alone set classes of children apart in their understanding of ownership in their education, as active players or passive receivers. Depending on how they have learned to interact with institutions, they may approach formal schooling differently. Are they there to be taught? Should they plan to receive information from the institution, with deferred submission? Or, as in the high income examples, do they believe they have a right to the education most fitting to them? Is the school a system there to serve their needs, and submit to their requests? These are two very different stances from which children and their parents may approach formalized schooling. Those stances will affect the way children act and interact with their teachers and classmates. Those observable behaviors will impact teachers' opinions of student 
performance and ability, which again results in sorting and the subsequent path of inequitable access and opportunity.

Along the way to and through school, middle-class children learn the skills of negotiating with adults and acquire a sense of entitlement, which adds a culturally-constructed difference in the ways children interact with teachers and the institution of school (LaReau, 2006). In addition, the pattern of middle-class parents to adopt a sense of entitlement, accompanied by demands and special requests for their children, often leads to advantages in classroom performance (LaReau, 2006). This illustrates ability is a cultural construct having much to do with patterns of behavior categorized by class, not biology of people categorized into different classes. Think about it. Do you have a family that demands more than other families? Does that impact the way the children are served? The attention they receive?

Another important pattern observed along categories of class that impacts teacher perception of student ability is language use. In more affluent families, the interactions between adult and child were observed to be more dialogical in nature, whereas in working-class families, the interactions were more directive in nature (LaReau, 2006). Why does this matter? These differences create two very different communication styles in children. One set of children has had practice in negotiation and reasoning with authority figures, while the other group may have rarely questioned or challenged adults. Cultural rules governing verbal interactions with adults results in a distinct difference between how children of differing classes use language to negotiate their formal schooling experiences, specifically with the adults in power. These differences are not absolute; rather, they are a product of interactions aligned with class, and they result in differentiated readiness for navigating formal schooling experiences. "Quite simply, they appear to lead to the transmission of differential advantages to children" (LaReau, 2006, p. 
5). These advantages must not be misconstrued as abilities of definitions of potential. They exist and should be acknowledged as contributors to different starting points, not determiners of end points or destinies.

Early and frequent exposure to a variety of institutions and systems, like those discovered through the concerted cultivation of sports teams, music lessons, and dance classes, teach - and perpetuate - the hidden curriculum of class. These findings underline other research related to "performing smartness" and behavioral compliance, leading to academic characterization (McDermott, 2007; Hatt, 2011). These implicitly taught skills provide an advantage in the eyes of teachers whose notions of ability are influenced by the culture of class and tangible evidences of it. Again, these are differences in starting points. As educators, we must guard ourselves from forming different beliefs about ability or potential influenced by these perceived advantages.

Not only does class contribute to notions of ability, but race does, also. African American students are over-represented in special education classes and intervention programs as early as preschool. In fact, racial disproportionality research from 2002 indicates that African American students were 2.35 times more likely to be labeled as intellectually disabled than their white peers and 59\% more likely to be considered emotionally or behaviorally disabled (Artiles, 2011). This should be a startling wakeup call if you haven't read any disproportionality literature, because it sends a clear message that our systems perpetuate beliefs about children of different races. I would encourage you to do a local audit along these lines. What does your data tell you about your school? These evidences of action will reveal more than what people say. Provide the data to a leadership team and facilitate a conversation about it. Include all 
stakeholders and listen for hard truths. You are not alone, as evidenced by this data, but that does not grant permission to ignore.

As formal schooling continues, national performance data illustrates a continuing spread in achievement between subgroups of students along racial lines (Darling-Hammond, 2010). This data, indicative of cultural constraints created by disproportionate opportunity, an oppressive history, and an imbalance of power, promote ideas about race (Harry \& Lingner, 2014). Those ideas become part of a cultural discourse informing notions of ability. Without the contextual understanding of resegregation, inequity of funding and opportunity, and the context of race and class, an uninformed populous has formed an idea about ability associated with race (Artiles, 2011; Harry \& Klingner, 2014). Those ideas inform actions, and actions communicate expectations.

Those expectations and resulting actions have created an over-representation of minority students in special education preschool programs (Nieto, 1996). At the earliest phase of formalized schooling, this presents a serious problem. Placed in specialized classes or programs, tracking begins, resulting in less rigorous curriculum, lower expectations, and subsequently lower achievement than their non-labeled peers (Oakes, 1985; O’Neill, 1992; Hu, 2009). Over time, these children may begin to believe in the socially-constructed labels to sort them, like "smart/dumb", "quick/slow", or "low/high," impacting their beliefs about self in the context of school (Nieto, 1996; Rowe \& O’Brien, 2002). We absolutely must push back against this form of fixed thinking because it limits opportunity along racial lines. We are wasting potential based on flawed constructs. Again, I urge you to analyze your local data. Let the actions of your school tell you the story of your beliefs. Then examine practices that may be unintentionally contributing to those beliefs. What is within your team's power to change? 


\section{The Danger of Deficit Thinking}

The historical and persistent over-representation of minorities in special education and failing schools, paired with disproportionate discipline referral and drop-out rates and documented differences in academic achievement is a failure of our school system, and one for which many scholars have proposed explanatory frameworks (Darling-Hammond, 2010). Longstanding patterns that give way to labels surrounding sorters like class, race, or disability can result in deficit thinking, one such theory for justifying the unjustifiable. This way of thinking attaches blame to those who are failing, suggesting that the cause is inherent, ranging from genetic disposition to family and class structure, culture, or socialization (Garcia \& Guerra, 2004; Valencia, 2010). In short, the group is assigned fault for discrepancies as though the deficits were somehow inherent rather than created by the culture in which the group is contextualized. Lacking in the explanation are cultural constructions and systemic failures, but the theory carries weight in popular discourse. Mainstream discourse can further impact our interactions with and expectations of students, as described by the frames of deficit thinking: blaming the victim, oppression, pseudoscience, temporal changes, educability, and heterodoxy (Valencia, 2010).

Considering these constructs through the lens of ability sheds light on the culture of labeling, of naming and blaming. The notion of blaming the victim is as current today as it was in 1971, when it was coined by William Ryan. Then, he described "programs of 'compensatory education' to build up the skills and attitudes of the ghetto child, rather than structural changes in the schools" (Ryan, 1971, p. 8). Have we made any progress? Substitute "learning disabled" or "impoverished" for "ghetto". If not careful, we could even substitute "fixed mindset" in its place. Regardless of the label chosen, this type of attribution opens the gate for assigning fault to 
the failing and addressing their perceived deficiencies through compensatory education, as opposed to making substantive change to the systems that could be perpetuating the gap, like ability-based tracking, or inequitable school funding. Holding its hand is the theme of oppression, as expressed through school segregation and desegregation, as well as governmental mechanisms of control, like Jim Crowe laws. Denying entire groups of people access to information and the power of literacy is oppression that perpetuates the genetic view easy to explain when attempting to blame the victim for their perceived failure on measures constructed by those in power (Valencia, 1990).

Valencia (2010) describes a third avenue to deficit thinking: pseudoscience. Through poorly constructed measures with the power of publication behind them, educators frequently use tests with poor validity, based on unsound assumptions, to categorize children. An example is the intelligence quotient, which has been previously discussed as being used for purposes other than its original intent. In fact, a language-based examination, it perpetuates the values of the class in power who holds the knowledge being measured and therefore sorts other groups into perceived lesser categories (Binet, 1912; Valencia, 2010). Another example is found in the misinterpretation of Gardner's (2006) work on Multiple Intelligences being used as a sorter by race and class in Australia. "... a list of various ethnic and racial groups coupled with the intelligences that each purportedly possessed and each purportedly lacked...I denounced the program as 'pseudoscience'... as a result of the clamor that followed, the state cancelled the program, much to my relief" (Gardner, 2006, pp. 54 -55). The fact that decisions about children's educational opportunities were being made on such faulty assumptions and irresponsible interpretation of a theory intended to help children learn and grow is evidence of the pseudoscience element of deficit thinking (Valencia, 2010). 
So-called deficits are also attributed through temporal changes, referencing popular thinking of the time about differences in race and class, educability, which deficit thinkers use to describe individual intellectual abilities with no causation in differences being assigned to school, power structures, politics, or social constructions of ability (Valencia, 2002). It has become social discourse to dismiss the differences in achievement between classes, races, and labeled individuals by attribution. In her discussion of the "anatomy of inequality," DarlingHammond (2010) warns against "recurring explanations of educational inequality among everyday people, pundits, and policymakers [which] often implicitly or explicitly blame children and their families for lack of effort, poor childrearing, a 'culture of poverty,' or inadequate genes" (p. 30). Considering ability as a trait associated with class, race, or label, in order to dismiss it as fact may lessen responsibility and alleviate fears of failure to equitably reach underserved populations, but the social construction of ability is evident and compounded as children enter formalized schooling.

It is important to understand these constructs as to avoid the easy path of assignment of blame or justification for differences in performance. Rather than focusing on justifying differences, this work will focus on utilizing the power of growth mindset with all learners. Along the way, if faced with hard data or evidence of failing in certain areas, deficit thinkers have a tendency to explain away differences in performance along the lines of deficit thinking. Valencia's (2002) previously explored framework for understanding it will assist us in avoiding unjust distractions from helping all children learn and grow.

When these influences are combined, it is clear that a child is impacted in a variety of ways, and each of these contributions are socially constructed - societal structure, class, family. The wide variation in context illustrates that ability is a product of experiences, not an absolute 
number or genetic definition. It follows, then, that growth mindset should be prevalent in our schools; that is, we should provide experiences for all to grow and learn and really believe that the experiences we create will cause growth to occur. These experiences should not be limited to those whose external influences illustrate a more advanced starting point according to the values held by traditional schooling.

\section{Mindset: A Developing Alternative for Framing Ability}

Considering the conflux of influences in our present understanding of ability, how might a teacher set aside the influencing issues of perception based on label, class, culture, and race to greet her incoming students? Especially if she does not even know those influences exist? The answer may be in recent work related to Mindset by Carol Dweck. In her 2006 book, Mindset: the New Psychology of Success, Dweck explores the nature of human thinking and applies it to all areas of life, from parenting to business, and ranging from sports to relationships. Education is a component of her work, but her writing is much more comprehensive. In consideration of the foundational question, How do we think about ability?, Dweck's writing is important material. This section will explain Dweck's work, as well as illustrate how it relates to the concept of how we form expectations.

To begin, Dweck defines mindset as "the view you adopt for yourself" (p. 6). She calls the two mindsets fixed and growth. Someone who adopts the fixed mindset believes his or her traits are unchangeable. A person who has adopted the growth mindset believes traits can be "cultivate[d] through your efforts" (p. 7).

Dweck (2015) argues people may have a combination of mindsets, but their patterns of behaviors make them predominately one of the two mindset categories: fixed or growth. Those whose behaviors align primarily with fixed mindset live life through a lens of set ability. These 
people believe abilities are predestined, inherited, or fixed at birth. There is not much someone can do regarding his or her ability except to accept it, or live up to it. If, for example, someone with a fixed mindset is labeled athletic, he or she would live to prove that label's truth.

Conversely, if someone from that camp is considered not athletic, he or she might as well avoid sports altogether because there is not much to do about it (Dweck, 2006).

Consider Dweck's other theory, one of growth mindset. Individuals possessing this mindset believe intelligence and ability are acquired and can be improved. While the fixed mindset tells someone there isn't much to do about one's lot in life, the growth mindset claims quite the contrary - there is everything to do about it. If, for example, someone with a growth mindset is labeled athletic, he or she would consider how to continue growing and improving upon natural coordination. At the same time, the growth-minded individual would carefully scrutinize others to find strategies for improvement. For growth mindset, present level is not a categorization; it is a starting point (Dweck, 2006).

These viewpoints have obvious ramifications for the ways in which individuals approach life. How would a fixed-mindset person approach challenges? Dweck posits he or she would avoid them altogether. Why? Her work claims these individuals are afraid of losing a positive label and simultaneously accept a negative label. Let's return to the athlete for another illustration. Bad at golf? This person won't pick up a club. He or she may avoid challenging situations in which his or her athleticism could be questioned. Why bother? An athlete with a fixed mindset non-athlete would avoid the trouble because that person has accepted athletics just aren't for him or her.

How would a growth-minded person approach challenges? In stark contrast to those prescribing to set-abilities and intelligence, people with growth mindsets see challenges as 
opportunities to improve. In this mindset, the successful athlete challenges himself to find tough competition from whom he can learn. She asks herself, What will make me better? Analysis of ways to improve would be a mainstay.

These mindsets impact the ways in which individuals view others. If we apply this theory to the school-level and consider how a teacher from each grouping would interact with peers and students, we can clearly see how these mindsets could perpetuate categorization of students by constructed notions of ability. If, for example, a teacher believes ability is defined by behavioral constructs, he or she is more likely to define students by their behaviors and think of them as "good" or "bad". If a teacher with a fixed mindset has a student with the label of learning disabled, he or she will treat that student differently. Further, if a teacher believes he or she needs to water-down the curriculum or lower standards to accommodate a misinformed deficit-thinking model, he or she may believe certain children are capable of less, thereby limiting their opportunities for success (Dweck, 2006; Oakes, 1985).

Conversely, a teacher with a growth mindset may look at children with a nod to current ability levels as a starting point, believing they all can achieve not-yet defined levels of mastery. These two approaches to teaching consider the previously explored notions of ability and take two different paths. Growth mindset can eliminate reliance on culturally-constructed notions of ability by focusing on our shared ability to grow. In doing such, educators can prevent traditional, fixed constructs from defining a child's destiny.

How can a teacher know if he or she has a growth or fixed mindset? How can the teacher know that about his or her students? Dweck (2006) began her creation of mindsets in an exploration of how people deal with failure, and she found people seem to thrive from failure and or seem to be crushed by it. People handle failure differently. But why does that matter? 
Dweck continued to probe the question about failure, seeking the why behind the differences. Ultimately, she created the categories of fixed and growth mindset, but how individuals cope with failure is just one consideration when understanding the way a person views the world. In our first year of studying mindset, our leadership team defined mindset as follows, "Mindset is how you view yourself and others in response to life's challenges and successes." With that definition in mind, then, it is equally important to consider how a person deals with success. A person with a fixed mindset, someone who thinks of his or her traits as "carved in stone" will seek to prove his or her value. A person with a growth mindset thinks he or she can change intelligence or talent; this person views current ability as a starting point. These beliefs impact how someone approaches challenges. They impact how someone views competition. They impact how someone thinks about others. In other words, they impact expectations (Dweck, 2000).

In the seventh chapter, Dweck (2006) applies her theory to parenting. It is here that we come closest to understanding her beliefs about how mindsets are formed. Depending on the type of feedback given during childhood, people develop a belief about themselves. For example, labeling traits help cultivate a fixed mindset. Telling a young child he is smart, or athletic, or not an artist will lead him to believe that is just who he is. A smart, athletic, nonartist. Conversely, feedback associated with effort or process places the child's focus on those two controllable traits, and cultivates a growth mindset.

Language choices are another contributing factor to the development of beliefs about ability and expectations (Varlas, 2016). Although the formation of mindset is interesting and has obvious applicability in the school setting, it is important to avoid the pitfalls of labeling and categorizing one mindset as good and one as bad. This would ironically cause us to end up 
where we started. Instead, acknowledging that most people are a combination of both mindsets, and certain situations or contexts may cause a person to act in a more fixed- or growth-oriented way allows people to adjust thinking toward growth-oriented choices when triggers for fixed thinking occur (Dweck, 2015).

As Dweck's (2006) work has gained in popularity, the core of her message has been occasionally misinterpreted, or watered down in some ways. Dweck (2015) addressed this misconception in a recent article, Growth Mindset, Revisited. While effort is central to the growth mindset, it is not effort alone teachers should tout. By emphasizing effort alone, a lack of progress is almost excused, as long as students are "trying their best" (Dweck, 2016). That is not at all the message behind a growth mindset; it is not a movement to make children feel better about failure, but to use failure as a way to better understand the learning that still must occur. "The growth-mindset approach helps children feel good in the short and long terms, by helping them thrive on challenges and setbacks on their way to learning" (Dweck, 2015). In addition, fixed mindset is not to be used as a reason for lack of progress or growth, nor is it an excuse to "effort shame" someone (If you would just try harder, you could do it!). If used that way, the label "fixed mindset" becomes just another way to categorize students and justify a lack of learning, which is not the purpose behind the theory. Instead, acknowledging that all people have a combination of growth-mindset and fixed-mindset approaches to life, and through reflection, note when the fixed-mindset is inhibiting growth. Additionally, trying hard is not the effort needed for growth. Effort paired with adjustments and flexibility, reflection and innovation is the type of effort required for a growth-mindset, and opportunities to practice those skills in a supportive environment will enact positive change to mindset (Dweck, 2015). 
This is an important distinction supported by recent research. If only a cursory attempt at creating growth-mindsets is implemented in the classroom, it could actually have detrimental effects (Sun, 2015). When studying middle school mathematics teachers' use of the growthmindset principles, Sun (2015) found the language of growth mindset alone was not sufficient in developing children who persevere toward improved learning. This illustrates the notion that growth-mindset beliefs are not sufficient for creating growth-mindset culture, nor is encouraging students to "try harder" or "not give up" (Dweck, 2015). Teacher practices related to perseverance and innovation after failure develop students' mindsets, regardless of vocabulary used (Sun, 2015). Beliefs about growth are different than practices related to growth, and when a disconnect exists, the latter has a greater impact on student performance (Sun, 2015). In other words, using the language of growth mindset will not impact change. Only the corresponding practices of perseverance and effort in the face of failure can do that. Mathematics students working with teachers who have adopted a "false growth mindset," or superficial implementation of the growth mindset through language but not practices, tend to develop a fixed mindset about their math ability (Sun, 2015; Dweck, 2015).

When teachers praise effort with no attention paid to outcome, children may feel good in the moment for trying, but still feel unaccomplished in their math abilities. Instead, focusing on the strategies that led to unsuccessful completion of the task, and making adjustments to the approach more accurately aligns with the effort to be associated with growth mindset (Varlas, 2016). Ultimately, for the theory of mindset to have the desired impact on school and notions of ability, the language of growth must be paired with the corresponding practices. Some of these practices implemented in the classroom level include optimism, persistence, flexibility, 
resilience, empathy, and grit (Mraz \& Hertz, 2015; Duckworth, 2016). These terms are defined in Table 1.

Table 1

Growth-Mindset Traits

\begin{tabular}{ll}
\multicolumn{1}{c}{ Practice \& Citation } & \multicolumn{1}{c}{ Definition } \\
\hline Optimism (Mraz \& Hertz, 205, p. 37) & $\begin{array}{l}\text { Feeling hopeful that risks are worth taking and } \\
\text { that problems will work out. }\end{array}$ \\
Persistence (Mraz \& Hertz, 205, p. 37) & $\begin{array}{l}\text { Sticking with something even when it is } \\
\text { challenging. }\end{array}$ \\
Flexibility (Mraz \& Hertz, 205, p. 37) & Seeing and trying many possible actions within a \\
& task. \\
Resilience (Mraz \& Hertz, 205, p. 37) & Bouncing back and recovering from setbacks or \\
failures. & Feeling how another person is feeling and \\
Empathy (Mraz \& Hertz, 205, p. 37) & imagining what it would be like to be in another's \\
& position. \\
Interest, practice, purpose, and hope.
\end{tabular}

Similarly, in recent research, Dweck (2015) found parents who espouse a growth-mindset but approach failure critically cultivate fixed mindsets about their children's intelligence. This recent research builds upon Dweck's (2006) earlier work related to the vocabulary of mindset, illustrating it is the practice of reflection followed by perseverance more than using the vocabulary associated with growth and effort. This may mean schools and families should partner to cultivate strategies those practices, including building resilience and offering effective feedback (Ricci, 2013). 
Angela Duckworth's (2016) theory of grit builds upon this foundation. Duckworth posits that perseverance plus passion equate to grit, or the characteristic required to continually improve. Like the theory of mindset, this theory requires improvement-oriented effort built upon reflection of previous failures (Duckworth, 2016). Those are the types of behaviors parents and teachers must cultivate in order to see growth for all children, regardless of their starting point or previously identified ability. Without perseverance toward improvement that is built upon reflection and analysis of previous mistakes, improvement will not be made, regardless of effort. That type of perseverance requires passion for the topic being studied (Duckworth, 2016). As such, focus on how to connect required content to each child's passion would undoubtedly be time more effectively spent than determining how to lower expectations for a particular label or track.

Teaching students their brains can be developed through growth mindset has demonstrated positive results related to achievement (Aronson et al, 2008; Dweck, 2008; Dweck, 2009; Dweck, 2010a). Aronson et al (2002) implemented a growth-mindset intervention with two groups of students. One group received a growth-mindset curriculum, one received a multiple-intelligence intervention, and one group did not have an intervention. The students in the multiple-intelligence and no-treatment groups showed no change in performance, but the students in the growth-mindset intervention demonstrated improved achievement. Of special note was the fact that African American students showed significant growth, closing the gap in performance between African American and white peers.

Another intervention implemented in a $7^{\text {th }}$ grade classroom by Good et al (2003) structured mentors and mentees meeting twice for ninety minutes, and maintaining electronic communication related to growth and improvement throughout that period of time. An 
improvement in both reading and math achievement tests was demonstrated when compared to the students who were not involved in the intervention group.

Further evidence exists to support the instruction of growth mindset through Blackwell et al's (2007) research. Two groups of seventh grade students received a study skills curriculum. Both groups of students were demonstrating difficulty in school. One group focused solely on study skills, while the other group paired study skills with brain-based research supporting the growth mindset. This content, called "Brainology" increased engagement as students found themselves in charge of their learning and growth. As a result, the growth-oriented study skills group demonstrated a significant improvement in grades (Dweck, 2008).

These studies illustrate the importance of explicit examination of our beliefs regarding ability, followed by an instruction to learners about their level of control over ability. But how we think about ability is not only important insofar as how it determines the expectations we set for ourselves, but it is also powerful in the expectations we hold for others. In the subsequent section, research about expectations will be discussed. 


\section{CHAPTER III: TEACHER EXPECTATIONS \& CLASSROOM CULTURE}

"Sow a thought and you reap an action;

sow an act and you reap a habit;

sow a habit and you reap a character;

sow a character and you reap a destiny."

\section{-Ralph Waldo Emerson}

Mrs. Farable rushes through the front doors of the two-story brick schoolhouse, proudly

proclaiming 1897 above its entrance. Jostling bags of bulletin board trim and Carson-Dellarosa punch outs, she absently thinks of the number of first-year teachers who have been met by the promise of those doors. She smiles at her fortune in fi-na-lly being among the professional class called "teacher". Greeted by her reflection bouncing off the recently waxed tile floors, she smells summer progress, and that distinctly-elementary school mix of lemon and hot laminating machines reminds her of the summers spent in her parents' classrooms, as they prepared for the students who would become their other children for the subsequent nine months. Her smile broadens and she looks past the disarray of summer-time cleaning toward the glass paneled doors labeled OFFICE.

With a deep breath of resolution, eager to make a good first impression, she straightens her shoulders and pushes open the office doors. A middle-aged woman talks into the phone trapped between her shoulder and jaw while hastily typing on the computer. "Uh-huh," she notices Mrs. Farable and rolls her eyes with a conspiratorial, another-one-of-those-call-winks. "I know it's going to be hot that first week back. Yep. Okay. Class lists will be posted next week." She hangs up and sighs. "Hi, darlin'. Can I help you?" 
Mrs. Farable's hopefulness is a full balloon, and her introduction, "Hi! I'm Mrs. Farable, the new third grade teacher," is punctuated with an eager smile.

With a chuckle, Marilee tells Mrs. Farable more than her name when she adds, "Oh, aren't you ambitious!" Thinking that was a unique word choice, Mrs. Farable acknowledges the secretary's introduction with yet another lovemelovemeloveme smile and asks for her class list, if possible. "Oh, I bet you're gonna want that, honey." Marileee smiles and winks again. Mrs. Farable's eye twitches in an agreeable effort to wink. What does that even mean? She wonders. “Here you go! Good luck!” Mrs. Farable's slightly-depleted balloon thanks Marilee and heads out of the office toward her classroom.

Fresh-faced and full of hope, over the next few weeks, Mrs. Farable meets with her new principal who reviews her class list with her. He stars a few students, suggesting she should be mindful of them, and even places a double star next to Alex and Juan's names. It's going to take double effort with these two. "But hey! I have confidence in you!" She momentarily wonders about his confidence in Alex and Juan.

Shake it off, sister, she tells herself as she leaves the principal's office and heads to her classroom, super-excited to begin creating nametags and filling in her gradebook alphabetically. Other than the double stars, the names mean little to her. She notices about half are boys and half are girls. Oh good, she thinks. At least I have equal girls to balance out those rowdy boys. Boys will be boys, Grandma always said, she thinks with a wink-wink-nudge-nudge to herself.

As she sits down to begin completing her record-book, she notices six of the students have "IEP" written next to their names. Wow, she thinks. I remember my three-credit seminar on special education, and they need a LOT of help. Doesn't that seem like a lot of low kids in one 
room?, she wonders. I hope their case manager plans to come in and help a lot. She jots a postit note to herself: "FIND SPED TEACHER," sets it aside, and gets back to those nametags.

Just then, her mentor walks through the door. Eager to be helpful, she asks to see the class list to give her mentee some information on the students she will work with this year. One by one, she talks about each student. Slowly, the words on the page that were just names become identities, and those identities, informed by a person's perception, start to become expectations.

Oh, this girl-you'll love her. Her family is so super supportive and kind. The two share a smile and a knowing nod.

No way! You got Joe? Good luck getting that mom to come in or call you back all year. Rolled eyes send a clear message about her opinion of the family.

Oh my gosh - Von and Aiden? Geesh - they sure do have a lot of faith in your classroom management skills to put both of those boys in your room! We will probably need to come up with a chart right away. They are huge behavior problems.

As the mentor leaves the room, the list of names has become a not only a mountain of worry, but also a mountain of expectations.

How will those expectations play out over the course of the year? What will they mean to the realities yet to be created? The picture begins to be painted even on day one, and it is a preview of what the children can expect over the next nine months as an innocent teacher's expectations become reality.

Mrs. Farable's-now-partial-balloon welcomes her children on that first day of school. Her earnestness toward the children and her interactions are innocent, but they are packed with what educators often coin prior knowledge. In reality, they are expectations. 
It's Alex and Juan! THE. DOUBLE. STARS. Oh my stars. Her initial meeting with them is kind, and hopeful, because she is after-all kind and hopeful, but is there doubt? Is she more guarded with them than she is in her initial meeting with no-star-Joe?

What Mrs. Farable doesn't know is that she will pay more negative attention to Alex and Juan due to their Double Star Treatment, while Sara-the-sweet will get longer wait time and more affirmations per minute. Her efforts with Joe's mom won't measure up to her attempts to involve Carrie's mom, because someone has already tried that and failed. We already know those six kids have IEPs, so she will tailor their assignments to be a little easier. These microadjustments to assignments, the miniature differences in feedback, and tiny variances in wait time will result in different opportunities and different outcomes for students.

Perhaps a few questions come to mind when reading this scenario, a scenario that is as regular as the calendar turning to September. First, how did the teacher view boys and girls? Why? What led her to those beliefs? Then, the label of IEP led her thinking. Why? What limits did she place on the children she had yet to meet? How about those Double Stars? Did she treat those children differently based on one conversation? These same questions could be asked of the labels placed on Joe, Von, and Aiden: one with no family support, two with behavior issues. What will she expect of Annie? How will she treat her, based on those expectations? Where did these beliefs originate? How did the teachers' responses to the beliefs enable or disable their abilities to work with different students and families?

When you acknowledge similar scenarios play out thousands of times per year, and you multiply each conversation times the number of students, teachers, and families impacted by the power of the words and embedded expectations, clearly, these questions are worth a closer look. 
This chapter will take a closer look at the power of teacher expectations, and how notions of ability ground in mindset can expand opportunities for children.

\section{Teacher Expectations}

If you took all the studies on teacher expectations and weighed them, you might actually be able to say there is literally a ton of research on the topic. Most of it is piled on my desk, in my filing cabinets, and on my bookshelves. The work I have reviewed extends back to 1968 with a groundbreaking study conducted by Robert Rosenthal and a team of researchers, and research on the topic continues through present day. It is obvious, simply by the amount written about it, that the topic is important. Really, our questions should not be whether or not teachers have expectations of learners, nor should we even bother asking if those expectations impact children. We know the answer to both of those questions is an unequivocal yes (Hattie, 2011, Marzano, 2003). Instead, we should be considering the basis for our expectations, and then talking about the myriad ways our expectations impact children.

\section{Pygmalion, Galatea, and Golem}

Researchers interested in exploring the power of expectations within the classroom turned to characters from two different mythological tales to help illustrate their findings. Settle in for story time. Greek poet Ovid wrote of a sculptor who detested women, a boy named Pygmalion who vowed to never love one. Ovid twisted the plot when this young artist became quite accomplished at creating statues of the one thing he despised most of all - women. Sure enough, even though he swore he would never love a woman, Pygmalion fell in love with one of the statues he created. Her name was Galatea. Pygmalion loved Galatea so much he began to believe she was real. Venus, the goddess of love, made his belief reality, and brought Galatea to 
life. The tale, then, is used to illustrate the power of positive beliefs - Pygmalion's beliefs were so strong that they could make a stone statue come to life.

Often, Pygmalion's character is used in management literature to describe how managers can get improved results from subordinates. Simply believing workers are capable of great things has been proven to cause managers to raise their expectations. That's right. Simply expecting more has resulted in improved results (Rowe \& O'Brien, 2002). This strategy is typically referenced as The Pygmalion Effect (Eden, 1990). If it works in business, can it apply to education? Can teacher beliefs bring life to greater student achievement the same way Pygmalion's beliefs brought life to his beloved statue?

In a controlled experiment, researchers Robert Rosenthal and Lenore Jacobson set up an experiment to measure just that (Rosenthal, R. \& Jacobson, L., 1968). They wanted to know how much of an impact teachers' expectations had on student achievement. Their study, published initially as Pygmalion in the Classroom (1968), illustrated a teacher expectancy effect. An expectancy effect can be defined as actually creating the reality an experimenter believed to be true.

At the beginning of the year, researchers administered an IQ test and randomly selected several students to be designated as "bloomers", or described as students who were on the cusp of exponential growth. This designation was randomly assigned, but teachers did not know that. This created an expectancy; the teachers should expect these students to grow more than the other children who were not designated as bloomers. Over the course of the year, researchers conducted in-class observations in the classrooms with "bloomers". At the end of the year, the IQ test was given again in order to determine if children labeled as special would have different learning results than children teachers perceived as normal or slower learners. They did. In fact, 
first and second grade students demonstrated statistically significant differences in their academic growth compared to the control group of children (Rosenthal \& Jacobson, 1968). How could this be? Analysis of teacher's decisions indicated they provided more opportunities to those children they believed were on the cusp of great growth. This was illustrated in longer wait time, more challenging questions, and probing for extended thought (Rosenthal, 1992). In essence, because the teachers believed the students were capable of great growth, their behaviors were impacted in a way that actually created greater growth for those students.

Although this study was initially criticized (Elashoff \& Snow, 1971 ) and was controversial for the emotions it evoked (Winestaff, 1987), a later meta-analysis of expectancy effects, or results matching expectations, validated Rosenthal's findings. The meta-analysis was a study of 345 studies examining expectancy effects, and their results were clear: expectations become reality (Rosenthal \& Rubin, 1978). "The implication for teachers is that teachers (as human beings) are more likely to have their students reach their "expected" outcomes" (Hattie, 122). Let that sink in. It is powerful.

So Pygmalion provides a positive example of what happens when teachers believe their students are capable of great growth, but if you're like me, I naturally wonder about the converse: What happens if the teacher does not believe a child is capable of great growth? What if their expectations are for little-to-no growth? We wouldn't be the only ones who were curious about that question. Theory and research developed around the consequences of negative Pygmalion Effects are called Golem Effects (Babad, Inbar, \& Rosenthal, 1982). Golem effects are a sort of self-fulfilling prophecy. They describe what happens when a teacher believes a student will not make progress or demonstrate growth. Termed after a mythological clay monster created to serve, Golem's creator believed he would be destructive on the Sabbath. As 
you might predict, the story goes that one Sabbath, the creator forgot to deactivate him, and because of his expectation that Golem would destroy, Golem did, in fact, cause great destruction. As a result, Golem himself had to be destroyed (Wisel, 1983). It was the creator's idea, planted in Golem's existence, that made him fulfill the exact thing they hoped would never happen.

Golem's story is used as an illustration in educational fields to convey the important truth that a teacher's negative beliefs about a child will not only plant such beliefs in the child's head, but will eventually lead him or her to act in accordance with the teacher's beliefs (Rowe \& O’Brien, 2002). Let us not forget the sad ending of Golem's tale. We also learn an important lesson from his demise. Ultimately, Golem was destroyed. Follow that logic to its sad end. Are opportunities for children whose teachers do not believe in them also destroyed? What about their potential? Again, powerful.

Additional research from around the world supports Rosenthal's seminal work, and the global nature of its application proves this phenomenon is not isolated to one area of the world, or one group of teachers. In England, a study of teacher expectations in relation to 4,000 elementary students revealed a direct causal relationship between teacher expectations and student achievement (Crano \& Mellon, 1978). A study from the Netherlands demonstrated teacher expectations dictate which migrant students are given advanced educational opportunities (Jungbluth, 1994). In India, teacher expectations were demonstrated to be higher for children from higher social classes (Sakya, 1980). In New Zealand, Maori children, who were the minority group, were viewed as having lower academic and intellectual abilities than white students, who formed the majority. A study of 90 nine-year olds indicated that those teachers' views perpetuated lower achievement from the minority group (Vaughn, 1972; St. George, 
1983). There are similar reports from around the world, and the findings are all the same. What teachers believe will impact their behaviors. Their behaviors will impact student achievement. Over time, repeated patterns will also create a self-image in the likeness of the beliefs. Figure 3 illustrates the interconnectedness and cycle of expectations, beliefs, and behaviors. The more often the same beliefs and behaviors are repeated, the thicker the identity becomes, not only to the student, but also to his or her peers and other adults (Crano \& Mellon, 1978; Rosenthal \& Rubin, 1978; Rosenthal, 1991).

Figure 3. Cycle of Beliefs, Expectations, and Behaviors

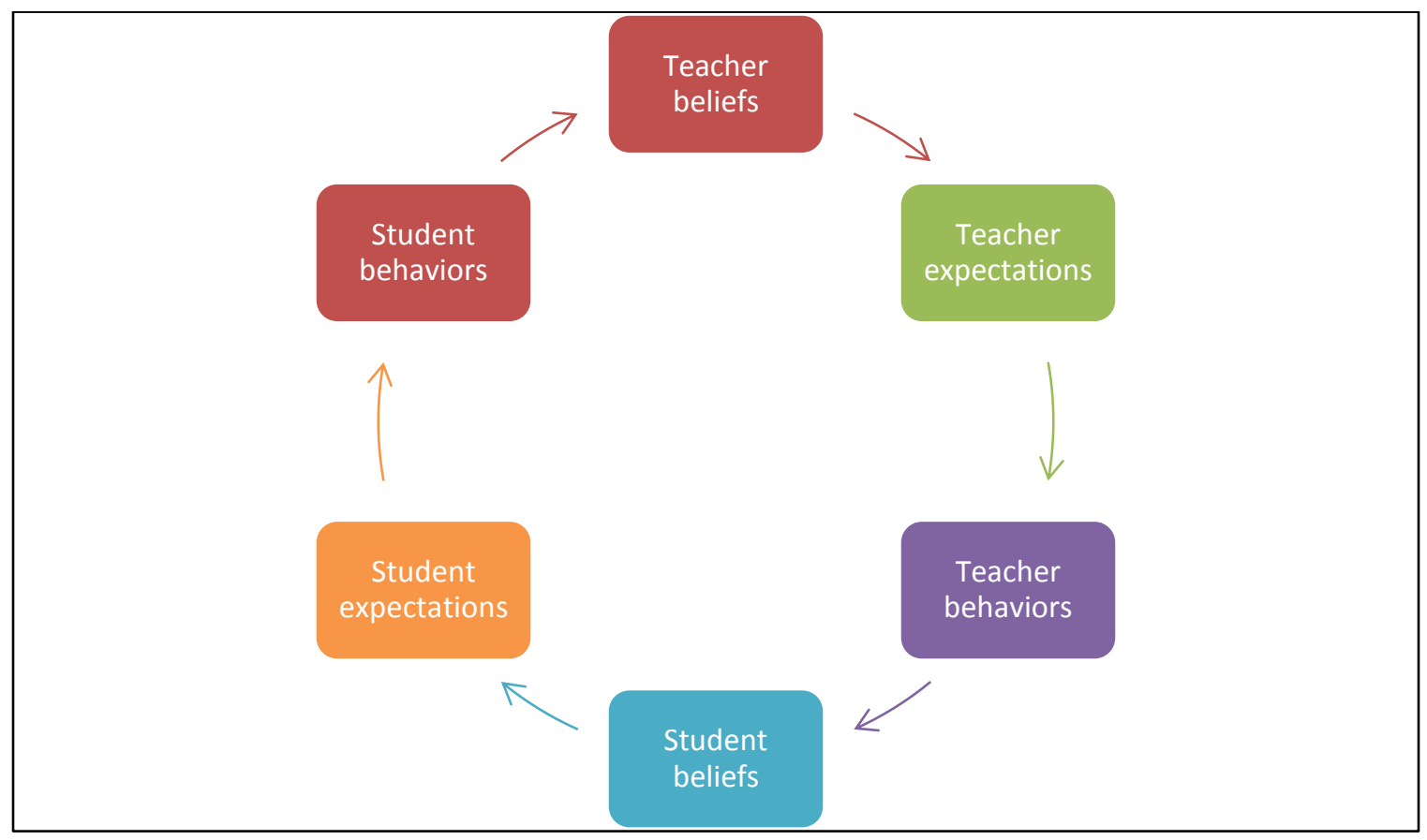

Amazing, isn't it? And so very important! I have always believed in the power of the teacher. But this research clearly supports how incredibly important it is for teachers to believe in the great growth capabilities of their students. All of their students! What teachers believe is what their students will become. I'm willing to guess if you are reading this, you care a great deal about the success of your students, and you want to ensure growth and achievement for all of them. Later in this chapter, we will talk about some strategies to monitor our thinking and 
beliefs in order to avoid any tendency to set low expectations or hold onto negative beliefs. You might already be drawing conclusions related to special education, tracking, and labels, and as we move through the book, an entire chapter will be devoted to those topics. Our expectations about student ability and achievement are crucial components to examine as we move toward creating a growth mindset school community.

\section{Galatea and the Self-Fulfilling Prophecy}

There is another character in these stories we have not yet discussed. Galatea, Pygmalion's statue. Although she was his creation, it was not only Pygmalion's beliefs that gave Galeta life. Because Pygmalion believed she was real, she began to believe it, too. His expectations for her impacted her expectations for herself. Can see you see the parallels to the classroom? Over time, what teachers believe about children can develop into children's actual beliefs about themselves. You may have heard people talk about self-fulfilling prophecies; in fact, the term seems to have become part of popular culture. But Robert Tauber (1997) reminds us of the term's seriousness in his book Self-Fulfilling Prophecy: A Practical Guide to Its Use in Education. He writes, "What the self-fulfilling prophecy process does is label someone and then have that person treated as if that label were correct. Over time, a hastily assigned label may become an accurate description of this person" (p. 30). We cannot afford to hastily assign labels, because when we do, we are hastily assigning destinies.

If you are a teacher, I hope you have always felt valued and important. If you haven't, please let me take a moment to tell you how incredibly important and powerful you are. But you know what? Don't worry about my opinion. Reflect instead on the power of the research we just discussed. I hope you are slightly in awe of your importance. I also hope you rememberwith great power comes great responsibility, and that is the purpose of this chapter. Your power 
means you must responsibly monitor your thoughts and expectations. This research illustrates that your beliefs about children will become reality. What you believe about each child in your classroom will impact your practices to the point of impacting each child's growth. What amazing possibilities that creates! How important that you believe each child is a bloomer! With that in mind, can we take a minute to honestly survey our thoughts?

How do you think about ability? Have you ever stopped to think about how you form ideas about the ability of others? Your own? Somehow, we form ideas that take the shape of words, and the words become labels, categorizations of types of people, levels of ability, and expectation-setters of sorts. These sorting mechanisms impact the words we use, and those words impact our actions related to the words. Those actions have significant impacts on children, and also on school systems. You may not consciously form expectations about certain children, but they exist. Think through the following questions, designed to tease out what beliefs may be driving your actions.

Take a minute to reflect on the following questions. It is important to acknowledge your thoughts, even if you think those thoughts do not change your actions. Jot your answers below, and then discuss with your team.

1. How do I view boys in a classroom setting? On the playground?

2. How do I view girls in a classroom setting? On the playground?

3. How do I view children with reputation of presenting behavioral challenges?

4. What does it mean when a child has an Individualized Education Plan, or IEP?

5. What kind of teacher-talk exists around children whose parents are not traditionally involved (e.g.; prompt in responding, lack of homework interaction) in school? 
6. Conversely, what kind of teacher-talk exists around children whose parents are traditionally involved in school?

7. What do these questions reveal about my personal beliefs?

8. What does our group discussion reveal about our school's collective beliefs?

9. What beliefs do I need to further explore or monitor?

\section{What Great Teachers Do Differently}

I truly believe great schools are created by great teachers. I further believe great teachers are defined by positive beliefs. It's really no coincidence this chapter starts the book; I will suggest teacher belief systems are where building a growth mindset cultures all begins.

Let's start this section with something fun. I want you to imagine your favorite teacher. Get a picture of him or her in your mind. What can you remember? Jot down two to three things that made this teacher stand out from the others.

\section{My Favorite Teacher:}

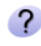

$?$

$?$

Now take a minute to share, if your team so chooses. Are their commonalities?

Can I tell you about mine? I was fortunate to have many great teachers throughout my life, and Mrs. Cazel was one of those teachers for me. She was my first grade teacher, and she called me Christina in a melodic tone, and I just knew she smiled at me differently than she smiled at everyone else. I was certain she paid more attention to me. After all, she knew my favorite color was yellow. She knew my mom was expecting a baby and that I wanted to bring him for show and tell. She knew I rushed through work. She didn't mind that I frequently forgot 
not to sing in the hallway - oh, quite the contrary. She always just winked and smiled with an encouraging word or quiet gesture. After all, she loved my singing voice, and she believed I could become a singing president. I absolutely knew I was her favorite. So you can imagine my surprise at our fifteen-year high school reunion when I found out everyone else thought they were her favorite, too. (Jury's still out on that one.)

Here's the thing. Great teachers make children feel special because they believe children are special. They know individual interests and what makes their students tick, but perhaps more importantly, they know all children have the potential to make great contributions. They make sure kids know they believe they can make great contributions. Not only do they believe in the value and dignity of each learner, but they also believe each learner can, must, and will grow. Great teachers leverage their knowledge of students to encourage growth; they weave their beliefs about growth into their lessons, their casual conversations, their gentle corrections, and their assessment methodologies. Their eyes are on a picture much bigger than a unit test, a spelling list, or a quiet line in the hallway. They see potential for growth, and they believe their mission is to make growth happen.

Teachers are at the heart of schools because they are the closest to the students. Not only that, but they are also the direct point of contact with the larger community of families and parents. Teachers have immeasurable power to build up, to encourage, to shape and mold; they also have the power to tear down, to humiliate. Teaching is a powerful, important calling, and one of the only careers that impacts human potential. That is why growth mindset matters, especially for teachers. 


\section{How Can Mindset Help Guide Expectations?}

Teachers' adopt a certain mindset, just like everyone else, but great teachers adopt a growth mindset about their students. As we have previously discussed, fixed mindset is a belief that individuals are born with a set amount of potential or ability. Growth mindset is a belief that ability is continually developed through a combination of effort, application of feedback, and passionate perseverance (Dweck, 2006; Duckworth, 2016). To me, that is the definition of a great teacher. A person can have a combination of mindsets, based on varying contexts. Maybe I am growth-oriented in my personal relationships, but more fixed at work. Perhaps you hold fixed-thinking about athletics, but adopt a growth-orientation toward music. Some people are fully fixed or growth-oriented in their thinking, but as Dweck (2006) points out in her text, for many people, varying contexts and situations place them in different places on the mindset continuum.

While a school leader should have concern about teachers' self-perception for those reasons, the primary cause for developing growth-oriented teacher beliefs is because of the impact those beliefs will have on students. What a teacher believes about student ability will impact student growth and opportunity.

It's certainly reflective of my beliefs that this chapter is at the beginning of the book. I have told you that I believe building growth-oriented teachers is how you begin the process of creating a growth mindset school community. I also think selecting and supporting teachers with growth-oriented beliefs is one of the most important responsibilities of a school leader. But enough about what I believe. What do the experts have to say?

Consistently and unequivocally, research supports the teacher as the primary contributor for student achievement (Hattie, 2009; Marzano, 2003; Marzano, 2011; Rubie-Davis, 2006; 
Wright, S., Horn, S. \& Sanders, W., 1997). In his widely-read text, What Works in Education, Marzano (2003) writes, “....all researchers agree that the impact of decisions made by individual teachers is far greater than the impact of decisions made at the school level" (p. 71). Wright, Horn, and Sanders (1997) write, "Effective teachers appear to be effective with students of all achievement levels regardless of the heterogeneity in their classes" (p. 63). Could this be because they believe in the growth potential of all of their students? To illustrate this concretely, a student's typical annual growth is 34 percentile points, and John Hattie (2011) suggests a learner gains six percentage points just by getting a year older. With the least effective teachers in the study, students gained about 14 percentage points over one year. With the most effective teachers? 53 percentage points (Glass, McGaw, and Smith 1981). Teachers, I hope this illustrates the importance in monitoring thoughts and behaviors as well as continuous improvement. Administrators, I hope this illustrates the importance of placing an effective, growth-minded teacher in every classroom.

What types of specific decisions do teachers make that send messages about their expectations of learners? The number of decisions a teacher makes daily is immeasurable; however, the decisions they make grounded in beliefs about ability establish opportunity for equity or inequity. These decisions include a continuum of challenge-level for each of the following:

- setting expectations for various learners,

- reinforcing effort,

- giving feedback and providing corrective instruction,

- questioning,

- establishing groups, 
- providing opportunities for cooperative learning,

- setting individual goals,

- offering cues, and

- disciplining (Hattie, 2006; Hunter, M. 1984; Brophy, 1996; Creemers, 1994; Cotton, 1995; Marzano, 2003; Sanders and Horn, 1994).

The following chart illustrates the ways in which these some of these decisions may be varied, based on teacher beliefs about individual student ability. Take a moment to reflect on your practices related to these classroom actions. Administrators, this is also a helpful tool for providing focused feedback after an observation. Use it to code a script, or - even more powerful - ask teachers to code their own script.

Table 2.

Decision Analysis Tool

\begin{tabular}{|c|c|c|c|}
\hline Decisions Related to: & $\begin{array}{l}\text { Actions for students } \\
\text { believed to be high } \\
\text { achieving or on the } \\
\text { verge of great growth }\end{array}$ & $\begin{array}{l}\text { Actions for students } \\
\text { believed to be low } \\
\text { achieving or capable } \\
\text { of little or slower } \\
\text { growth }\end{array}$ & $\begin{array}{l}\text { Something I notice } \\
\text { about my practices }\end{array}$ \\
\hline $\begin{array}{l}\text { Setting academic } \\
\text { expectations }\end{array}$ & $\begin{array}{l}\text { Above grade level } \\
\text { content }\end{array}$ & $\begin{array}{l}\text { Below grade level } \\
\text { content }\end{array}$ & \\
\hline Reinforcing effort & $\begin{array}{l}\text { Only praising quality } \\
\text { work }\end{array}$ & $\begin{array}{l}\text { Offering praise for any } \\
\text { response }\end{array}$ & \\
\hline Giving feedback & Specific and directive & General & \\
\hline Questioning & $\begin{array}{l}\text { Higher level thinking } \\
\text { stems, more wait time }\end{array}$ & $\begin{array}{l}\text { Lower level stems, } \\
\text { searching for teacher's } \\
\text { idea, shorter wait time }\end{array}$ & \\
\hline
\end{tabular}




\section{Classroom Culture and Peer Influence}

Further contributing to the development of students' self-perception is classroom culture and peer interaction. These two contributors fit into the chapter on teacher expectations simply because the teacher is the orchestrator of classroom culture and climate. Some researchers tend to focus on classroom management, which is a component of creating a classroom culture, but only a small portion. This text will define classroom culture as the expectations for interaction and establishment of shared values.

In a classroom where teachers convey beliefs about who is "smart" and "good" in contrast with students who are "slow" or "bad", other students perceive these beliefs and can help cement those expectations in their interactions (Hatt, 2012). Peer influences are listed as one of the most powerful effects of the school, and if you can remember junior high years at all, you probably have some anecdotal evidence to support that research (Hattie, 2006). In fact, early creation of a "reputation among peers that they are learners" can be quite powerful contributor to success (Hattie, 2006, p. 60). Hattie's analysis of topical studies concludes classrooms that foster an "openness to experience, willingness to invest in learning, and intellectual engagement" should be prioritized when considering classroom contributors to student development (p. 60). Conversely, early labels of smartness can create an established hierarchy that lasts equally long (Buhs \& Ladd, 2001). Further, a teacher's negative response to a student can create low peer acceptance, which has been linked with student disengagement (Buhs, Ladd, and Herald, 2006).

Over time, that disengagement leads to lower academic achievement (Ladd, 1990; Buhs \& Ladd, 2001). Social relationships and friendships can be beneficial for support and empathy, which can lead to increased achievement (Angerman \& Anderman, 1999); however, the stronger the friendship, the larger impact on development of self-identity. This can be good, when a 
relationship is good. But when labels of "non-learner" or "troublemaker" are applied, the effects can be detrimental to not only academic achievement, but also self-identity (Berndt, 2004). Positive peer influences can have a significant effect ( 0.53 standard deviations) on student achievement.

How, then, can we create a classroom that cultivates positive peer influences and a culture built on growth? Daily decisions, language, grouping - everything should send a growthoriented message. Practically speaking, in an elementary and middle level, instituting some form of Morning Meeting, whether through circle time in elementary or advisory period at middle school, has been proven as an effective strategy for establishing a shared classroom culture (Hattie, 2006; Responsive Classroom, 2015). During this time, relationships are strengthened. Specific content during this structured social introduction to the day will help specify the type of culture you want to create, and an engaged teacher will incorporate targeted lessons when peer interactions need to be addressed, or content on grit and growth need to be revisited. Through this time, a classroom family culture can be established, and the benefits of positive relationships and high expectations for all can be introduced, reviewed, and solidified.

\section{Your Story: What Steps Can You Take to Grow in this Area?}

\section{Self-analysis}

$\checkmark$ Probably the most important thing you can do is acknowledge you have expectations. Use the activity from the beginning of this chapter to identify what your personal triggers are. Be honest with yourself.

$\checkmark$ Start each morning with a statement of your beliefs. This works well if you have incorporated a morning meeting with your class. In her TED Talk, "Every Child Needs a Champion,” Rita Pierson shared her morning mantra: “"I am somebody. I 
was somebody when I came. I'll be a better somebody when I leave. I am

powerful, and I am strong. I deserve the education that I get here. I have things to do, people to impress, and places to go." Take a few minutes to figure out what you believe. Write something to your students so they know. Try it out, revise it with their help, and come up with a morning pledge.

End each day with 5 minutes of reflection. Use the following stems:

○ Was I bothered by a particular student's actions today?

○ Do I believe each child will accomplish this year's learning targets?

- If not, why?

- Within that list of reasons, what can I control that will change my beliefs? (Schedule, resources, time, new approaches)

- How did I show my students I believe in each of them today?

- How will I show my students I expect great growth from them tomorrow?

○ Remember Rosenthal's bloomers!

$\checkmark$ Use our Glow and Grow journal. Take two minutes at the end of each day to find something to Glow about. Then take another two to identify something from today you want to improve for tomorrow - some way you want to grow.

$\checkmark$ Find an accountabilibuddy. This should be someone you have a strong, trusting relationship with, and someone who also wants to grow. Ask that person to help you monitor your expectations and beliefs, and do the same for them. Every Friday, share one of your Glows and Grows Journal entries with them. Ask them to help you with your Grows next week. 


\section{Classroom observations}

$\checkmark$ Video tape your morning meeting or advisory. Watch peer interaction and student responses to you. Watch your nonverbal responses to students. Anything noteworthy?

$\checkmark$ Video tape indoor recess. Watch for inclusive and exclusive behaviors.

$\checkmark$ During morning meeting, encourage students to identify ways their peers contribute to the classroom. Use this form of reputation enhancement to assist all students viewed as learners.

$\checkmark$ Ask an accountabilibuddy to observe your tangible responses to students with IEPs. Do you wait as long? Do you ask as challenging questions?

$\checkmark$ Ask an accountabilibuddy to watch your responses to boys and girls; affluent and lowincome, minority and majority.

$\checkmark$ Watch a friend's classroom. Gather ideas to incorporate in your classroom and give feedback to your colleague on any manifestation of his or her expectations.

\section{Classroom and Schoolwide Messaging}

$\checkmark$ Do a visual tour of your classroom. What messages do your postings, posters, and displays send?

$\checkmark$ Take a walk through your school. What messages do the school's displays and postings send?

$\checkmark$ Make suggestions for growth-oriented visual messaging where you see visuals that are limiting.

$\checkmark$ Browse the classroom management literature and expectation packets you send home with families. What messages are you intentionally or unintentionally sending about your expectations? 
$\checkmark$ Take a growth inventory of your school's procedural guide or handbook. What messages does that tool send about the school's expectations of students, either intentionally or unintentionally? Are there sections that could be improved for more growth-oriented messaging?

$\checkmark$ Read your school's vision and mission statement. In light of the research presented in this section, does it say enough about expectations? What about your district's mission and vision?

If the heart of the school is the teacher, this is a chapter to invest in with your leadership teams. Review the literature, provide time for reflection and discussion, and support sustained efforts for reflection and growth. After all, growth mindset can be cultivated, and as a school leader, I hope you believe in your teachers the same way you want them to believe in their students. 


\section{CHAPTER IV: FEEDBACK, ASSESSMENT, AND GRADING}

From a traditional perspective, grading has a fixed nature. If we are checking to see if student responses are right and simply providing a score, we are not facilitating growth. Similarly, if students are passive recipients of grades or scores, they are not applying feedback for improvement or ongoing learning. Finally, families can perpetuate fixed approaches to grading by focusing on the letter grade instead of the learning it represents. Conversely, grading from a growth mindset perspective is providing feedback to help learners improve. There may be a symbol or score associated, but that is more of a by-product of the learning, not the purpose of the assignment. When growth-oriented teachers pick up a pen to grade, they are seeking ways to coach their students with tailored feedback. When growth-oriented students receive the feedback, they make changes and set goals. When growth-oriented parents review grades or reports of learning, they acknowledge progress and support continued improvement.

In this chapter, we will explore feedback, assessment, and grading with the intent of transitioning to a growth-mindset approach throughout the school community.

Think About it: Respond to the following prompts and share with your team. The intent is to open a discussion about your school community’s beliefs about grading.

- How would a child earn an "A" in your class?

- Think of a time earning an " $\mathrm{A}$ " taught you more than earning a "C".

- When you were a student, did you ever redo work? Why or why not?

- Did you ever receive a zero on an assignment or test? Why? What effect did that have on your learning? Your motivation?

- How does your school communicate the path to an "A" to families? Students? Between grade levels? 
Grades are a traditional way of describing a student's performance - widely accepted, but not widely consistent; widely recognized, but not widely understood. When we consider traditional grading through a mindset lens, it's easy to see fixed thinking at its core. After all, learning exists without grades. One could easily argue, then, that a student's final grade whether on an assignment or report card - is separate from their actual learning, yet it somehow sends a message about their final ability. C in Math? You are an average math student. Performance is labeled, most frequently with an A, B, C, D, or F, but even in situations where districts have switched to numbering or some other symbol, the grade communicates a final judgment. If, however, learning has occurred regardless of grades, why do we need them? Rick Wormeli, widely considered an expert in the field of grading, suggests the purpose of grades falls into two broad categories: effective and ineffective (2006). Effective purposes include "to document student and teacher progress; to provide feedback to the student and family, and the teacher; and to inform instructional decisions" (p. 102). Conversely, he lists common, but ineffective uses of grades as "to motivate students; to punish students; to sort students" (p. 102). Traditional grading practices fall into the latter of the two categories and are fixed. They provide labels, categories, and communicate fixed notions to learners. Growth grading practices are improvement-driven, and fall into the former of the two categories. Progress, feedback, and instructional decision-making all assist with growth.

To think we could (or should) ever rid ourselves of grades might seem ludicrous, I know, but with the right mindset, we may be able to more effectively communicate about progress and growth. Grades themselves could become irrelevant; in fact, this is occurring in many districts pursuing a competency-based approach to learning (ISBE, 2017; O'Connor, 2018). In a competency-based approach, students are presented with a set of competencies, or skills derived 
from learning standards, they are required to master. Through a variety of innovative approaches, students work through the competencies at their own pace. Once a particular gradelevel's competencies are achieved, they simply move on to the next set of competencies. In this way, learners progress through material as they learn it as opposed to moving through content at a regulated pace determined by teacher plans and irrespective of student learning.

Individualization at this level requires students and teachers to move beyond a traditional grade. In fact, the grade would be irrelevant. Learners would not move on until they achieved mastery of the required competencies. Clearly, in order to work effectively, this type of learner-based pacing requires assessment rather than grading; more specifically, teachers and students must be able to make accurate claims about student understanding before presenting a new competency. But doesn't it make sense to be learner-focused? To set our pace by the progress of the learner? At our core, isn't our purpose to ensure student learning? Traditional grading practices would suggest our purpose is to cover content, to finish the curriculum guide or textbook. Growthoriented grading practices shift the focus from coverage to acquisition of understanding. Stepping back from the minutia of school operations, it also just makes good sense. Now, returning to the realities of our bureaucracy, there are still requirements through school codes and college admissions offices. Those particulars related to this innovative approach, particularly in high schools, are being tested in a variety of states, including Vermont and New Hampshire, with Illinois most recently releasing a pilot opportunity for district participation (O’Connor, 2018; ISBE, 2017).

Certainly, we need to be accountable to families, and we also need a system of reporting progress in learning. Our traditional method is the school report card, and in later grades, the Grade Point Average. Is our traditional method the only way to be accountable and report 
progress? Is it an effective way to do either? I would say, no. It is not the only method, nor is it an effective method; it is simply the traditional method. If we can communicate clear present levels, and update progress regularly, aren't we describing our students more accurately? Doesn't it also send a growth message and set a growth expectation? I would say, yes. Involving students in monitoring their own progress toward a goal is one of the most effective learning strategies we can implement (Hattie, 2011). Grading and feedback should be for student growth - it should provide them information that leverages improvement. Grading and feedback should not be something a teacher does to students, but instead, a process done with them. Returning to the competency-based learning model, where students and teachers are assessing for learning and pacing based on said learning, schools like Champlain Union High School in Hinesburg, Vermont, use tools that "communicate clearly about student learning, not just grades or course credits" (p. 309, O’Connor, 2018). While they endeavored to communicate to stakeholders more clearly about student progress in learning, at the same time, the high school maintained their objective of providing their students an opportunity for college admission, even in the most selective universities. Tools that are developed locally are one option, but there are also tools widely available, such as the Mastery Transcript Consortium (www.mastery.org/a-new-model). These early advances provide a glimpse into improved approaches for student assessment, in that the traditional barriers of credits, GPA, and ambiguity are removed. A starting point has been created so educators have a path to creating more meaningful reporting, based on more meaningful pacing, created by meaningful assessment.

Conversely, I want you to picture this: After four weeks of studying the Revolutionary War, a student takes a test. It is the first time the teacher will evaluate the students' understanding of the concepts he or she has been teaching. The student turns in the test. The 
teacher grades it and hands it back. At the top of the front page is a letter grade. " $\mathrm{D}$," it proclaims. The student puts the test in a folder and opens the book to the next chapter while the teacher announces, "Moving on!" and begins discussing the Constitutional Convention. Has the child learned? No. So what is the point? We are here to help students learn content and skills. The report of the learning should be a derivative, not the driver. Traditional, fixed practices focus on the grade or report, not the learning or lack thereof. What message does the traditional learn, grade, and move on approach have in relation to mindset? Where is the "yet" message within a final grade? It doesn't exist. In contrast, growth-oriented grading practices are all about the yet. In fact, author Laura Greenstein even calls them restorative (Greenstein, 2018). Most obviously, effective assessment restores a student's understanding; it fixes a broken piece of cognition. This restoration allows the learner to move on to more complex or advanced skills and standards, but in order for the restoration to occur, the assessment must be much more than a traditional grade. The assessment should support the individual's understandings in an effort to repair his or her misunderstandings. This cannot always be accomplished through a quick multiple-choice exam, because it may not provide the necessary insights into the source of the misunderstanding. Rather, assessment practices that produce a clear picture of a student's thinking and progress in learning are required for the next step of restoration to occur. These types of practices can include interviews, conferencing, portfolios, simulations, and written assessments that require students to explain their thinking. The key in effective assessment is to discern student understanding, not provide a grade.

In addition to restoring the learner's understanding, effective assessment will cultivate "noncognitive skills" such as perseverance, flexibility, resilience, intrinsic motivation, collaboration, creativity, and optimism (Greenstein, 2018; Mraz \& Hertz, 2015). Simply put, a 
student who passively receives a D on a test has no authentic reason to persist, to collaborate, or to problem solve for improved understanding. If, however, the assessment informs the teacher and student of the source of the misunderstanding or deficiency, and the learner knows he or she must master the listed competencies prior to moving on, authentic reasons exist, and the crucial "noncognitive skills" are required of the learner.

As we will discuss in this chapter, there are three major issues with our traditional grading system. The first two are closely connected, and the third is the largest roadblock to growth mindset.

1) There is wide variance in the grade's purpose and its meaning;

2) There is a lack of clear communication about the grade's purpose and its meaning; and

3) There is an over-emphasis on summative products.

\section{Variance and Miscommunication}

What does a grade mean? Ask fifteen people associated with schools, and you're likely to get fifteen different answers. That's because arbitrary decisions lead to a wide variation in the meaning of grading symbols, and our communication about them is superficial at best. A's usually result in positive responses; F's, not so much. But shouldn't our consistent reaction go beyond that? If I have earned an A, what are my next steps? How can I continue to grow? If I have earned an F, what are my next steps? How can I continue to grow?

Typically, schools have systemic guidelines for how students should earn certain grades. For ease of conversation, let's use a grading scale, and to make it really simple, let's go with $90 \%, 80 \%, 70 \%, 60 \%$ as the cutoff mark for earning an A, B, C, and D, respectively, and assume for the sake of our conversation today that anything below a $60 \%$ would earn an F. Likely, this grading protocol would be published in a handbook or procedural guide for parents, and then 
teachers would adopt it for their classrooms. In this typical approach, that is where consistency ends and wide variation begins.

Let's start with an example that assumes only one difference. Mr. Johnson and Miss Smith both teach seventh grade science. They plan together and give the same assignments. They even give tests and quizzes on the same day, and they include the same things in their gradebooks. (Already this is a unique situation, right?) Now for the only difference: Mr. Johnsons does not give zeros on late work. Miss Smith deducts $50 \%$ for late work, and gives a zero after two late days. Still, both teachers are reporting on a $90 \%, 80 \%, 70 \%$, and $60 \%$ scale, and they are entering the same assignments in their gradebooks. Is it plausible that a student from Mr. Johnson's classroom and Miss Smith's classroom could have the same level of mastery of content but earn different symbols? Take a look at the simplified gradebook example in Table 3, in which two students earned the same score on their content, but one was deducted for lateness and the other was not.

Table 3

Gradebook Comparison

\begin{tabular}{|c|c|c|c|c|c|c|}
\hline $\begin{array}{l}\text { Student } \\
\& \\
\text { Teacher }\end{array}$ & $\begin{array}{l}\text { Assignment } \\
1 \text { (Both } \\
\text { students } \\
\text { turned this } \\
\text { work in one } \\
\text { day late) }\end{array}$ & $\begin{array}{l}\text { Assignment } \\
1\end{array}$ & $\begin{array}{l}\text { Assignment } \\
1\end{array}$ & $\begin{array}{l}\text { Assignment } \\
1 \text { (Both } \\
\text { students } \\
\text { turned this } \\
\text { work in one } \\
\text { day late) }\end{array}$ & $\begin{array}{l}\text { Assignment } \\
1\end{array}$ & $\begin{array}{l}\text { Average/Final } \\
\text { Grade }\end{array}$ \\
\hline $\begin{array}{l}\text { Sarah } \\
\text { (Mr. } \\
\text { Johnson) }\end{array}$ & $88 *$ & 70 & 90 & $100 *$ & 78 & $85.2 \%, \mathrm{~B}$ \\
\hline $\begin{array}{l}\text { James } \\
\text { (Miss } \\
\text { Smith) } \\
\end{array}$ & $50 *$ & 70 & 90 & $50 *$ & 78 & $67.6 \%, \mathrm{D}$ \\
\hline
\end{tabular}


Not only does this example illustrate variance created by teachers' decisions, it is also a simple path toward miscommunication. Now, James's parents believe he is "no good" at science, and those comments might help establish an identity. If his peers see his grade, he may earn a peer reputation of a non-learner in science. These identities and beliefs are constructions that become real, and they are all because of a grade-book game. I am playing this out with James because I want to illustrate how one seemingly minor grading decision can have real, lasting, and serious impact on students. Most gradebooks and classroom grading procedures have much more than one difference.

This illustration also brings to light another important question. What is the purpose of this grade? Should it be communicating how well Sarah and James understand the science content, or should it be a report of their overall compliance to procedural requirements? Regardless of which side of that question you land, can you agree that everyone should at least be consistent? Further, can you agree that one of these may encourage more growth than the other? Imagine you are James. Maybe you have extra responsibilities at home, maybe you had a late soccer tournament, or maybe you just prefer playing video games over doing science homework. Set aside the reason and your judgment of the reason for a moment and answer this: If he doesn't do the assignment the first night, what motivation is there for him to complete it? Now, if a teacher is assigning something, we should assume the assignment was meaningful and important to solidifying his understanding of science content, that it was necessary to helping him grow as a student scientist, because if not, we should be having a different conversation entirely. That aside, if a grading policy is interfering with James's motivation to learn, I would argue it is promoting fixed thinking. Conversely, Sarah knew if she completed the assignment, even if something prevented her from completing it on time (choice or not), she could still get 
"credit". She has a reason to keep growing, even if the intrinsic motivation of learning the content is not sufficient, the policy does not stifle the growth mindset.

What about the flip side to late work or zeros: Extra credit. If I have a policy that gives 50 points every time a child brings in a box of Kleenex and James does it twice, look at Table 4 to see how that impacts his grade.

Table 4

Impact of Extra Credit

\begin{tabular}{llllllll}
\hline $\begin{array}{l}\text { Student } \\
\&\end{array}$ & $\begin{array}{l}\text { Assignme } \\
\text { nt 1 (Both }\end{array}$ & $\begin{array}{l}\text { Assignme } \\
\text { Teacher } 1\end{array}$ & $\begin{array}{l}\text { Assignme } \\
\text { students turned } \\
\text { this work in } \\
\text { one day late) }\end{array}$ & $\begin{array}{l}\text { Assignme } \\
\text { nt 1 (Both } \\
\text { students } \\
\text { this work in } \\
\text { one day late) }\end{array}$ & $\begin{array}{l}\text { Assignme } \\
\text { nt } 1\end{array}$ & $\begin{array}{l}\text { Extra } \\
\text { Credit }\end{array}$ & $\begin{array}{l}\text { Average/ } \\
\text { Final } \\
\text { Grade } \\
\text { (Total/5 }\end{array}$ \\
$\begin{array}{l}\text { graded } \\
\text { assignments) }\end{array}$ \\
\hline $\begin{array}{l}\text { Sarah } \\
\text { (Mr. } \\
\text { Johnson }\end{array}$ & $88^{*}$ & 70 & 90 & $100^{*}$ & 78 & 0 & $85.2 \%$, B \\
) & & & & & & & \\
\hline $\begin{array}{l}\text { James } \\
\text { (Miss }\end{array}$ & $50^{*}$ & 70 & 90 & $50^{*}$ & 78 & 100 & $87.6 \%$, B \\
Smith) & & & & & & & \\
\hline
\end{tabular}

Now, I've done even more damage. I have sent the message that you don't have to complete the important learning I've assigned, you can just buy your way to a higher grade. Now James is learning the lesson of how to game the system. Does that create a growth mindset? No. Does it create the type of citizens we want? No. I know this is perfectly innocent, and I also know it is wide-spread. Extra credit creates a deceptive report of student performance. It contributes to the issues of variance and miscommunication, and I would suggest does more damage than late grades. However, we can fix two things at once. Instead of creating a need for extra credit, why not avoid penalizing through late grades in the first place? Then a child's score can reflect their actual understanding of the content. "Nonacademic factors should not be 
included when determining a students' academic performance grade, because the goal of the student's grade is to communicate how much he or she knows" (Heflebower, Hoegh, \& Warrick, 2014, p. 63). This explains why there is such an interest in standards-based grading. It helps educators focus on the learning targets instead of making generalized judgements about every aspect of schooling, boiled down to one letter grade or symbol.

That does not mean you cannot report on things like punctuality, adherence to timelines, neatness, or effort; rather, a growth-oriented grading approach would specifically separate requirements in a way that would enable children, teachers, and families to develop specific goals. If a student earns a $\mathrm{C}$ in Science, she might not know why. Is it because she constantly misplaced her assignments or she doesn't understand the genetic concepts taught in the previous chapter? By separating behaviors from content, a student can more skillfully set targeted goals for improvement. Our district worked to accomplish this through development of an academic behavior report card, which was separate from our traditional content-drive report card. You can see our example in Appendix $\mathrm{C}$, but the work of developing the tool was simple in relation to the work of changing classroom practices. The heavier lift was in ensuring those behaviors were truly separated in the teachers' grading practices. The growth mindset component comes in conversation with the students and their families about areas of improvement, either on the content report card or the academic behaviors checklist. Either way, the specificity and separation helps the child know whether he or she needs improvement in organization skills, content, or both. Without that level of specificity, setting goals from a general symbol like a C becomes challenging. There is not an appropriate level of communication about what needs to be improved for children to take control of the improvement. 
Simply separating academic behaviors from content scores does not solve the issues deeply embedded within grading practices. However, step one for your school community is to ensure that grading practices do not stifle growth.

Think About It: Take a moment to first individually consider the following stems, and then discuss them with your leadership team. From there, identify two or three concrete changes you might recommend in order to ensure grading practices do not promote fixed thinking.

- In your classroom, do you assign extra credit? Why?

- In your classroom, do you assign zeros? Why?

Acknowledge that changing long-standing, culturally accepted practices like these will be difficult. In Fair Isn't Always Equal, Wormeli (2006) suggests “thirty-six tips" for understanding resistance and collaboratively developing a plan for moving forward (p. 181). Of those suggestions, our team utilized his last one: Ask faculty members to write their own grading policy. We started simply, by articulating individual beliefs about the purpose of grades. After conversations and reading literature, teachers on our leadership team developed a purpose statement. As Wormeli suggested, it did three things:

"1) affirm(ed) our efforts that have proven successful over the years;

2) confront(ed) any of our grading philosophies that seem(ed) stale and counterproductive; and

3) rededicate(d) our efforts with students and for their learning" (p. 194).

I would add a fourth outcome for our team: It forced us to reconcile our practices with our beliefs about growth mindset. While simultaneously learning about growth mindset, teachers saw the blatant contradiction in oversimplified grades and ineffective grading practices. How can I communicate that learning from mistakes is important to me, but not allow redos of work 
for full credit? In this way, grading from a growth mindset standpoint became an outcome of our beliefs, not an initiative or push for a different grading system.

\section{How Do I Earn an "A"?}

Were you ever in a class that began with the distribution of a syllabus or course outline? If yes, I'm willing to wager you had at least one classmate who immediately flipped to the last page to see what the assignments were, or maybe you even had someone who asked, "How do we get an "A" in this class?" I am sure I did that a time or two. These behaviors illustrate not a failing on the student's part, but on the system's part. We have been trained to work for a final

symbol instead of working for the inherent growth in learning. Asking how to "win" by earning an "A" indicates many children are trained to "win" at school. We meet the requirements, jump through the hoops, earn our points, and get an "A". Traditional grading practices train children to focus much more on what they have to do than what they will learn. I believe the learner's emphasized focus on product is a direct result of a system's emphasis on summative-grading practices as opposed to formative-grading practices. IT is also indicative of a fixed mindset system. In a growth-oriented approach, we would be asking what do I have to learn instead of what do I have to earn.

\section{Formative and Summative Grading Practices}

For the purpose of our time together, let's define "formative assessment" as assessment that informs instruction or is intended to help a learner make adjustments on their way to mastery. This type of grading practice exists to guide the development of a skill or concept, and it is intended to help a learner grow. Formative assessment could be how a teacher responds to a student's answer when called upon in class, it could be watching and listening to a reader during guided reading, it could be analyzing the steps a student took in a geometry proof. Formative 
assessment is designed to analyze the process - what is the learner doing right? What is the learner doing wrong?

For the purpose of this text, I am going to use the term "summative assessment" to describe tools designed to elicit a student's final level of mastery. This may be on a test or for the whole class, but with the term summative, I'm describing a grade that communicates an end result. Examples might include a final exam, a project score, or a report card grade. Traditionally, summative assessments are intended to measure mastery, and the feedback typically focuses on the product.

Which of the two assessment types would you consider leans more toward a growth orientation? Formative assessment, surely. But the catch is that formative assessment cannot encourage growth unless feedback is its partner. When focused on what the learner needs to change, formative feedback creates an opportunity for growth. Take a moment and think about the steps involved in an effective formative feedback moment:

1. The teacher or coach analyzes the performance.

2. The teacher or coach identifies what is right and what is wrong.

3. The teacher or coach formulates feedback intended to communicate what needs to be changed and how.

This process is complex, and with good teachers or coaches, it happens naturally thousands of times a day. If, however, any step in that system is missed, an opportunity for growth is also missed. If, for example, the teacher analyzes and identifies, but only gives general feedback ("Good job" or "Almost there"), the learner may not know what to change, and growth will not occur at the same rate. Feedback is actually one of the strongest school factors in contributing to improvement for students, but it has to be specific and timely (Hattie, 2009). Marzano (2009) 
supports the importance of feedback, specifically pointing out strategies educators should use, including: 1) recognize progress toward learning goals throughout a unit, 2) provide specific feedback on all assignments, and 3) track progress on learning goals, with monitoring done by the teacher and by the learners.

Think About It: Answer individually and then discuss as a team to develop a clear understanding of how you are using formative and summative assessments, and where you can focus growth.

- At what point do you give feedback to students on their learning?

- How do you use summative assessments?

- How do you use formative assessments?

- Which do you grade in the gradebook?

- How do you give feedback to students?

We have acknowledged the major problems with traditional grading related to variance and our over-reliance on summative performances. In order to promote growth mindset through grading, what can schools do? Fortunately, most researchers in the field agree that two major adjustments to the traditional method of grading should be to grade on skills rather than content, and to allow redos and retakes until students demonstrate mastery or a formal outside deadline, like the end of a quarter, is imposed. In both contexts, frequent formative assessment, with specific feedback, should be instituted.

In a growth-mindset school community, teachers of all subjects would grade to communicate progress in learning. What I mean by this is instead of right/wrong answers on tests and quizzes, students would be assessed on their ability to apply concepts through reading, 
writing, speaking and listening. For example, instead of simple memorization of dates and times throughout history, arranging them on a timeline and explaining how each served as a cause or effect of its neighboring event would measure student progress in learning. Teachers would not average scores on all of the assignments throughout the year; rather, they would report what a student's final understanding of the content was.

In growth-mindset school community, teachers assess whatever they would like, but allow children to continually improve their performance until they reach mastery. This is the mainstay of growth mindset, because it requires the learner to look at current performance, analyze mistakes, make a plan for improvement, and then act upon it. Wormeli suggests "allowing students to redo assignments and assessments is the best way to prepare them for life" (2011, p. 22). This may seem like a nightmare to many teachers, especially secondary teachers with hundreds of students on their rosters. Wormeli pushes back, however, saying, "The recursive nature of successful learning shouldn't be discarded because it's inconvenient or we haven't figured out how to do it logistically" (p. 25). Examples of lawyers retaking the bar exam, teachers delivering and perfecting the same lesson multiple times, and surgeons practicing on cadavers further underline his point. Growth is in learning, in practice, essentially, in redos. In order to answer the real managerial questions surrounding "how can we do this?", our team used "14 Practical Tips for Managing Redos in the Classroom” (Marzano, 2011). There are many other resources, as well, that can guide your conversation.

\section{Challenges}

This sounds simple, but truly is a significant change. Thomas Guskey (2011) points out five major obstacles educators will need to address on a journey through grading reform: 1) Grades are traditionally used for sorting learners and they should not be; 2) Grades should not be 
distributed on a bell-curve. All children can demonstrate mastery of content and should be expected to do so; 3 ) Similarly, grades should not be determined by rank in a group of peers. They are not comparisons to peers, but should be comparisons of performance to content standards; 4) Some people believe low grades will encourage children to work harder, yet there is no research to support this belief; and 5) Each subject area should have only one grade. This last one may seem like the most radical idea, but I like how Guskey explains it. "If someone proposed combining measures of height, weight, diet, and exercise into a single number or mark to represent a person's physical condition, we would consider it laughable...Y Yet every day, teachers combine aspects of students' achievement, attitude, responsibility, effort and behavior into a single grade that's recorded on a report card - and no one questions it" (2011, p. 19). Wow. Isn't that the truth? A simple step our district took to begin sorting out this complex process was to create a checklist of academic behaviors, which would be reported separately from academic content. Therein lies the greatest challenge - you can change your tool, but if practices do not change with it, teachers may continue to include those behaviors (neatness, deductions for late work, effort) in the content grade and doubly report on the academic behaviors checklist. I urge caution - you must be sure practices are separated before an additional report is added.

Although caution is warranted, there is great danger in not changing. Without this type of a system in place, grades could unintentionally perpetuate fixed mindset thinking. Children without an opportunity to improve scores could begin to identify their performance with their ability. We know those things are not synonymous, but without an opportunity to improve, growth is not a factor in grading. Because grading is such a large part of schooling, left unchecked, it could weaken a school's ability to promote growth mindset. 


\section{What Can We Do?}

1. Decide upon the purpose of assessment in your learning organization (Costa \& Kallick, 2008) and come to consensus (Brookhart, 2011). We did this through individual reflection of the purpose of grades, followed by a study of grading and assessment literature, at the same time we were learning about mindset. Ultimately, we are developing a grading purpose statement for our organization. This would serve as the guidepost for all grading decisions.

2. Review the research on feedback and determine how it will play a role in your learning organization.

$\checkmark$ The best one-stop shop and easily-digestible resource I can recommend is the 2011 issue of Educational Leadership called Effective Grading Practices. It's a veritable Who's Who of grading gurus, and the articles are short but discussionprovoking. Our team would read an article with guiding questions and then discuss at our monthly meeting. Then team members would facilitate a similar discussion on their own teams. This also encouraged the distribution of leadership and allowed connections to naturally emerge between this team and the work going on with other teams, including professional development and mindset.

$\checkmark$ In our first steps toward implementing this type of system, our leadership team devised a simple "Growth Note" (Brock \& Hundley, 49) to use with students in their classrooms. A blank copy is available in Appendix D.

3. Establish guidelines for formative assessment

4. Make decisions on the role of academic behaviors in grades 
$\checkmark$ Again, our district's template is in Appendix C, but please remember that the work is in the practices, not just the tool. What will change in our classrooms as a result of adopting such a tool?

5. Discuss zeros and extra credit

$\checkmark$ Can your building come to consensus on the implication of zeros and extra credit on a growth mindset culture? If so, what practices will you support and prevent in your school community? 


\section{CHAPTER V: BEHAVIOR MANAGEMENT}

A growth mindset school community will view the behaviors children display as signals for instruction; as in all things, mistakes provide an opportunity to grow. Students with repeated behaviors are not labeled as "troublemakers" because in a school culture with a growth mindset, educators not only avoid these types of dangerous labels, but they also believe there is a solution and they are committed to finding it. They also realize this occurs by first seeking to understand the child, know him or her as a person, and work collaboratively to discover strategies that will lead to success. This chapter will contrast traditional approaches to behavior management with growth-oriented approaches, including restoration and reflective analysis.

I attended Kindergarten, first, and second grades at Powers Elementary School, which was one of those towering Horace Mann designs from the Common School movement in the early 1900s. I believe the year 1906 was inscribed above the front door, just below the school name and the word "Boys", indicating which door each gender was to use. In a certain sort of nostalgic way, it was a beautiful building - stone, with large steps, big windows, shiny floors. I remember being in Mrs. G's second grade class, which was all the way on the third floor - it was cozy in the winter, heated with cast iron radiators, but unbearably hot in the early fall and late spring. It was in that classroom one late spring day that my classmate, Samuel Cavasos, convinced all of us about the importance of behaving at school. The classroom doors were all open in an attempt to lure the breeze through the windows and hallways. The high hallway ceilings provided an acoustic tunnel, so sounds traveled easily. Samuel had been called down to the principal's office for misbehaving on the bus, and I remember him walking out of our open classroom door. I also remember his footsteps echoing down the hallway. Why do I remember all of this so clearly, but not even what his specific infraction was? It's because Samuel was "in 
trouble", and that's all we needed to know. Ten minutes later, I jolted upward in my chair as our whole class heard him crying out from three floors below. Samuel had been paddled for his "bad" behavior, and we were all terrified.

Certainly, this wasn't the first paddling at my school, but for whatever reason, I can recall it like it was yesterday. For me, it was the moment fear at school created compliance at school. I also know we "towed the line," because in our school, accountability meant punishment. Thomas Newkirk, author of Embarrassment, refers to what psychologists call "flashbulb memories" (2017). These memories are so vivid because of the intense feelings associated. After this particular incident, I know my mind was made up: We behaved "or else", and for the most part, we must have been compliant, because I do not recall many other instances like that one. Many of you may have similar stories, either from school, or from your childhood home life. This type of behavior management is certainly effective in forcing compliance from a perspective of fear, but did it encourage us to learn and grow behaviorally, or were we just complying because we didn't want a spanking? That's a rhetorical question, I believe.

I understand the topic of student discipline causes frequent debate. Embedded in daily discourse are two divergent beliefs. One group of you may prescribe to the Who-Cares-if-TheyAre-Learning-and-Growing-They-Need-to-Behave Camp. Others of you may feel children need to understand the impact of their behaviors and the benefit of good behavior for everyone if we want to create compassionate citizens. Why these different views? Most of our thoughts on discipline are created from our personal experiences as children, and because we were all children once, we tend to view ourselves as experts on the topic. We view the way we experienced behavior management as either effective or horrible, and that establishes the way we will encourage compliance as adults. If we become parents, we might adopt the same strategies 
our parents implemented, or maybe we will vow to be totally different. As teachers, we bring our childhood experiences from home and school into our classrooms, because those formative experiences have framed our beliefs (Smith, Fisher \& Frey, 2015).

\section{Take a minute:}

- Do you think of behavioral growth in the same way you think of academic growth?

- Do you recall specific instances of student discipline growing up? Describe how this has possibly impacted you.

- What was behavior management like in your home? Has that impacted you as an educator?

\section{Fairness in Schools}

Frequently, beliefs about student behavior are intertwined with a sense of fairness. It's not surprising, really, that it is a topic rife with emotion. If you look at the news, you see politicians arguing over a health care bill because adults cannot agree on what is "fair". Elected officials constantly debate tax code, and why? Because different people have different ideas of what is fair. As adults in schools, dealing with disruptive behaviors and the importance of consequences, the word "fair" is used frequently. Fairness is a very important concept for many people. Some researchers even suggest the concept of fairness is established in early childhood (Schmidt \& Sommerville, 2011). Have you ever seen snack time in an elementary school? "He got more goldfish than I did! That's not fair!” That exact snack-time battle cry may be

responsible for the popular preschool phrase, "You get what you get, and you don't throw a fit!"

In this chapter, I will suggest that instead of punishing and evoking fear, we should encourage restoration, built upon feelings of empathy and justice. I also believe we need to approach behavior in the same way we approach academics - they are skills that should be 
taught, retaught, and if that doesn't work, collaboratively investigated with the student or a team

of colleagues. At no point should a teacher, administrator, or school espouse fixed beliefs about student behaviors. Growth mindset should be the mainstay, especially with behavior, and that will encourage us that improvement is possible with everything. Our actions related to student behavior should reflect that belief.

\section{The Case for Growth Mindset in Discipline}

Why do we need to change the way things have been done? The traditional sequence looks something like this: A child misbehaves so we give them a consequence. If that consequence doesn't work, we add onto it or administer a more harsh consequence. If we can't find a punishment bad enough to create compliance, then the child is labeled a delinquent and maybe even sent to another school; one for "those" types of kids. This may seem dramatically exaggerated, but some form of that sequence exists in almost every school. Why?

I believe this traditional path is used for two reasons. First, what other option do we have? What tools are we equipping our teachers with in terms of uncovering the reason for the behavior and supporting the child's needs instead of treating the symptom? I would say not enough. In pre-service education, courses on functional behavior assessments should be requisite to help teachers do less managing of behavior and more teaching and meeting needs. At this point, however, schools can provide professional development on more effective approaches, including training on Functional Behavior Assessments, Restorative Justice, and formal reflection.

The other reason I believe educators still use this traditional path is because it is how they were taught. In the absence of a better path, people will resort to what they know. After all, "It worked for me!" Well, people may say it worked, but did it, really? Data suggests traditional, 
punitive approaches to student discipline are not only ineffective, but also inequitable. According to the United States Office of Civil Rights data, black students are three times more likely to receive exclusionary discipline, including suspensions or expulsions. Black boys and girls are suspended more frequently than their peers, with $20 \%$ of black boys getting an out-of-school suspension and $12 \%$ of black girls, compared to $6 \%$ of white boys and $2 \%$ of white girls (OCR, 2014). Did you also know that male students receive eight times as many corrections as females? Eight times! How can that be? Surely, you don't believe boys are inherently worse than girls, or minority children worse than their peers in the majority. Unfortunately, however, that is the story our data is telling. That is not the story we want told. The dissonance between reality and our ideal should cause us to carefully examine our practices. Such examination of these practices lead to questions about our beliefs.

In addition to concerns about disproportionality, these exclusionary policies create opportunity gaps. If children are not in class, they are unable to learn the new content at the same rate as their peers. If a large percentage of one groups of people is excluded from class, the results could have a significantly inequitably negative impact. Consider, for example, suspension data. If $20 \%$ of black boys miss long division in $4^{\text {th }}$ grade, what impact might that have on their ability to enter an advanced math track in middle school? Contribute to advanced mathematics beyond high school? This sickening possibility of wasted potential makes our approaches to behavior management incredibly important.

Incentives, rewards, consequences, shame, humiliation, fear, suspensions, expulsions: Many of these strategies may have short-term effects, but are they lasting? Do they foster growth? The simple answer is no. Each are attempts to control rather than to foster self-control 
through learning and personal growth. Why not implement systems that value empathy over power?

The other lesson my classmates and I learned from Samuel's experience in second grade was that he was a "troublemaker". Sadly, that label stuck. In the same sort of way you might debate what came first, the chicken or the egg, you could either say the label followed Samuel, or created Samuel. Behavior management with a growth mindset would have the notion that you are not defined by your behavior. It would focus on teaching students they can learn and grow in behavior the same way they can improve their skills in reading or on the basketball court. This would require teaching skills, practicing them, and affirming the process while avoiding labels such as "good" or "bad".

\section{What Do Effective Teachers and Schools Do?}

In his book, Star Teachers of Children in Poverty (1995), Martin Haberman profiles highly successful teachers in situations with significant challenges. Haberman's work illustrates commonalities between urban teachers collected over twenty years of observations, surveys, analysis of student performance, and interviews. He unapologetically points out what "star teachers" do in contrast with "failures and quitters" (Haberman, p. 5). His harsh language may seem off-putting unless you read his passionate forward, in which he plainly points out his purpose for writing such clear and pointed work. "For the children and youth in poverty from diverse cultural backgrounds who attend urban schools, having effective teachers is a matter of life and death. These children have no life options for achieving decent lives other than by experiencing success in school. For them, the stakes involved in schooling are extremely high" (Haberman, p. 1). The teachers who beat the odds in these challenging settings are different than their colleagues in many ways, and at the core of those differences are the ways in which they 
approach student behavior. Specifically, these teachers use meaningful learning activities to create disciplined students, they use logical consequences instead of punishments, and they develop classroom climates in which learning interesting content is the reward instead of trinkets or external motivators. Each of these strategies is built upon authentically knowing their students. Through discovery of each individual, teachers can find interests, learn triggers, and understand how to engage their individual students. That sounds challenging, doesn't it? But one of the greatest parts about Haberman's research is that his subjects faced the most challenging circumstances in public education, yet they were able to accomplish those challenges. So maybe instead of asking whether or not those expectations are realistic, perhaps we should ask how much of a teacher's time is spent correcting, disciplining, or attempting to control behaviors if these characteristics are not present in our teaching.

Behavior management is not separate from teaching, nor is it simply a bulletin board of rules. Teaching behavior is embedded within the natural work of interactions between teachers and students, and effective do not spend the majority of their time or efforts singularly focused on behavior (Haberman, 1995; Marzano, 1996; Hattie, 2009). Instead, effective teachers assume they will have behavior issues instead of expecting a classroom full of children who are identical (Kohn, 2005). Effective teachers know they will be needed, especially because they have the closest relationship with and understanding of their students.

Effective teachers have simple expectations for behavior, they avoid meaningless work, and they understand there will be behavioral issues for which their guidance will be needed. Their individual attention and work with children results in caring relationships - they know their students' likes and dislikes, they know their families, and they have formed connections with them. This relational trust makes misbehavior less likely for several reasons. First, it is 
much easier to misbehave or show disrespect to a stranger than someone with whom you have a relationship. In a caring classroom culture, children do not want to damage relationships with their peers or teacher because those relationships are not only important and valued, they are the key to being part of the classroom community. When a child and a teacher genuinely care about each other, typical classroom management nightmares are avoided. In addition, truly knowing a child can alert the teacher to heightened emotions and situations that may trigger behaviors, allowing an opportunity to avoid them altogether. Teachers who are not successful are often unaware of such antecedents, or they perceive compliance as a duty.

\section{Positive Behavior Supports and Interventions}

Positive Behavior Supports and Interventions, or PBIS, is an approach to preventing problem behaviors through teaching expectations and focusing on positive examples. It finds a place in this chapter because its philosophy is built upon finding a way for all students to find behavioral success. It is not a punitive design, a point system, or a gotcha. Instead, this structure is set up to provide varying levels of support based on varying levels of students' needs. A universal tier, or Tier 1 , teaches expectations, models and reinforces the expectations. This level of support is typically sufficient for about $80 \%$ of the students in a building. Tier 2 is a supportive intervention tier, designed for $10-15 \%$ of the students in a school building, and it offers targeted interventions to help these students improve. The top tier, called Tier 3, is even more intense supports designed for children who still have difficulty meeting expectations with Tier 1 and Tier 2 supports. Often, this 5-7\% of the population are the children for whom this chapter is written. These kiddos require extra problem solving and individualized instruction in order to meet behavioral expectations while at school, and often for good cause. Regardless, a PBIS approach is designed with the belief that the school and its partners will work with a child 
until the right level of support is found for them to be successful. This is growth-oriented. We will help you until you can succeed on your own, and we believe you can! This approach "can decrease the intensity and frequency of misbehavior, increase instructional time, improve student academic achievement, and enhance the school culture and climate" (Lawrence \& Hinds, 2016, p. 21). That should come as no surprise, given what we've discussed about Pygmalion Effects and Self-Fulfilling Prophecies (Rosenthal, 1968; Tauber, 1997). If we believe in a child's ability to improve his or her behavior, our actions will be reflective of that. Our actions will communicate our beliefs, and that will influence their own beliefs about their abilities. Their actions will reflect their beliefs. In contrast, if educators do not believe a child can or will improve his or her behavior, that belief will likely become truth. PBIS provides a structure to help develop improvement initiatives for behaviors.

Still, PBIS is not without criticism. Heavy focus on external motivators like "Behavior Bucks" creates a misplaced focus on the points Haberman (1995) made about star teachers. While the system approach to examining data and supporting student behavior is a growthoriented approach, bribing children to comply is not an investment in developing their skills. Additional research revealed PBIS does not assist in reduction of disproportionality, and can, in some cases perpetuate institutionalized racism (Bornstein, 2017). In the example, an overreliance and misplaced faith in the "neutral parameters" of PBIS caused the district to treat the symptoms of a systemic issue instead of investigating and addressing the root cause. In other words, by relying on PBIS to solve their disproportionality issues, the district failed to authentically determine the cause of their failure to serve students equitably (Bornstein, 2017, p. 135). The lesson in this case study is to use PBIS as a tool, but not a one-stop-shop solution to creating ownership of systemic issues and or developing growth through behaviors. 
Additional criticism of PBIS and traditional classroom management results from heavy reliance on culturally-constructed, ambiguous terms like respect. Interpretation of the word respect requires filtering through personal lenses. In other words, each person's definition of respectful behavior is built upon personal experiences, cultures, and influences. Carol S. Weinstein (2004) writes, "Definitions and expectations of appropriate behavior are culturally influenced, and conflicts are likely to occur when teachers and students come from different cultural backgrounds" (pg. 25). Misinterpretation of the intent behind actions can occur when behaviors are taken at face-value and applied singularly to a teacher's beliefs about respectful actions, instead of filtering student choices through their cultural lenses. Therefore, systems like PBIS which popularly tout "Be Respectful, Be Responsible, and Be Safe" as mainstays of behavioral expectations set up conditions for cultural bias to impact student discipline data. This is especially true if the group in authority (teachers) are not representative of the group to whom the standard is being applied (students).

Additionally, in many cases, implicit bias may also contribute. Teacher implicit bias is "a behavior that arises from subconscious associations, which may even contradict someone's explicit values" (Suttie, 2016). Implicit bias may explain why a teacher may passionately and honestly espouse beliefs about all children's capacity for learning and growth, but data indicates differential treatment. The reality is we all have biases, based on a variety of experiences, and some of those contributions were discussed in the opening section when we discussed cultural construction of ability. Embedded within each of those contributions - society, community, class, race, gender - are factors that create bias, opinions, beliefs. It does absolutely no good to proclaim neutrality; in fact, that can exasperate the problem and manifest the harmful effects of implicit bias. Instead, a growth mindset school community would take the time to carefully 
unpack what biases may exist in order to monitor thinking and behaviors toward those inclinations. If we do not take the time to develop an awareness and subsequent protections against our biases, our children will become victim to our likely unintentional, but still differential treatment.

Specific steps you can take with your leadership team combat unintentional prejudice are outlined in an article by Jill Suttie (2016) called Four Ways Teachers Can Reduce Implicit Bias, and her work informed the activities and progress of our team. Specifically, teachers can prevent bias from impacting their work with students by: 1) "develop an awareness of their biases", 2) “work to increase empathy and empathetic communication", 3) "practice mindfulness and loving-kindness", and 4) "develop cross-group friendships in their own lives": (Suttie, 2017, pg. 4). As in everything, trusting relationships must be established in order to help teachers move through these four strategies, but with honest conversations, metacognition, and regular reflection, these steps have proven to decrease actions associated with implicit bias.

\section{Restorative Practices}

Restorative Practices are established to repair damaged relationships and resolve conflicts (Gonzales, 2017). Restoration requires a growth-orientation, because it is about teaching and learning rather than punishing. Instead of being punished or "cast aside", which in severe cases leads to being excluded from school, Stella Levey, the founder of the Restorative Schools Vision Project explains restoration as an opportunity to offer "a nurturing environment to grow, learn, make mistakes, develop good judgment, and thrive" (Gonzales, 2017). Restorative Schools support children by helping them identify not only what they did wrong and why, but also how their actions impacted those around them. This provides a starting point for making positive change in the future, which implies growth. In fact, proponents for focusing on restoring 
relationships damaged through poor behavior choices have described it by saying "each incident of conflict and wrongdoing represents an opportunity for learning" (Costello, 2009, p. 53) When viewed that way, behavior management can perpetuate a growth mindset school culture.

Through restoration, the growth is not isolated to their personal actions. There is also an embedded expectation - and appropriate support - for growth related to effective relationships. Restorative practices emphasize the importance of repairing the damage done to relationships that matter. In Restorative schools, students are asked to consider the ways their actions hurt people about whom they care: How did their actions hurt their teacher, their classmates, their friends, their family members? After facilitated conversations intended to help the child identify and articulate those effects, the child makes amends with those their actions have hurt. This can be done through conversations, conferences, class meetings, circles - the approaches are varied, but their goals are similar. Instead of punishing, the focus is on reflecting and facilitating change because while the actions are undesirable, growth minded educators always see the child for the valuable person he or she is. They "separate the deed from the doer" or "separate the person from the problem"; in order to do so, emotional reactions should be kept in check (Costello, Wachtel, \& Watchel, 2009, pg. ; Gonzales, 2017). Although emotional reactions are undesirable, adding a personal dimension to the reflective conversation is important. Children should see they are cared for, and because of the caring relationship, their actions were hurtful. This communicates value in the relationship and the child's place in the classroom community (Costello, Wachtel, \& Watchel, 2009).

Restorative practices help students see how their actions impact others, requiring them to be accountable to their peers and school by making amends and strengthening relationships (Costello, 2009). By adopting such a stance, we are sending a message of the value we put on 
our relationship with the child, as well. Instead of assigning a consequence or kicking a child out, we are seeking to understand and inviting him in. Implementing such practices communicates a clear belief about improvement and growth. Through building stronger relationships, we get to know one another better, and that fosters respectful engagement throughout the school building.

Restorative practices have created significant improvement in climate and student behavior at school (Costello, Wachtel, \& Wachtel, 2009). When a school community believes conflicts can be resolved collaboratively and that children can be taught traits of empathy and conflict resolution to develop caring communities, a growth mindset related to behavior will result. Therefore, it is worth your team's time to invest learning and understanding in the development of restorative practices. Just as PBIS has the potential to provide a systemic structure for examining data and trends for the purpose of growth, restorative practices have the potential to invest in individual students for their ongoing development as learners. Without such practices in place, punitive measures like exclusionary discipline will perpetuate fixed thinking about children with behavioral issues. Further, those types of consequences exacerbate a child's ability to learn, participate as part of their classroom community, or foster relationships with adults in the school. Traditional discipline policies are ineffective, and when viewed through a growth mindset lens, are contradictory.

\section{Growth-Oriented Behavior Management}

This is not meant to be an exhaustive resource on behavior management; rather, the chapter's purpose is to emphasize the importance of behavior approached in a growth mindset way. In order for that to occur, your school community must objectively inventory teacher, student, and parental beliefs about behavior. From there, your leadership team should provide 
tools that show traditional fixed methods are not the only way. As a team, examine the behaviors of effective teachers. They most certainly do not accept poor choices or allow disruptions to rule their classrooms. What specific things make their environments more conducive to learning and growing? Three key factors are caring relationships between teachers and students, simple and positive expectations for all children, and meaningful engagement in content (Haberman, 1995; Marzano, 2003). Certainly, those criteria should form the basis for any successful approach to behavior management. In addition, adding a growth-oriented perspective to behavior will remove some of the emotions attached to behavior difficulties that are not inherently attached to academic challenges. Seeing all children as capable of achieving good behavior becomes easier when you intentionally "separate the deed from the doer" (Costello, Wachtel \& Wachtel, 2009).

Our team utilized a reflection form as the first step in a restorative conversation with students. You can see it in Appendix E and modify it for your use. It was most effective when paired with a coaching conversation with a caring staff member, which we provided. You will notice that the form requires students to think forward: What will I do differently? How can I learn and grow from this situation. In that, our growth mindset was effectuated through our discipline conversations. Similarly, we used a series of questions for restorative conversations when behaviors reached a point they were damaging relationships and classroom community. Those questions are included in Appendix F.

Teachers begin each year knowing their students must learn academic content they do not already know. Haberman (1985) says Star Teachers adopt the same stance with behaviors. They assume their professional skills will be needed in teaching children how to manage their emotions, resolve conflict effectively, and meet expectations. A growth-oriented behavior 
management plan will articulate the plan for teaching behavior the same way an instructional plan might articulate how to teach phonics. Some children learn academic content more quickly than others, and some children will learn behavioral expectations more quickly than others.

Think about it: Do you have students in your class who are a year or more behind as readers? Why should you not have children who behave more immaturely than their peers? Do you have students who seem to have difficulty grasping specific math concepts? Why should you not have students who cannot seem to conform to social rules? Deficiencies should be assumed, for teaching behaviors is not separate from teaching children. Your job is to teach children what they need and to meet them where they are. This is true, obviously, of content. It is also true of behavior. Plan for challenges with behaviors in the same way you anticipate having difficulties in mastery of academic content, and that paradigm shift will be a good first start.

You have created the optimal conditions for learning. You have stated your expectations and students understand them. You know your children well, and you feel connected as a classroom community. Those foundations must be in place. In addition, you need to take some time to reflect on your personal beliefs about behavior. Do you think teaching behavior is part of your job? If not, this isn't going to work, and really, it's best to be honest about that. Many educators would agree with you, noting the role of the family, or the church, or an innate desire to behave. If you feel that way, your work in this section is going to be more reflective and personal than the rest of this chapter suggests.

The following questions are important and not something to rush through or overlook. For meaningful change to occur, it must start internally. The development will happen at different paces for different teachers, and it shouldn't be rushed or forced. If it is, you will get 
superficial compliance instead of growth-oriented results. And really, isn't time spent on those questions meaningful growth?

\section{Think About It:}

- Take some time to identify the positive and negative consequences of your current beliefs. Then think about what is occurring in your classroom. When behavioral issues arise, how are they handled?

- How do students respond, both those who have the challenge and those who are watching?

- What labels or fixed thinking may be attached to specific children?

- How do those labels connect to your implicit bias?

Once you feel ready, communicating with your classroom that you believe in their growth as learners and people is a crucial statement and should be part of your recurring conversations. Paired with reflective journaling and metacognition to monitor your bias, this type of overt statement of belief can have a significant impact. An explicit mini-lesson at the start of the year will assist with establishing your beliefs about the children in your room, and also your expectations for their growth. In a middle level classroom, that might look something like this:

Teacher: We are going to learn a lot together this year. I'm looking forward to hearing your ideas and watching you grow. Other than the academic content we are going to cover, I am also excited to watch you develop personally. Some of you may have personal habits you are ready to outgrow - calling out, biting your nails, dominating or avoiding group work; and others of you may have behaviors that you want to overcome outbursts of anger, feelings of inadequacy, hyper-awareness of others' opinions of you. One thing I need to improve on personally is dealing with my stress constructively. At 
the end of the day, I can get overwhelmed, and sometimes I let things build up, so this year, I'm hoping to find some specific strategies to cope with that so I don't collapse in exhaustion at the end of the day, or snap at my husband when he gets home from work. Today, we are going to spend some time thinking about how we want to improve from our work together this year, because I am here to help you grow as a student - and that means in your academics as well as your behaviors. 
Figure 4. Academic and Personal Growth Tool

\section{What I Expect for my Academic Growth}

Something I Would Like to Improve:

\begin{tabular}{|l|l|l|l|}
\hline Teacher's Role & Student's Role & Growth Target & Progress Check \\
\hline & & & \\
\hline & & & \\
\hline
\end{tabular}

\section{What I Expect for my Personal Growth}

Something I Would Like to Improve:

\begin{tabular}{|l|l|l|l|}
\hline Teacher's Role & Student's Role & Growth Target & Progress Check \\
\hline & & & \\
\hline & & & \\
\hline
\end{tabular}

This could be done individually, with the teacher interacting with students as they complete it, or in pairs, depending on the climate of the classroom and group of students. The important thing is that the teacher goes first, and that there is no requirement to share publically.

In an elementary classroom, the Morning Meeting provides a perfect structure for ongoing connections to create the culture you want for behavior and beyond. The standard setting for morning meeting is some type of circle that begins with a greeting. Using children's names and including a chant or cheer to make each child feel welcome is a signature part of the routine, designed to demonstrate each participant's value to the community. From there, the teacher can facilitate a mini-lesson that is responsive to the classroom's current needs. Sometimes that lesson may be more academic in content; other times, it provides social- 
emotional instruction. In the case of managing specific behaviors, it can offer a structure for restorative conversations and shared expectations for one another (Responsive Classroom, 2015). By addressing issues in this manner, resolving situations is embedded in the fabric of the classroom culture and teaches children that conflict is part of life. It also communicates the interconnectedness of all members of the classroom as a community of learners, dependent upon each other.

\section{When Behaviors Occur}

Remember, star teachers assume they will have behaviors to address over the course of the year, and their responses will communicate their beliefs more than any mini-lesson ever could. All behavior has a reason, and is designed to communicate something (Minahan \& Rappaport, 2012). Fixed thinking attributes behavior to a student's personality or set trait. For example, He's doing this because he is a troublemaker. Or, Her dad was always in trouble, and

the apple doesn't fall far from the tree. These types of responses are fixed; they leave little belief in the student's ability to change. Another example of a fixed response would be, I don't know what else they expect me to do with him. He really belongs in the special education room. While some children definitely need a structured setting for behavior and emotional disabilities, the statement communicates the teachers' fixed thinking about his or her ability to help the child grow behaviorally, and interventions will have a difficult time overcoming a teacher's expectations, which we have previously discussed as incredibly powerful. These reactions all indicate a fixed approach to developing the child's behavior, because they communicate change and improvement cannot occur. You can catch this thinking through daily journaling in the Glow and Grow Journal, or by analyzing your thoughts in another systemic manner. Patterns may reveal implicit bias that can be discussed with your accountabilibuddy or leadership team. 
Whatever system works best for you, use it. The approach is less important than the commitment to ongoing self-monitoring.

A growth-oriented approach to student behavior focuses on improvement through understanding. Rather than labeling, this approach requires teachers to understand behavior is communication and typically presents patterns. Teachers must believe that behavior can be changed, and their work should be focused on those beliefs. In minor instances of behavior corrections, this is easier than in situations where behaviors are repeated and more significant. It is in the more challenging instances we typically see fixed-thinking emerge, and that is where we will spend the remainder of this chapter.

For repeated behavioral concerns, teachers should involve a team that consists of people who could help develop a growth-oriented plan for improvement. Each situation is different, so professional discretion should be used to develop the team, but certainly anyone the teacher thinks could contribute to an understanding of the purpose of the behavior, leading to a plan for changing the behavior, should be included. This could range from a school nurse, the child's family, a colleague, a school psychologist or social worker, or other specialist. Depending on the student's age and the specific situation, the child could be included. Once established, the team's work should include collecting data to determine a pattern of antecedents and responses. This data, typically collected through observations, interviews, and individual input, is then used to develop a behavioral intervention plan. The behavioral intervention planning begins when the team analyzes their data to form a hypothesis of the purpose (or function) of the behavior. Why is the child performing this behavior? Typically, those functions include attention, escape, tangible reward, or sensory satisfaction (Minahan \& Rappaport, 2012). The data is also used to develop a pattern of consequences, What is the child getting as a result of the targeted 
behavior?, and setting: Is there a certain place or time this occurs most frequently? Again, this data must be viewed through a problem solving lens in that the team believes a solution exists and improvement is not only possible, but will occur. If fixed-thinking begins to permeate the conversation (He's never going to change. I've tried everything.), taking a break and addressing the thoughts behind those comments is essential. Please note, fixed-mindset comments are different than dismissing a specific strategy or approach, especially when dissent is grounded in data from previous attempts. Pointing out flawed thinking is not fixed; in fact, encouraging divergent thought can be helpful for growth. If, however, comments suggest the child's behavior will never change or that the child is incapable of change, the efficacy of any Behavioral Intervention Plan is unlikely, because the implementer's expectations will interfere with its implementation. One method for monitoring this is to identify a team member as a mindset monitor. When conversations begin to take on a fixed mindset perspective, that person would suggest a break. After the break, the monitor should facilitate team identification of the fixed thinking and understanding of its inception.

There are several good resources for behavior intervention plans, and our teams have found huge support in The Behavior Code (Minahan \& Rappaport, 2012) and The Behavior Code Companion (Minahan, 2014), as well as Positive Behavior Support at the Tertiary Level (Riffel, 2011). A growth-oriented tool for developing a functional behavior assessment (FBA) and subsequently a Behavioral Intervention Plan (BIP) are two tools that can support the shift from fixed-thinking about behaviors to more growth-oriented approaches. Following is an example of each that may be of use to your teams. 


\section{Functional Behavior Assessment}

1. Collect data

a. Conduct at least three observations, interview the student and teacher, and ask for any discipline data or teacher notes.

2. Analyze the data individually. Each team member should

a. Code for antecedents, what happened before the event and consequences, what was a result of the event. In this instance, consequences are not things the teacher assigns; rather, the team is looking for what the child got out of the action.

b. Draft a possible hypothesis by considering what might be motivating the choices.

3. Discuss analysis as a team

a. Table 5 is intended for group discussion, adapted from Jessica Minahan \& Nancy Rappaport's The Behavior Code: A Practical guide to Understanding and Teaching the Most Challenging Students, 2012. 
Table 5

Behavior Analysis Tool

\begin{tabular}{|c|c|c|c|c|c|}
\hline $\begin{array}{c}\text { Date \& } \\
\text { Time }\end{array}$ & Setting & Activity & $\begin{array}{l}\text { Antecedent* Behavior* } \\
\text { (what } \\
\text { happened } \\
\text { right before } \\
\text { the } \\
\text { behavior) }\end{array}$ & $\begin{array}{l}\text { Consequence } \\
* \text { (what } \\
\text { happened } \\
\text { immediately } \\
\text { after the } \\
\text { behavior) }\end{array}$ & Hypothesis \\
\hline
\end{tabular}

General hypothesis of targeted behavior:

*The ABCs (Antecedent, Behavior, Consequence) will be used for the Behavioral Intervention Planning process.

\section{Growth-Oriented Behavioral Intervention Plan}

Once the team feels they have analyzed enough data to fully understand the function of the student's behavior, they can develop a growth-oriented behavioral intervention plan. This plan's purpose is to carefully identify the behavior that needs to be changed in light of why it is occurring and what may be unintentionally contributing to its existence. Because it is designed with change in mind, it can inherently be considered growth-oriented, but if done incorrectly, it is not growth-oriented at all. For example, if a team sees a Behavioral Intervention Plan as merely a data collection mechanism to prove the child cannot behave, or to fulfill a requirement for a special education referral, it will not be effective. The purpose of improving the targeted behavior must be agreed upon and believed in by all members of the team, otherwise it is doomed from the start. Following are some guiding principles: 
1. Acknowledge that challenging behaviors are emotionally draining and tough. Your staff needs to know you are there to support them in order to support the child, and they need to hear that you believe in them, as well as in the ability for the child to grow. Behavior Intervention Plans are messy, but they are opportunities for everyone involved to grow. $\mathrm{Be}$ in the process together.

2. Cleary articulate the purpose of a Behavior Intervention Plan. It is designed to help the student find success, have his or her needs met in the classroom, while respecting the needs of his or her peers. It is a tool for growth, and all team members will have a role.

3. Carefully develop the target behavior so it is very specific, measureable, and observable. If a team wrote, "Christy will behave appropriately," the plan is not growth-oriented because it is not specifically designed to help her improve, and it will therefore be ineffective. The behavior must be specific.

4. Spend time discussing the antecedents and what can be altered in the environment to avoid the antecedent.

5. In discussing the targeted, replacement, and goal behaviors, carefully consider what intentional or unintentional benefits exist for each.

6. Create a simple way to track improvements.

7. Table 6, adapted from Riffel's Positive Behavior Support at the Tertiary Level (2011), may be helpful in guiding the development of a plan. A landscape version is available in Appendix G, and an editable version is available on the electronic resources. 
Table 6

Growth-Oriented Behavior Intervention Plan

\begin{tabular}{|c|c|c|c|c|c|c|c|}
\hline \multicolumn{3}{|c|}{ Student Name } & \multicolumn{3}{|c|}{ School } & & \\
\hline \multicolumn{3}{|c|}{ Team Members Participating } & \multicolumn{2}{|c|}{ Teacher } & & & \\
\hline Envir & nment & & & $\mathbf{B e}$ & ivior & & \\
\hline $\begin{array}{l}\text { Antecedent } \\
\text { What event or } \\
\text { setting takes } \\
\text { place prior to } \\
\text { the target } \\
\text { behavior? } \\
\text { What is the } \\
\text { student getting } \\
\text { from that? }\end{array}$ & $\begin{array}{l}\text { Antecedent } \\
\text { Manipulation } \\
\text { What } \\
\text { settings/context } \\
\text { s/antecedents } \\
\text { can you modify } \\
\text { to make } \\
\text { proactive } \\
\text { changes in the } \\
\text { environment to } \\
\text { make the target } \\
\text { behavior } \\
\text { unnecessary? }\end{array}$ & $\begin{array}{l}\text { Targeted } \\
\text { Behavior: } \\
\text { What } \\
\text { behavior do } \\
\text { you want to } \\
\text { improve? }\end{array}$ & $\begin{array}{l}\text { Targeted } \\
\text { Behavior } \\
\text { Benefit: } \\
\text { What adult or } \\
\text { peer behaviors } \\
\text { may be } \\
\text { encouraging } \\
\text { or reinforcing } \\
\text { this behavior? } \\
\text { Positive and } \\
\text { negative } \\
\text { consequences } \\
\text { should be } \\
\text { included. }\end{array}$ & $\begin{array}{l}\text { Replacement } \\
\text { Behavior: } \\
\text { What new } \\
\text { behaviors } \\
\text { might you } \\
\text { teach to } \\
\text { replace the } \\
\text { targeted } \\
\text { behavior? }\end{array}$ & $\begin{array}{l}\text { Replacement } \\
\text { Behavior } \\
\text { Benefit: } \\
\text { How might you } \\
\text { change the } \\
\text { adult behavior } \\
\text { regarding the } \\
\text { original } \\
\text { targeted } \\
\text { behavior and } \\
\text { the new } \\
\text { replacement } \\
\text { behavior? }\end{array}$ & $\begin{array}{l}\text { Goal } \\
\text { Behavior: } \\
\text { What do you } \\
\text { want the } \\
\text { student to do } \\
\text { instead? }\end{array}$ & $\begin{array}{l}\text { Goal } \\
\text { Behavior } \\
\text { Benefit: } \\
\text { What adult or } \\
\text { peer responses } \\
\text { or behaviors } \\
\text { will encourage } \\
\text { the goal } \\
\text { behavior? } \\
\text { What is the } \\
\text { benefit to the } \\
\text { student, and } \\
\text { how will the } \\
\text { student know? }\end{array}$ \\
\hline
\end{tabular}

What is the child's reason to grow?

How will this plan be monitored? By whom?

Start Date: Data Review Date:

\section{Scenarios}

Either individually or with your team, discuss the scenarios in Table 7 and how you might respond from different perspectives in your building. 
Table 7

Behavior Intervention Planning Practice

\begin{tabular}{|c|c|c|c|c|}
\hline Scenario & $\begin{array}{l}\text { Star Teacher } \\
\text { Analysis } \\
\text { What could } \\
\text { have prevented } \\
\text { this from } \\
\text { occurring? }\end{array}$ & $\begin{array}{l}\text { Teacher Take } \\
\text { The class is } \\
\text { watching you. } \\
\text { How do you } \\
\text { respond? }\end{array}$ & $\begin{array}{l}\text { Colleague/team } \\
\text { Member } \\
\text { Your teaching } \\
\text { friend tells you } \\
\text { about this in the } \\
\text { hallway. How do } \\
\text { you respond? }\end{array}$ & $\begin{array}{l}\text { Building } \\
\text { Leader } \\
\text { The teacher } \\
\text { comes to you } \\
\text { and shares this } \\
\text { situation. How } \\
\text { do you } \\
\text { respond? }\end{array}$ \\
\hline
\end{tabular}

It's Tuesday, and Gavin

stays at his dad's house

on Monday nights. You

know he typically stays

up all night, playing

Grand Theft Auto, so

sometimes Tuesday

mornings are rough for

him. By 9:45 a.m., he is

edgy, and you know it.

You are working with a

small group when he

blows up at his neighbor

for tapping her pencil.

Michaela slumps in her

chair and picks at her

pencil eraser. After being

asked to get started on

her worksheet for the

fourth time, she throws

her book and climbs

under the desk.

When it comes to student behavior, difficulties will arise. Approaching discipline from a growth-oriented frame of mind can encourage students to learn from mistakes instead of accepting labels and fulfilling negative prophecies. As adults, our actions, reactions, and choices surrounding the development of behaviors are as important as the lessons we develop to deliver 
our content. Individually, or as a team, use the following checklist to evaluate and improve your plan for addressing behaviors in your context.

\section{Planning Checklist for Effective and Growth-Oriented Behavior Management}

- My expectations include assisting students with challenges with academics and behaviors

- My classroom expectations are simple

- My classroom expectations are positively stated

- I have a plan for communicating growth expectations for behavior early in the year

- I have time built in for individual interactions with students

- I have developed a mechanism for getting to know my students before challenges arise

- The work in our classroom is meaningful

- The work in our classroom is engaging

- The work in my classroom will be appropriately leveled

\section{Other Steps for Success}

1. As a building leader, acknowledge that emotions are often wrapped up in behavior. Facilitate a discussion on ways to shelf our emotions and approach behaviors as we do academics.

2. Spend some time exploring the concept of implicit bias with your staff. Again, this must occur in a trusting environment, as teachers who fear being labeled as prejudiced may try to overcompensate through pretense (Suttie, 2016).

3. Have each teacher connect with a behavior buddy. The purpose of this partnership would be to facilitate growth in behavior management techniques, including:

Reflective conversations during or after a behavioral challenge. (Use life space interview protocol to create appendix)

Peer observations (Use observation checklist in appendix) 
4. Proactively, have teams watch videos of classroom interactions. Collaboratively complete a Functional Behavioral Assessment in small groups. Discuss application in contexts.

5. Read more about Restorative Practices and conduct conversation about their possible role in your building. The Restorative Practices Handbook by Costello, Wachtel, \& Wachtel (2009) is a great resource.

6. Consider the ways your building is supporting the development of behavior in contrast with the ways your building is distributing consequences for behavior. Are you developing empathy or valuing power?

Ultimately, the Growth Mindset School Community will be committed to exploring how to help children grow in all aspects of their lives. Behavior can be challenging, because we tend to focus on traditionally-fixed methodologies and allow our emotions to become entangled in our responses. The added complexity of implicit bias makes authentic personal reflection a crucial, albeit challenging, aspect of developing a responsive culture around behavior; however, use of systems like Positive Behavior Interventions and Supports and Restorative Practices can lead to a toolkit appropriate for growth minded educators. 


\section{CHAPTER VI: SPECIAL EDUCATION}

This chapter will suggest schools adopt a growth mindset approach in special education processes and services. This begins with a clear articulation of present levels, specifically targeted goals for improvement, and rigorous progress monitoring with feedback done in collaboration with learners. The purpose of special education in a growth mindset school community is to provide specialized instruction to promote progress with the goal of avoiding lifelong labels, unless absolutely necessary.

Sorting. Grouping. Grading. Judging.

Diagnosing. Intervening. Monitoring. Assessing.

"Those who enter the profession of education must answer one basic, philosophical question: Is my purpose to select talent or develop it?" (Guskey, 2011). Those two lists illustrate Guskey's important question, and one is clearly growth-oriented; the other has a fixed orientation. One list could describe a variety of professions, ranging from judging 4-H cattle fair to gem selection. The other list might describe a medical intervention or scientific method. As divergent as those activities are, the lists actually describe two co-existing approaches to special education practices and processes. The approach is determined by a variety of nuances, but ultimately, the teacher's perspective is what will decide how learning and growth will be approached over the course of the year. Will children be sorted and selected? Or will they be known and developed? This might seem like an oversimplification, surely no educator would chose to select over develop; however, practice may tell us otherwise. That disconnect may again point to an implicit bias related to special education labels. Do teachers inherently believe "special education children" are less capable? It might appear feasible, when the term "moron" 
was created to initially describe neurotypical learners (Gould, 1996). If built upon this notion, does the traditional school system perpetuate those negative implicit bias?

Founded on a factory model, our schools were originally designed to sort (Bobbitt, 1913). Only through decades of research and refinement have we begun to develop more sophisticated, effective ways of helping children learn and grow. Unfortunately, practices don't seem to develop as quickly as research. You've heard the old sayings, Can't teach a dog new tricks!, or Old habits die hard! We use those phrases flippantly, but there is a grain of truth hidden behind our humor.

In 1913, Franklin Bobbit published "The Scientific Management of Schools”. In it, he laid out a factory model for schools, with guidelines for sorting, selecting, and placing pupils effectively, complete with placement exams. Results would determine student placement on a track of courses, which would result in a certain occupation and even social class. This was a very clean, organized system for selection that was founded on - and perpetuated - a belief that children had a fixed amount of ability. Upon placement, the ability was determined along with their future.

Over eighty years later, many schools still use tracking for placement. Why? It is a simple organizational method. Selecting, grouping, and tracking allow for ease of scheduling. They make class lists more manageable. They allow more homogenous planning and less differentiation. In sum, this type of schooling is easier for the adults. It is also disastrous for students. In Keeping Track (1985), Jeannie Oakes fully illustrates how this type of selection process perpetuates inequity and stifles the development of all learners, especially minorities and lower socio-economic classes of students. Yet, forty years later, the practices persist. 
With piles of research against such scientific management of schooling, why does it continue? Schooling practices are grounded in a historical attempt to sort for socialization, and evolution is slow, because teachers went to school and tend to teach the way they were taught. At the same time, I believe schools are full of intelligent, caring educators who want to do what is best for their children. The solution, then, seems to be somewhere in the sum of two quotes:

- Philanthropist Tony Robbins said, "Change happens when the pain of staying the same is greater than the pain of change" (Robbins, 2016).

- Educational Researcher Mark Forget said, "Teachers do the best they can under difficult circumstances. When shown a better way, and supported by systems, they will change" (Forget, 2011).

When presented with the research illustrating damage done by tracking and simultaneously supported by a system that develops teacher ability to differentiate and promote growth of all students, I believe the pain of staying the same becomes greater than the pain of change. That is what this chapter is about.

\section{My Kids, Your Kids, Our Kids}

In my experience, teachers are generally passionate about their children. They take pride in being a teacher and the accomplishments of their children over the course of a school year spent together. For many teachers, their personal identity and professional identity are merged. This is important to remember, because when examining the efficacy of their teaching, that merger of identities might make such an examination feel like an evaluation of self. In other words, my effectiveness as a teacher equates to my effectiveness as a person. Such high stakes present a situation where perceived "failure" could be very dangerous. 
This year, one of my second grade teachers has visited with me on multiple occasions about her concerns regarding several students in her class. Often, she frames our conversations around the statement "They just aren't where they need to be!" I remember feeling that way, and I'm sure many of you have shared her concern at one point in your career. Perhaps that feeling was based on slower progress than other students in the class. Or maybe it was less about individual student progress, and more about the end-of-grade-level expectations set by standards. Other times, it may have been perpetuated by worries about what the teachers in the grade ahead might think if children come to them below grade level. Although valid socialized concerns, these fears are rooted in Bobbitt's scientific management (1913). We move selected students on based on a variety of factors: age, a checklist of skills, acquisition of standards. If children do not meet those requirements, teachers sometimes feel they must be sorted differently. We need to put them in special education! We need to retain them! Perhaps. And let it be known I believe these requests are grounded in a genuine desire to help their students. But what does the research say about special education or retention? For who is it intended? For whom is it effective? Does this student fit that bill?

\section{Special Education}

Something I noticed early in my career was a lot of talk about IQ scores. As a mid-year graduate, I was fortunate to be hired in January as a third grade teacher in the suburbs of Chicago. Fresh-faced and full of hope, I stepped into a classroom of 19 boys and 6 girls, 11 students with IEPs and felt like I had won the lottery! To be truthful, I didn't know the formal components of an IEP from a hole in the ground, but what I lacked in knowledge I was determined to make up for in a wholesome combination of love and effort. It was a small school, so there was no formalized mentoring program other than my next-door third grade teacher 
showing me the ropes and a supportive principal cheering me on. Looking back, I realize the impact informal mentoring had on my practices and beliefs. That informal mentoring consisted of an interpretive crash course in special education. I learned to make things easier. I learned to have lower expectations. I learned no-matter-what-do-not-fail-them. Why? Well, because they have an IEP!

Now, since that time, I have read the Individuals with Disabilities Education Act. (If you haven't, please put it on your To Do list.) You know what? None of that is in there. Shocking, I know. So how on earth did the policy take a trip down the winding path of practice to end up as the informal mentoring of "make it easier"? Is it because they have a lower ability or a lower starting point? Why do we create notions of ability? Why are we so consumed with labeling or categorizing learners? Could it be that ability, and perhaps more specifically the "disability" to learn, is a culturally-created notion designed to help adults more easily categorize students for efficient instruction in school settings? (McDermott, 2006) Is it easier for the adults to group students by one characteristic? Perhaps plans and grades are more easily completed when schools adhere to the factory model, but children are not parts or widgets, and significantly detrimental results exist for students when we track or ability-group, even if that grouping occurs only in our minds (Oakes, 1985).

When considering the notion of a learning disability, it is equally important to consider the context in which the behaviors categorized as "disabled" are exhibited. The context of school is a cultural one, and that culture, historically influenced by an industrial model, expects children to learn at a relatively similar pace and structure, so they can move through the system and be "scientifically managed" (Bobbitt, 1912). Instead of focusing on what a child knows or still needs to learn, this culture of American schooling is designed to collect evidence around the 
children who are falling outside the normative expectation (McDermott, 2006). This evidentiary proof provides justification for adults to group children into categories like high, medium, and low. As a result of those grouping strategies, it is quite possible that a child's access to Calculus could be determined as early as age ten, based on the math track he or she is placed into at that point in their youth (O'Neill, 1992; Hu, 2009). Even more concerning, though, is that the ability-based courses perpetuate differences in students through variance in not only curriculum presented, but pedagogy, level of question, type of assignment, and engagement in discourse. The fact that minority students are disproportionately placed in lower tracks and special education and seven times more likely to be identified as low ability than high ability, raises serious concerns about equity and opportunity, as well as power structures in schools (DarlingHammond, 2010; Kozol, 1991; Oakes, 1985; Oakes et al, 1990; Valencia, 2010).

It is typical for school personnel to use observations, assessments, notes, and interactions to uncover individual present levels, and that can be a very productive practice when used as a starting point for learning (Hattie, 2010). However, the cultural and historical patterns of formalized schooling lead us astray when we treat those data as evidence of disability, instead of a starting point for learning. Think of the word disability: An inability to do something. Now pair that with learning. The label alone communicates the school's belief that the labeled child is unable to learn. Is that the message we want to send? Is it what we believe? If so, how does that limit our efforts? Lesson our responsibility? Take a look at the April 2017 volume of Educational Leadership. The journal's title for the month is Differences not Disabilities. Each article pushes readers to consider the embedded expectations in their word choice, and it is a wonderful resource for teams exploring the power of perspective. 
When children do not learn at the same pace, or in the same way, the culture's response is to label those children disabled, and then provide different services. Why not just provide the altered instruction without the label? Who does the label benefit? The system of identification as a disability instead of a difference promotes an idea, not a biological fact. Treating neurodiversity as a difference asks us to reconsider typical approaches; treating it as a disability places value on the child's biological composition (Armstrong, 2017). The effects of a valueridden label can cause actual differences in learning and outcomes for children, and the lines between belief in cultural construction and biological fact can be blurred for some. Historically, it appears they have been (Binet, 1912; Harry \& Klingner, 2014; Oakes, 1985).

\section{Ability as Perception Rather than Biology}

In The Cultural Work of Learning Disabilities (2006), McDermott writes, "people are looking for and producing evidence of LD in educational settings designed to make symptoms of LD visible" (p. 13). This becomes especially problematic when expectations for student learning are built upon this notion as if it were fact. Once labeled learning disabled, or LD, a student's interaction with curriculum, other students, and even placement within a regular classroom are all at jeopardy, with tangible and obvious differences interrupting their trajectory for success. Specifically, researchers have noted differences in how time is spent in lower and higher track classes, whether on high-quality instruction, procedures, discussion, or work completion. Additional differences exist in expectations for learning content versus simple exposure to or coverage of content. These differences were so great in level of track it should not be surprising that the outcomes for children within those tracks were different, as well (Oakes, 1985). Yet we continue to sort and place students in groups for leveled instruction, under the guise we can more effectively meet the students' needs, whether those children are labeled as gifted or disabled 
(Ricci, 2013). Considering the benefits in ease of scheduling, lesson planning, pacing, and meeting parents' demands, one might wonder if it is the students' needs or the school's needs being met first.

It is equally important to consider how notions regarding children categorized as highly intelligent are formed. On one end of the spectrum, we look for delays, differences, and exceptions to the normative expectations of learning, and we label that a learning disability. On the other end of the spectrum, teachers use differences and exceptions to the normative expectation to construct their ideas about who is smart. By this description, what does it mean to be "smart"? Several authors have considered this question (McDermott, 2006; Hatt, 2012; Sternberg, 2007; Weis, 2004). McDermott (2006) described a student, who teachers described as "promising...performing smartness for the teacher and building an academic image" (p. 14). This child's actions and behaviors were described as a performance. What does it mean to perform smartness? Children who conform to a culture's expected behaviors appear to be "smarter" than those who do not, and this returns to the wheel of perpetuated differences as the children viewed as "smartest" are given greater opportunities to learn "high status" knowledge, while those with difficulty meeting low-level behavioral requirements spend time relearning rules and compliance-driven content. (Hatt, 2012; Oakes, 1985).

Frequently, those expected behaviors in formal schooling align with an emphasis on lowlevel skills or compliance (Weis, 2004). Children learn these expectations through experiences in the settings that expect them, and the sooner they learn to comply and please, the more rapidly teacher behaviors toward them adjust to challenge and promote their ongoing learning. There is great variation in children's understanding of institutionalized learning as children's experiences with expectations in alignment with formal schooling vary, based on culture, class, race, and 
even values, and those experiences begin at birth. Those influences determine performance in formal schooling, and the subsequent cycle of beliefs about ability, expectations for performance, and actions based on those expectations within an institution begins.

The conflux of influences between birth and age five are on public display for their first official sorting when children enter Kindergarten. The variety of inputs to this point have influenced children's development, often coded "readiness," and that staggered start impacts interactions in the Kindergarten classroom. What does it mean to be "smart" in school? Surely, adults have an idea. Their notions may be formally based in language or standardized screening scores, but as McDermott (2006) pointed out, they could also be from marinating in the culture of school. In fact, in her work Smartness as a Cultural Practice in Schools, Hatt (2012) illustrates how Kindergarten teachers used classroom mechanisms to control behavior, resulting in children's creating of a smartness-identity for themselves as well as their peers. Not only was the identity interchanged with their behavior, but it was also used for social positioning and communicated value.

Teachers live and breathe the cultural expectations of school, so they are excellent surveyors of children who meet or fall beneath those expectations. Children who fall beneath will be grouped accordingly and the sorting machine of formalized school will begin anew. The fact that poor and minority students are disproportionately placed in the lower tracks causes an equity issue in the ways schools serve all children, and it causes that issue early (Harry \& Klingner, 2014).

I want to tell you a story about a child I met early in my career. I met Jonie when she was five years old. A beautiful, happy girl with big brown eyes and long dark hair, she was placed in a Self-Contained Cross-Categorical classroom in Kindergarten, based on early 
intervention testing. The purpose of the classroom was to provide a wide variety of services for students with disabilities that could not be effectively provided in the traditional classroom setting. At that time, the age range in the classroom was five to eight, and the needs were incredibly diverse. The classroom had a much lower student-to-staff ratio, and was a place designed to effectively achieve the goals collaboratively developed through individualized education plans.

The first time I formally observed in the classroom, Jonie stood out to me. She came into the room later than the other children, having started her day in a regular Kindergarten classroom. She then went to an independent work station, where she sorted and classified beads, smiling as she worked. Over the course of the year, I would observe the classroom several times, and I rarely heard Jonie speak. I also rarely heard people speak to her.

Jonie's needs were primarily communication-based, and I recall a distinct feeling of discomfort when I contrasted the verbal overstimulation of the traditional Kindergarten classroom with the setting where Jonie was getting the bulk of her instructional minutes. Here's where I got hung up. In the classroom were eight students. As you would expect from any classroom, not one of the eight was like another, but in this instance, that was the extreme truth. They were vastly different. It seemed the only thing they had in common was that they had Individualized Education Plans with significant minutes required to achieve their goals, and their standardized test scores were all low in at least one area - not necessarily the same area, either. That hardly seemed like a reason to group them together all day; in fact, it seemed like a reason not to group them together all day. Jeannie Oakes, the resident expert on tracking and ability grouping, laid out an ironclad, indisputable argument against ability grouping, unequivocally pointing out that it actually contributes to accelerated achievement gaps rather than closes them 
(Oakes, 1985; O’Neill, 1992). Yet here we were, over forty years later, blatantly ability grouping with the very population who more desperately needed accelerated learning than arguably any other group of students in the school.

I am very proud of the end of Jonie's story. I was not alone in the desire to reconcile beliefs about mindset and the services available to students needing specialized instruction. Our team went spent some time envisioning options that would expand the ways we meet kids where they are, using present levels, and provide instruction tailored to take those levels to the outlined goals. There are many models out there, and in this context, the selected model is secondary to the fact that the teachers led the discovery and creation of a new system. Jonie recently delivered an outstanding oral presentation summarizing an extended research project. She did this for typically-developing peers. There was no magic approach or purchased curriculum. The difference was our teachers chose to not only change their mindsets, but also change the system to enable growth mindset to effectuate in student performance.

The story I shared with you was not intended to communicate self-contained classrooms are inherently bad. I believe there are many students who absolutely need specialized instruction in order to make meaningful gains toward achieving carefully articulated goals, and for some students, that may require a self-contained placement. Where I think we need to exercise caution is in monitoring the purpose behind our actions, because I also believe there are many students we have note only made eligible for special education, but also served in a self-contained setting, in order to make life easier on adults.

Special education can help children grow, but it, too, must be framed in a growthoriented way. Too long, special education processes and procedures have adopted a fixedorientation, welcoming students at their initial eligibility meetings and never letting them go. 
Too long, special education processes and procedures have disproportionately welcomed minority children based on unfair tests with a bias toward race and socio-economic class. Too long, once made eligible for special education services, the rigor and rate of learning are in stark opposition to the rigor and rate of general or accelerated education classes. For these reasons, historical practices as they relate to special education are unacceptable. Luckily, in IDEA's reauthorization, the addition of new eligibility criteria and requirements of data illustrating student's response to scientifically-based interventions narrowed the gateway and eliminated special education as the one stop shop for struggling students.

This is not to say that students stopped struggling. Instead, the addition of more specific consideration of whether or not a child had a learning disability made districts and schools examine their processes and procedures for accessing additional supports for students who were behind.

Why is it so important to get this right? Simply stated, when we label a child with a learning disability, everything we have previously discussed related to teacher expectations, labels, peer influences, and growth comes into question. I have heard educators use Learning Disability as a reason to excuse lack of growth in a student. Remember Marzano's work on teacher effects? The best teachers made progress with every child, regardless of ability (2006). Attributing lack of progress to a child's label is deficit thinking and blame at its best. John Hattie (2009) reviewed 79 research studies related to the label "learning difficulties" and found that "labeling leads to differential performance" (p. 123). He goes on to say, "teachers must stop over-emphasizing ability and start emphasizing progress (steep learning curves are the right of all students regardless of where they start), stop seeking evidence to confirm prior expectations but seek evidence to surprise themselves, find ways to raise the achievement of all, stop creating 
schools that attempt to lock in prior achievement and experiences, and be evidence-informed about the talents and growth of all students by welcoming diversity and being accountable for all” (p. 124). Amen.

In our district, we recently engaged in a conversation about the state-mandated inclusion of student growth data as part of the teacher evaluation. Your states may have similar requirements. One component of our plan had to be exclusionary criteria, that is, which children could be excluded from consideration when looking at growth targets. Would it surprise you that someone suggested students identified as eligible for special education should be excluded or treated differently? Perhaps it doesn't surprise you. Perhaps you even think there is merit to that suggestion. Let me tell you this. As a school leader, I want my very best teachers to have the students who are eligible for special educations. Do you know why? Because they will make sure they grow. They will get great results. They will believe in their ability to grow, and their beliefs will not only transfer to the student and their peers, but they will make it happen. I know something you won't be surprised about - I wasn't a huge fan of their exclusionary suggestion. In the end, I am very proud to say our district did not adopt exclusionary criteria for special education students. In fact, the only children whose data is not considered in the student growth component of the evaluation are the ones who were not present. Everyone else? We expect them to grow. That's a growth mindset culture.

Because of the clarity of research surrounding determining eligibility correctly, meetings to discuss the possibility of a child become eligible should be more than mere formality. As a school leader, you must engage in those conversations and ask important questions. You very likely have caring teachers who only refer students for consideration if they are struggling. Sometimes those referrals will result in an obvious need for specialized instruction. Sometimes 
they will not. Being radically candid and having trusting relationships with your staff members should enable you to clearly articulate that special education is not about being behind, or not keeping up with the class. It isn't a safety net, or a caring gesture. If a student's IEP team determines there is a learning disability and makes the child eligible for specialized instruction as a result, a few things must happen. First of all, the eligibility decision needs to be weighed carefully. Secondly, the adverse effects need to be thoroughly fleshed out, including the possibility that the label itself could have potentially harmful side effects, including unintentional lower expectations (Oakes, 1985, O’Neil, 1992). Finally, the team must frame the work of the team as growth oriented, and equipping the individual with the right type of teaching so the child can learn and will make meaningful process. Unfortunately, too often, once a child receives a formal eligibility, some teachers release responsibility to a special education teacher and sigh relief. Special education is not about passing the baton, it is about widening the support and increasing the size of the team committed to helping the child achieve great growth. You need to articulate and champion that vision for it to become part of your growth mindset school culture.

I feel this is another good time for a disclaimer. As an administrator, consultant, and teacher myself, I have worked with hundreds of teachers, and I firmly believe teachers want to help their students learn and grow. Most of them have a heart for kids and they believe they can make a difference. At the same time, many do not feel equipped to handle the diverse needs of the students with whom they work. When I say teachers "sigh relief" I do not believe it is because they do not care. Quite the contrary. When teachers exhibit relief, I believe it is attributed to a feeling that finally someone can help the child in a way they could not. But this is where I believe special education has inappropriately become a "catch-all" of sorts. Special 
education should not be the default place we "send" kids once we've exhausted our extensive bag of tricks. It should not be the place we send kids who are failing our classes. It should not be the classroom where we drop them off after the pledge so they can get caught up on homework. Carefully and clearly work with your leadership team to articulate the purpose of special education in your building, and revisit that purpose collectively when working to not only determine a child's eligibility, but also to monitor their progress, set new goals, and brainstorm strategies.

Certainly, our team's experiences can fit right in with the descriptions in this chapter. Our staff is among the most dedicated, caring, and professional I have ever met. They do not back down from challenges, and they will go to the mat for their students. I would describe our practices related to special education like many schools I have worked in; they were a product of history and tradition rooted in scientific management. If a child was not making adequate progress, his or her teacher would know, because they monitor progress regularly. They would collaborate with colleagues, lessen work or make it easier, and do whatever it took to help the child succeed. For the most part, in intermediate grades, the definition of "success" was to achieve a passing grade. These good intentions resulted in lowered expectations, which resulted in lowered achievement. But what other option was there? The school operated smoothly, kids were happy, parents were happy, and teachers were happy. At about second grade, many students' lack of progress began to catch up with them, and special education referrals blossomed. A traditional school psychologist would conduct IQ testing, an eligibility meeting would be held, and the child would most likely be made eligible for special education services. This took the form of resource, which varied in 30- or 60-minute pull out sessions, or could mean placement in a self-contained special education classroom. Some variance to these options 
were occasionally implemented, but for the most part, a standardized approach was applied to an individualized education plan. Problematic? Yes. Intentionally harmful? No. Harmful nevertheless? Likely.

Remember me saying that teachers will change if they see a better option? That is the real story here. In 2014, we began exploring Mindset. One of my two self-contained special educators "got it" right away. She and her colleague proposed a change to their service delivery model, which was three grade levels in one classroom. They saw an opportunity for more growth and access to regular education if they focused on one grade level and pushed out to achieve more of their students' goals. Also on that original team was a new school psychologist. She had a good understanding of the new requirements for eligibility and began teaching those expectations to regular educators and applying them in our eligibility meetings. Next, a resource teacher joined our group and started asking questions about how to accelerate the learning of students with IEPs and dismiss when data illustrated the gap had been closed. These ideas are not new, but the learning that occurred through our exploration of mindset and applied our school did it right. The point is our school did something. We saw we could do better, and we applied our learning to improve our systems for student growth and opportunity. You can do the same.

I'm extremely proud of the progress our entire staff has made in widening their understanding of labels and the power of expectations. I see the effects of that learning in our conversations about special education service delivery, and I see an incredible commitment to problem solving outside the world of special education. For us, that's a huge step forward. No longer is the only door to academic assistance an IEP. Our teachers are meeting students where they are, expecting growth, and inspecting progress with their learners. Sky's the limit! 


\section{What Can You Do?}

1. Take an honest survey of your special education landscape:

$\checkmark$ Eligibility

○ How do your percentages for each eligibility align with state averages? National averages? This was a huge wake-up call for us. We were nearly double the national average for some eligibility areas.

- Take a look at your eligibility rates along lines of race and gender. Are there discrepancies you need to share with your leadership team for conversation? What implicit bias might this reveal?

\section{$\checkmark$ Service Delivery}

O One of the big red flags for us was the obvious contradiction in a fairly universal approach to individualized plans. Is your schedule dictating services? Are you thinking outside the box of ways to serve students? An example of this for us was a kiddo who had just finished his first year of Kindergarten, but was not academically or socially "ready" for first grade. Still, the team felt peer models in his age group were beneficial. Traditionally, the team may have made a selfcontained recommendation for primary grades or Kindergarten with resource, but instead, the team got creative. Starting by creating authentic and truly individualized goals based on present levels, they determined an academic placement in Kindergarten paired with a first grade homeroom, exploratory classes, lunch, and recesses would be a more appropriate placement option to help him achieve his academic and social-emotional goals. Was it messy? Yes. Did it 
take forever to figure out? Yes. Did we build relational trust? Yes. Did we create a truly individualized plan? Yes.

○ Think about your IEP teams. How do they handle the discussion of placement? How do they determine the minutes associated with the goals?

○ Do you have self-contained classrooms? Carefully work with your special educators to clearly articulate their purpose. Review Oakes's work and discuss whether or not your services are in conflict with her findings.

\section{Efficacy}

- One of the reasons I am so passionate about special education is because of students like Thomas. I reviewed Thomas's triennial evaluation information and was sickened to see he had made NO PROGRESS since his previous evaluation. That's right. None. Now, I knew Thomas, and he was capable, creative, and funny. Not only were the tests deceiving, but clearly our services were less than stellar. Even more disheartening was that many cases were similar. Who was examining this? Why weren't we making changes when our data told us something wasn't working? Or, if we didn't know, why not? Didn't we have progress monitoring data? Fortunately, once systems for examining progress were established, my special educators took to it like wildfire. Now, they are not only regularly monitoring progress, but we aren't waiting until annual reviews (or for goodness' sake, triennial evaluations!) to make changes. Our services are responsive. We can still improve in this area, but we are miles from where we began. And even better news - Thomas will start his fifth grade year in a regular classroom with consultative services only. Learn from our failures the way we 
have, and consider how your team monitors the efficacy of its interventions.

How often? With what mechanism? How are results shared with students, families, IEP team members?

- Be sure to constantly check in with your special educators about what supports you can offer for their continued growth and development. Just like you encourage regular education teachers to observe each other and give feedback, extend that opportunity to your speech pathologists, your social workers, and your learning behavioral specialists. Investing in their growth is just another investment in the creation of a growth mindset school community. 


\section{CHAPTER VII: TEACHER EVALUATION}

Teacher evaluation in a growth mindset school community focuses more on coaching than judging. The emphasis is on developing skills through collaborative identification of targets, supportive professional development, and constructive feedback. Like the other

constructs in this book, this is achievable only through trusting relationships. It takes courage to openly describe weaknesses, but through a growth minded leader modeling that type of vulnerability, a message is sent about valuing improvement gained through transparency, selfawareness, and trusting the contributions of colleagues. This chapter will confront beliefs about evaluation and present strategies for shifting to a growth-oriented evaluation approach.

Think About It: Take a few minutes to reflect on your current beliefs about the teacher evaluation process. Then talk about your thoughts with your team.

1. What do you believe to be the administrator's role in the evaluation process? Why do you think you hold those beliefs?

2. What do you believe to be the teacher's role in the evaluation process? Why do you think you hold those beliefs?

Remember Miss Farable from the expectations chapter? She's back, and she's being evaluated. Take a look.

Miss Farable stumbles on the question she wants to ask her students, fully aware of her principal's eyes watching her every move, his keyboard recording her every utterance. This is so awkward - I am so awkward, she thinks. Her discomfort and uncertainty related to being formally observed for evaluation continues to weigh on her mind as the lesson drags on. Each mistake feels like another notch down the ladder of proficiency scales, and she can tell her students know something weird is going on. Why can't I just be myself?, she wonders. By the 
end of the lesson, she is exhausted. Her students file out of the room on their way to PE and she slumps in her chair, exhaling in a mixture of relief and defeat. I can only imagine what he is going to have to say about that, she thought.

What is it about observation or evaluation that can send us into panic mode? Have you felt this way before? I know I have! My first job, I just wanted to impress. I felt like if I wasn't impressive enough, my principal might second-guess his decision to hire me. Plus, I WASN'T TENURED! Gasp! I wanted everything to be perfect, which meant my evaluation cycle was about getting a good rating more than getting good feedback for growth. Now let's just take a second to think about that. In what field do you want to plateau, especially in your first job? I can't think of any. I really can't. That approach is crazy, actually, and can border on dangerous. I recently read an article in The New Yorker by a very successful surgeon, Atul Gawande (2011). In the piece, he reflects on the necessity of coaching for continued improvement, and invites a coach into his operating room, even at the risk of appearing inept to those who are watching. The article is brilliant, in my opinion, as it brings to light an oddity about feedback. It seems we are obsessed with natural talent, and occasionally, as a society, we view the need to be coached as a weakness. This obsession was also featured in Malcom Gladwell's book David and Goliath (2013). Gladwell features stories of underdogs and theorizes our obsession with their success is that it is incongruent with our implicit belief that the most powerful will always win. When they do not, the success story is captivating, mostly because the natural talent is the one we assume will win. Gladwell argues, however, that the disadvantages faced by those who are not considered naturally talented, force them to think creatively and failures do not scare them (2013). Still, if you ask people if they would rather be naturally good at something or have to work really hard to achieve greatness, most would probably go with the romance of The Natural. 
Therein lies the conflict. I want to get better, but I don't want others to think I need to get better. It's laughable, really, a battle between desire for growth, and the fixed value of appearing to need improvement. Well, here's the thing. I know I don't want a first-year surgical student outwardly trying to impress while inwardly doubting decisions, just like I don't want an educator trying to prove instead of improve. Instead of trying to impress my principal, I needed to be invested in figuring out how to keep improving! Jim Knight, director of the Kansas Coaching Project at the University of Kansas, would agree. Acknowledging that the largest factor in students' growth is the quality of their teachers, his program is designed to create effective coaches for classroom teachers, and it's situated around the concept that every teacher has something to work on (Gawande, 2011). Clearly, I had the approach wrong, and after almost twenty years in school buildings, I know I'm not alone. I also know the tension between wanting to improve but not wanting to look incompetent is not isolated to new teachers. Recently, I met with an experienced, tenured teacher who is widely regarded as an excellent educator. Children love her, parents love her, and her colleagues love her. In preparing for our evaluation sequence, she confided in me how nervous she was. She wasn't sleeping well, she was anxious, and she just wanted to get it over with. Her desire to do a good job was wrapped up in her identity, and it was because she cared so much. At the same time, she viewed the evaluation process as a judgment, not a coaching session. In that way, it was something that would validate her closelyheld beliefs about herself, or cause her to feel like a failure. In this type of an emotional headspace, no one is going to grow from the experience.

When you combine coaching with evaluation, which could be viewed as a judgement, a ranking, or performance indicator tied to personal efficacy, the pressure rises. Yet this is exactly what we ask school administrators to do, isn't it? Can a school leader coach and evaluate? What 
do you think: Can that dichotomy exits? How? What can you do, as a school leader, to create a culture supporting growth as it relates to the evaluation cycle? What steps need to be taken in order to transform the first observation scenario into something like this:

As Miss Farable's principal enters the room, she catches his eye and nods toward the desk in the back she has set up for him. She placed him at that seat for optimal viewing of the whole class, which will be important for the feedback she needs. This cycle, her administrator is there to watch and analyze her questioning, because they discussed it as an area for growth this year after viewing data from last year's work. Her stomach has butterflies, but she pushes them down and focuses on her students. She proceeds through the lesson typically, and although she spent more time preparing her questions than in previous lessons, it was business-as-usual with her principal in the classroom. At the end of the lesson, her students head to PE while her principal hands her a list of questions to consider before their post-observation conference.

With your team, analyze the evidence of fixed and growth mindsets from the two scenarios. What evidence of fixed or growth mindsets do you notice?

Certainly, a trusting relationship exists between the teacher and principal in the second scenario. Additionally, it appears they have a shared understanding of the purpose of evaluation. As a building leader, you have some influence over those things, and while it won't be easy, your philosophy, time, and commitment can help make evaluation about growth

There are two important contributions to consider in cultivating a growth-oriented evaluation approach:

1. The evaluating administrator's beliefs about and approach to evaluation can be fixed- or growth-oriented.

2. The teacher's beliefs about and approach to evaluation can be fixed-or growth-oriented. 
The combination of these two contributions can be viewed on a continuum similar to Figure 5. In the best-case scenario, the teacher and administrator's beliefs about and approaches to evaluation will align. In the very best scenario, they align and are both growth-oriented. Kids will benefit because growth will occur.

Figure 5. Teacher and Administrator Continuum of Evaluation Approaches

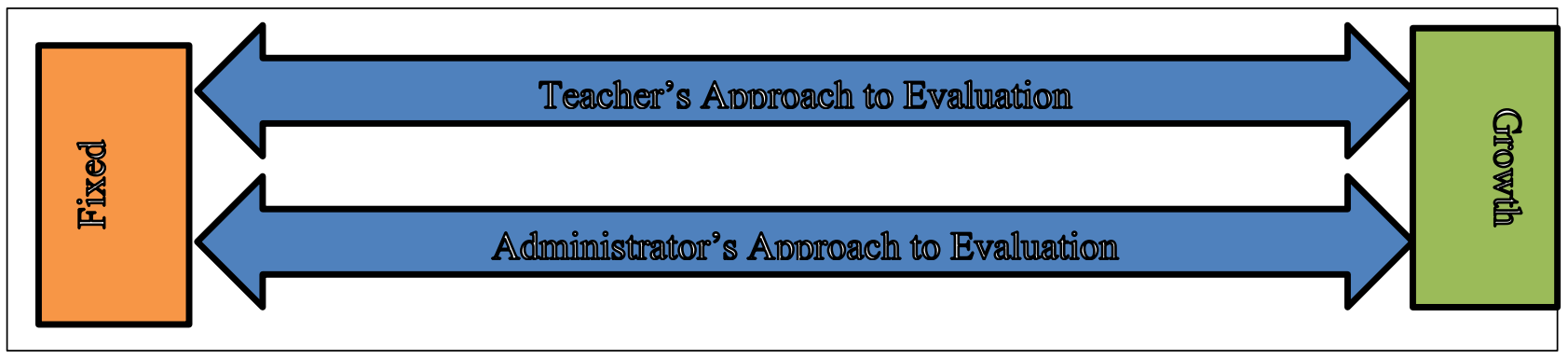

Think About It: How would you describe the approach to evaluation in your context? Why do you think that is the case? If your team is comfortable doing so, discuss your thoughts.

The effect of an administrator's and teacher's approaches to evaluation will impact its efficacy, and they do not exist in a vacuum. Those approaches will be built not only on conversations about evaluation and coaching, but on every interaction and initiative in the building. A principal who says he or she believes in growth-oriented evaluations but does not facilitate opportunities for growth may not be as believable. As in each chapter of this book, relationships built on trust will contribute to the overall effectiveness of growth-oriented evaluation, and though this chapter will focus on strategies related to cultivating growth through the evaluation cycle, it will be difficult to do without establishing relationships. That is why a growth-oriented school culture is so important; if you believe in growth, it will be allencompassing. Working together on various applications of growth will only strengthen the relationships and credibility that you truly believe the evaluation process is a vehicle for supported improvement. 


\section{Principal's Role in Evaluation: Traditional vs. Growth-Oriented}

Traditional evaluative measures were a ranking. It's easy to see why fixed thinking exists about evaluation when a teacher's passion and life's purpose is reduced to a "Satisfactory" or "Unsatisfactory". But nearly all improvement literature describes a climate conducive to constructive feedback as necessary for growth. In Illinois in 2014, Charlotte Danielson's Framework for Excellence was widely adopted as a model for teacher evaluation. Ironically, Danielson created the framework for coaching and improvement, and suggested adding an evaluative component would weaken its efficacy. Nevertheless, it was added as a model for teacher evaluation, and it provided a very descriptive rubric for improved practice, with many illustrative components contributing, still, to an overall rating.

As a principal in this situation, you simply need to acknowledge the dichotomy, but I would encourage you to include the teacher in that. Articulate your vision of the work you will do together and emphasize growth, not ratings. You might say something like, "At the end of this process, we are going to have a final rating. But I am much more interested in the work and growth that occurs between now and then than what that final rating will be. At the same time, I am evaluated every year, too, and I understand how important a label on our practice is, so there will be no surprises. We are going to focus on some areas of improvement, and I am here to support you. I am here to help you grow, because I want you to be part of our staff. My job is to help you." While starting with that does not take away the reality of a rating, it is your job to assign the final rating. You need to acknowledge that, but then put it aside. Show the teacher you are there to coach, to guide, to support, to offer resources, and to push. You need to be professional invested in your teachers. Elena Aguilar, an instructional and leadership coach in California, offers several suggestions for ways to effectively coach (2013). You might 
collaboratively identify areas of strength and then use those as leverage for growth. "I can tell you put a lot of time and thought into your unit design and individual lesson plans. You obviously know what materials you are going to use and have everything prepped. Let's talk about putting that same level of preparation into questioning. What do you think would happen if you planned out at least one higher-level thinking question each student was required to answer, instead of asking questions as they came to your mind?" Additionally facilitative questions can be found in Aguilar's text.

Many principals start with, "How do you want to improve this year?" I think asking the teacher for their ideas and hopes for improvement is crucial. I also think, when that is asked in isolation, you will get superficial answers. Without a belief that weaknesses are not viewed as failures, your teachers are not going to be incredibly eager to display all of their insecurities. Additionally, without a trusting relationship, you aren't going to get much openness. Imagine you only met with your superintendent twice a year - once for your pre-conference and once for your post-conference. How excited would you be to tell him or her everything you feel like you are doing wrong?

Depending on the size of your staff, effective evaluations, including building trust, will take a lot of time. In fact, it could take all of your time. That's okay, because without it, nothing much will be accomplished through the evaluation, anyway. You can't help people grow if they don't trust you. If you only want to complete evaluations for compliance purposes, you're missing the point. Please do not approach them as a completion checklist. If, as research suggests, effective teachers are the most powerful contributor to student growth, then the most important thing you can do is hire good people and help make them better. That does not mean you have to have all the answers - that would be fixed thinking, anyway, and it's impossible - it 
means you have to care enough to invest in your people. You have to help them find ways to grow and then create a culture of shared learning in your building. This can be done through the evaluation cycle by pairing teachers up with each other. You have a new teacher who needs assistance in strengthening classroom management? Pair him or her up with a veteran teacher who creates a caring classroom community. Then, ask that veteran teacher to go observe the way the new teacher is incorporating technology. You haven't told them anything, but you've shown them you value their learning, you see the expertise in your staff members, and everyone has something to improve.

\section{Teacher's Role in Evaluation: Traditional vs. Growth-Oriented}

As a teacher, you need to decide how you are going to approach evaluation. You could put in the time, meet the requirements, accept a rating, and then just wait for two years until the next one. Or you could do the dog and pony show, hold your breath, hope for (or demand) praise, and then agonize for two years until the next cycle. Or, you could seize the opportunity for focused feedback. Some schools have the luxury of instructional coaches and peer observers; in our crazy financial times, most do not. In that case, your principal may be the only person who formally observes your teaching. Fixed approaches to evaluation will use the process as an opportunity to prove value. Carol Dweck (2006) describes these teachers as "finished products" whose purpose "is to simply impart their knowledge" (p. 201). With this type of teacher, the ability to disassociate the evaluation from coaching may be too difficult. Instead, you might offer time for this person and a colleague to observe each other and provide a scaffolded coaching tool to guide their conversations and focus their efforts.

Another fixed approach is to passively accept a label. (There's nothing I can do about it, anyway.) More likely than not, fixed-thinking will lead to the feelings Miss Farable felt in the 
opening scenario. This type of evaluative culture leads to judgement-based thinking. The observations and subsequent conversations will either prove I'm an idiot, or validate I'm the greatest. Wherever you land in those validations, the same outcome exists: Little to no growth. In this scenario, growth can occur when an area of interest is uncovered. Back to Angela Duckworth's theory of grit (2016), there is a crucial element of passion that must exist. What portions of their profession excite them? How can that be leveraged to help others grow? Growth can be contagious.

I am suggesting that evaluation can - and should - co-exist with coaching, and that it is not a process that should be done to someone or for someone, but with someone. Hand in hand, an administrator can act as a guide, helping a teacher sharpen strengths and improve weaknesses. Simultaneously, a caring, trusting relationship is built while the administrator also learns new strategies, approaches, and encourages growth. Considering those options, a preferred approach to evaluation is to seek meaningful feedback and grow.

Teachers, it needs to be stated here that I realize a lot has to do with your principal. Principals, it needs to be stated here that I hope you know how much this has to do with you. Every relationship is a product of both parties involved, but simply because it is part of the principal's job to complete evaluations, working with a fixed-minded principal may make it difficult to ascertain quality feedback. That's why the first part of this section was directed at school leaders. Because the rating rests with administrators, this relationship is different than the typical coaching relationships - if the rating is paramount, there is an imbalance of power. If growth is paramount, both the teacher and the administrator are able to equally grow. Still, administrators must understand the value in growth, and acknowledge the tension existing in assigning a rating. 
Teachers, with all of that said, you still can control how you benefit from your evaluation. Be prepared with pointed, feedback-driven questions. Ask for continued learning in alignment with areas your administrator has pointed out for improvement. If your building does not have adequate funding (welcome to public education!), ask if there is someone in the building he or she would recommend you observe, and if they could observe you. You can encourage the development of a growth mindset in your administrator by approaching evaluation as an opportunity to improve.

Think About It: Take a few minutes to consider how you can communicate your objectives for the teacher evaluation process:

1. What words do I want to include in my work with teachers to clearly communicate that purpose?

2. What intentional conversations do I need to structure to further clarify that purpose?

3. How am I going to address the natural tension between coaching and assigning a rating?

\section{Procedures and Practices}

How can we work together to shift your evaluative culture to a growth-orientation? In this section, we are going to discuss systemic shifts and practical strategies for ensuring growth is at the forefront of your building's observation and evaluation cycles.

\section{Systemic Shifts}

Is the principal the only one in your building who conducts observations? If so, why? Consider the possibility that a single observer might solidify the belief that observations are for evaluation purposes only. If there is a culture of frequent observation and feedback by multiple people in the building, then the evaluation process can feel like an extension of that culture. If the principal is the only person observing in the building, the likelihood that evaluation and 
observation will always seem evaluative is high. The natural response to an idea like this is push back related to resources. Who am I going to have do that? We can't afford to hire someone! Of course, it seems like an ideal situation would be to hire an instructional coach or someone whose singular job was to provide feedback and conduct coaching conversations. If you have the means to do so, I would highly suggest spending adequate time researching effective approaches and hiring the right person. If, however, you are like the majority of us, you may need to get creative with your approach. I suggest starting with a strengths inventory. Frame the following activity with a growth-orientation. "I have the good fortune of observing in many classrooms and seeing lots of great ideas in place. This year, I would like to expand that by creating an opportunity for faculty to observe one another. I'm hopeful this will help us all grow and develop, and I'm excited to see how you learn from each other." Using a concrete tool like Danielson's framework, ask interested staff members to generate a list of areas they would identify as a strength area. Collect their input, and then create an observation databank you can use throughout the year. When you have a teacher ask for professional development on a certain area, you can help set up an observation date and time with one of the people who identified the topic as a strength. Think of the professional capital developed through such an arrangement. The teacher being observed feels valued for his or her expertise, and the teacher observing is getting new ideas for implementation. Additionally, the cost is relatively minimal, even if you offer a substitute to cover while they discuss the observation. I have also covered classrooms for teachers to be able to collaborate, and I always grow by gathering new ideas in classrooms.

\section{Giving and Receiving Feedback}

Feedback improves performance, it develops skills, it clarifies expectations, and it signals investment. In his book, Visible Learning, John Hattie (2009) identified it as "among the most 
powerful influences on achievement” (p. 173). But through his meta-analysis of 1,287 studies related to feedback, it became clear that some forms of feedback are more effective than others. As a school leader in the evaluation process, you need to know how to give effective feedback, and as a teacher in the evaluation process, you need to understand how to receive feedback.

Obviously, both parties need to be adept at giving and receiving feedback, but in consideration of the evaluation process, the emphasis on improving practice places weight in those specific roles. This section provides guidance on how to give and receive feedback, for growth purposes.

\section{Giving Effective Feedback}

I've been a Cubs fan since I was a little girl, and I distinctly remember attending many games with my dad. Growing up, I didn't think much about how Ryne Sandburg could read pitches, or later, how Kerry Wood knew type of pitch to throw. But recently, my family and I went on a tour of Wrigley Field. It was obviously very cool, but even amid the insider stories and behind-the-scenes information, something else stood out to me. It was that Anthony Rizzo, Cubs first baseman, was taking extra batting practice. I asked our tour guide why he was there, and he shared with me that he was practicing hitting to the opposite field, even though it wasn't required of him. It certainly struck me that he was growth-oriented. Beyond that initial reaction, I became fascinated by watching his batting coach. After each attempt, he gave some kind of feedback. It was immediate. Then Rizzo would adjust. Now, I'd be happy to debate my preference in sports teams any day, all day, but what's certainly not debatable is that it takes a lot of dedication to get to the majors in baseball. It also takes a lot of good coaching. Once you're there, it's easier to get cut than to stay. Players like Rizzo, who not only take extra BP, but are willing to listen to a coach's ongoing and immediate feedback, are likely to experience more growth than players who show up just before the game. And what can we learn from that? 
Jim Knight and his team at the Kansas Coaching Project suggest a simple three-step process for instructional coaching, and what they suggest reminds me a lot of what I saw at Wrigley that day. Based on their experiences studying successful coaching models for more than twenty years, many processes are embedded into three steps: Identify, Learn, and Improve (Knight, et al, 2015). Their model was developed for instructional coaches, not administrators conducting evaluations; however, many of the components can be utilized for growth-oriented evaluation processes. For example, in the Identify step, the coach and the teacher collaboratively identify an area for growth. Knight suggests use of video to help teachers develop a clear understanding of their teaching, but this can also be done through student work and observation data. The coach then facilitates a conversation about the data, intended to help arrive at a shared goal for improvement. Once the goal has been identified, the coach and teacher select a strategy to implement that would improve the targeted area. The second major step in the three-step process is Learn. During this phase, teachers invest in learning the strategy, which can include a checklist of components, having the coach or another expert model the strategy, co-teaching the strategy, observing a peer, watching a video of the strategy. Finally, the teacher implements the strategy. From there, the third and final step of coaching can be implemented, which is Improve. This portion of the coaching cycle consists of implementation of the strategy with observation or video recording, and subsequent reflection on its efficacy. The coach facilitates a reflective conversation about the particular strategy and its implementation. Then, the cycle repeats.

Here's the thing about coaching: Regardless of the process's design, coaching itself will only be as effective as the relationship between the coach and teacher. There has to be honesty grounded in caring. For a simple illustration, let's return for a moment to Anthony Rizzo. If his relationship with the batting coach did not have honesty but did have caring, the coach may be so 
worried about Rizzo's feelings that he wouldn't tell him what he was doing wrong. He would focus instead on making him feel good. Would Rizzo improve? No. Now, consider that the relationship had honesty, but didn't care. That might be a step better, because at least Rizzo would be getting honest information on how to improve, but I'd wager a guess he wouldn't listen to the coach very long, and a new one may be in place before the end of a season. Any effective coaching relationship has to have a balance of honesty and genuine caring. Kim Scott, former leader at Apple and Google and co-founder of Candor, calls this approach Radical Candor, and her 2017 book of the same title illustrates how to balance caring personally and challenging directly (Scott, 2017). Too much caring without enough honesty lands you in what she coins "ruinous empathy"(p. 32). Conversely, caring too little with too much challenging lands you in “obnoxious aggression"(p. 25). Scott's suggestion is to genuinely care about the people you are coaching or leading, and then to directly challenge them. Both factors need to be present in order for successful growth to occur. Again, this is something that takes time, and as a busy school leader, I am sure that is the one resource you crave more than all others, but let me suggest that without this critical relationship, fostering a culture of growth will be slow or nonexistent.

How can someone challenge directly without damaging the caring personally requirement of candor? Especially if the feedback you have to give is not flattering? Scott (2017) suggests inviting feedback. Creating a culture of feedback is crucial to creating a growth-mindset school community. If you want your teachers to be open to feedback, to use the evaluation process as an opportunity to improve, you need to model that by first inviting feedback. Table 8 includes eleven strategies for initiating a move toward that type of culture, adapted into a reflective action template (Scott, 2017). 
With your team, read each action step and then describe current practice. Culminate your discussion with collaborative goal-setting in relation to where your organization needs to grow. 
Table 8

Tool for Improving Feedback

\begin{tabular}{|c|c|c|}
\hline Action Step (Scott, 2016) & $\begin{array}{l}\text { Reflection on Current } \\
\text { Application }\end{array}$ & Concrete Step for Growth \\
\hline $\begin{array}{l}\text { 1. Develop a question } \\
\text { designed to solicit feedback } \\
\text { you are comfortable asking. } \\
\text { (e.g.; "Give me some } \\
\text { advice.") }\end{array}$ & & \\
\hline $\begin{array}{l}\text { 2. Employ wait time. (Scott } \\
\text { calls this, "Embrace the } \\
\text { discomfort" and suggests if } \\
\text { the person cannot comment, to } \\
\text { tell them you will follow up } \\
\text { for an answer tomorrow. Then } \\
\text { follow up. }\end{array}$ & & \\
\hline $\begin{array}{l}\text { 3. "Listen with the intent to } \\
\text { understand, not respond." } \\
\text { Using active listening } \\
\text { strategies help validate you } \\
\text { have heard them. }\end{array}$ & & \\
\hline $\begin{array}{l}\text { 4. Show you appreciate the } \\
\text { feedback, even if you do not } \\
\text { agree. Even better, if it's good, } \\
\text { apply it visibly. }\end{array}$ & & \\
\hline
\end{tabular}

6. Criticize yourself publically, or point out areas you need to work on.

7. Call out body language that sends a message teachers may be uncomfortable to verbalize.

8. Show it is okay to be wrong

9. Show that you care.

10. Don't change your style What is your style?

11. Find "theatrical" ways to encourage teachers to give you

feedback about your work or

the school's overall

effectiveness. 
Showing you are a leader who expects feedback will be an important step in creating a culture of feedback. It also will begin to take some of the edge off evaluation processes, as they will not be the only way employees see feedback distributed. Still, regardless of how growthoriented you are, opening your door to scrutiny and inviting in critical feedback can be nervewracking. Even if the person coming in to watch is your best friend who has seen you at your worst, you are still encouraging someone to watch you for what you need to fix. Inherently, many people find this unnerving. It is a natural tendency to believe if something needs fixed, it must have been "bad" or "ineffective", and often too many of those types of labels find their way into internalizing. Describing many "Bad" and "ineffective" practices can quickly morph into labeling "bad" or "ineffective" teachers. That personalization, or fear of that personalization, is where much of the angst related to teacher evaluation begins, and truly, those types of labels are exactly what get us into trouble. To consider things categorically in a dichotomous way can become dangerous, because the process ends with the label. That is fixed-thinking at its finest.

Instead of looking for what is "good" or "bad," a collaborative understanding of effective practices in contrast with current practices help a collective identification of areas for improvement. A Growth-Mindset School Community will create a culture to push through that so each time the door to criticism is opened, it becomes less scary. As feedback for improvement becomes the norm, the self-doubt and need to prove rather than improve will decrease.

\section{Receiving Feedback Effectively}

Receiving feedback can be tricky, as well. Teachers, in order to get the most from your evaluation, feedback must resonate and be applied. But research suggests receiving feedback can present major challenges, causing managers to avoid those challenging conversations 
altogether. In fact $64 \%$ of senior human resources executives cited managers' inability or unwillingness to have difficult feedback discussions as their larges management challenge (Heen \& Stone, 2014). Why would that be? Perhaps it is in the ability to give feedback, and we have addressed strategies for improving that half of the equation. Could the difficulty also be attributed to the way feedback is received? In their article "Find the Coaching in Criticism" (2014), Sheila Heen and Douglas Stone suggest receiving feedback "strikes at the tension between two core human needs - the need to learn and grow, and the need to be accepted just the way you are" (p. 1). It is with acknowledgement of that dichotomy they present suggestions to the person receiving feedback. So teachers and administrators on the receiving end of evaluative feedback, this section is for you. First, they suggest you manage your feelings through three lenses: truth triggers, relationships triggers, or identity triggers. Truth triggers are related to the content of the feedback. Does the assessment seem way off base? Inaccurate? Perhaps the feedback is that you did not ask questions of everyone equally, when you typically do so. Or, maybe, it's about behavior management, and your class was simply squirrely today because there was an assembly at 2:00. Or it could be that you think the evaluator has an unclear picture of your actual performance because their feedback is based on such a small sampling of your work. Unpack your feelings when the content of the feedback seems off-base, and then search for the nuggets of truth to consider.

Relationship triggers are based on your impression of the person providing the feedback. Typically, this comes up when you feel like the person giving you feedback has no experience in your position. Or, you might reject the information because you feel so hurt that the person isn't putting more stock into your relationship and all the extra things you have done for that person. 
Either way, the content of the feedback is ignored because of your impression of or relationship with the person giving the feedback.

Finally, sometimes feedback strikes a personal nerve. If it causes you to reconsider a deeply-held belief about your personality (I'm so friendly!) or abilities (I can get any kid to learn double digit multiplication!), the feedback can hurt. Often, in this case the personal injury takes center stage with your emotions instead of the content of the feedback. (Maybe I am nicer to children from affluent families - I need to monitor that.; or, Wow! My style of teaching is not clicking with those two kids. How else can I present double-digit multiplication?) Going into feedback sessions with the awareness that these three types of triggers may be set off can help you acknowledge your feelings and then set them aside long enough to consider the validity of the feedback.

In addition to considering triggers, Heen \& Stone offer six steps for filtering feedback for growth (2014). Those steps are listed in the chart below, with a space for you to do some reflecting. Getting better at receiving feedback makes you better at giving it. Students need effective feedback as much as teachers do. And truly, at the heart of a growth-mindset school community is honest and open feedback for improvement built on a culture of genuinely caring relationships.

Feedback Filter: Use Table 9, adapted from Heen \& Stone's "Find the Coaching in Criticism" (2014) to think about how you respond to feedback from your evaluator. Then, prior to any evaluation conference, consider these triggers. A blank copy, with additional formatting, is in Appendix H. 
Table 9

Feedback Trigger Analysis

Date of Feedback Conference:

\begin{tabular}{lll}
\hline Trigger Consideration & $\begin{array}{l}\text { Before Feedback: What do I } \\
\text { need to think about before this } \\
\text { feedback conference? }\end{array}$ & $\begin{array}{l}\text { After Feedback: How might } \\
\text { this trigger be interfering with } \\
\text { a growth message I need to } \\
\text { hear? }\end{array}$ \\
\hline
\end{tabular}

1. What "truth triggers" may I

be disposed to with my

evaluator?

2. What relationship triggers

might taint my openness to

this person's feedback?

3. How do I identity myself as

a teacher? If I receive

feedback in conflict with that

identity, how can I look for

truth?

Feedback Filter

Before Feedback Conference: what do I need to consider in relation to this strategy before my feedback conference?
After Feedback Conference: How did I respond in the conference, and/or how can I apply this strategy?

\section{PATTERN: How do I}

typically respond to feedback?

(Defensively,

argumentatively, passively,

emotionally)

2. RELATIONSHIP: How can

I sort out the "what" from the

"who"? What do I need to set

aside about the person who

will be giving me feedback so

I can listen for growth-

opportunities?

3. SORT: How do I typically

listen to feedback - as

judgement or coaching?

4. UNPACK: Ask for specifics instead of politely nodding. What specific action

should I take to improve that

area?

5. REQUEST: Instead of 


\begin{tabular}{lll}
\hline Trigger Consideration & $\begin{array}{l}\text { Before Feedback: What do I } \\
\text { need to think about before this } \\
\text { feedback conference? }\end{array}$ & $\begin{array}{l}\text { After Feedback: How might } \\
\text { this trigger be interfering with } \\
\text { a growth message I need to } \\
\text { hear? }\end{array}$ \\
\hline $\begin{array}{l}\text { waiting for your evaluation for } \\
\text { the lone source of feedback, } \\
\text { seek it frequently in small } \\
\text { doses from many people. }\end{array}$ \\
$\begin{array}{l}\text { How can you, or have you, } \\
\text { incorporated feedback into } \\
\text { your general practice? } \\
\text { 6. EXPERIMENT: What } \\
\text { small steps can you take to } \\
\text { improve, based on previous or } \\
\text { current feedback? }\end{array}$ \\
\hline
\end{tabular}

\section{What Can You Do?}

If you are an administrator, choose your words about the evaluation process intentionally. Focus on the coaching and feedback cycle, while acknowledging that there is a final "rating" assigned. You cannot ignore the dichotomy of coach and evaluator, but you can emphasize your purpose. If you do not intentionally address this, you will unintentionally remain a judge, and the first evaluation scenario will be more frequent than not.

In relation to this, something that has worked well for our team was to emphasize that when we spend our time and energy on growth and improvement, much of the other stuff in the evaluation takes care of itself. Now, please don't misunderstand me to mean that you should turn a blind eye to everything else. Oh, no. Just because someone is working to improve does not mean they can violate work rules, or have a three-ring circus in their classroom. Nope, nope, nope. Rather, I'm suggesting that you provide an intentional emphasis on everyone's need to grow and improve, and directly state that the purpose of the evaluation cycle is just that - a formalized process to help each teacher grow and improve. It's basically differentiated professional development. Over time, emphasizing that the evaluation is a vehicle for finding 
and implementing a focus for improvement, not just a place to earn a rating, will illustrate your commitment to serving as a coach, not just a judge. Essentially, this first strategy is developing and articulating a clear vision for evaluation.

If your school is a closed-door culture and does not have much internal feedback in place, begin simply! Invite teachers to self-select a peer coach. Give them each two days to spend over the course of the year observing each other for feedback. Do not overly structure this process at the beginning; the purpose of this is to begin increasing comfort with having someone observe practice and then give feedback. Also, remember Kim Scott's advice about seeking feedback before giving it (2017). When your employees see you value feedback enough to invite it about your own performance, your school's culture will begin to shift.

Another strategy is to start with one characteristic of effective instruction. As a staff, or in a leadership team, depending on your faculty size, select, discuss and study this characteristic. Maybe it's questioning, perhaps it's independent practice, or maybe it's feedback - whatever you choose, find something clearly observable with a load of evidence supporting effective practices in relation to it. Use the following process to communicate not only about the practice, but that you value growth and shared understanding. In addition to elevating teaching practices on the topic you've selected, these principles will also lay the groundwork for collaborative, growthoriented leadership. Figure 6 will assist with this process. 
Figure 6. Developing Targeted Feedback

\begin{tabular}{|c|c|c|}
\hline Action & Step & \\
\hline & Read & about the characteristic \\
\hline & $\begin{array}{l}\text { Deve } \\
\text { brain }\end{array}$ & $\begin{array}{l}\text { lop a shared definition of the characteristic. This could be done by } \\
\text { storming the following: }\end{array}$ \\
\hline & & Bullet points to describe effective implementation of the characteristic \\
\hline & & $\begin{array}{l}\text { Bullet points to describe classroom "Look Fors" in relation to the } \\
\text { characteristic }\end{array}$ \\
\hline & $\begin{array}{l}\text { Facil } \\
\text { videc } \\
\text { cond }\end{array}$ & $\begin{array}{l}\text { tate a viewing of prepared classroom footage with your team. This can be a } \\
\text { of a volunteer team member, or you can ask someone to video you } \\
\text { icting a demonstration lesson }\end{array}$ \\
\hline & & Ask staff to notate examples or non-examples of the "Look Fors" \\
\hline & & Press pause at selected intervals to pull out certain discussion points \\
\hline & & $\begin{array}{l}\text { At the end of the viewing, ask team members to prepare growth-oriented } \\
\text { feedback. }\end{array}$ \\
\hline
\end{tabular}

\section{For Further Consideration}

1. Everyone is evaluated. If you are a building administrator, how do you approach your evaluation? What shifts can you make to ensure you are seeking growth, not affirmation?

2. Culture of Candor: At the beginning of this chapter, I noted the relational requirement necessary for growth-oriented evaluation processes. What, if anything, needs to change in your relationships with staff in order for this evaluation shift to occur? 


\section{CHAPTER VIII: LEADERSHIP FOR A GROWTH-ORIENTED CULTURE}

"Never doubt that a small group of thoughtful, committed citizens can change the world."

-Margaret Mead

As an undergraduate teaching candidate, we heard horror stories of teacher's lounges, full of derogatory comments, and we pictured black holes of negativity, certain to suck us in. Wideeyed, we shook our head in youthful disdain, imagining the type of school that would have teachers who dared say such things. Fifteen years and six school districts later, I have yet to find a school without some form of those comments. Often off-handed, teachers don't always save these comments for the teachers' lounge. In classrooms, hallways, during passing periods, during meetings - anytime people interact, opinions and feelings are shared. If teachers do not understand the power of their expectations, the power of labels, than a conspiratorial eye roll accompanied with "He's so slow!" may be written off as simple venting. But a growth mindset school community will ask how those off-handed, perhaps innocently-intended comments perpetuate implicit bias. How do they affect schools? How do they affect kids?

Unequivocally, expectations of self and others impact behaviors. Those behaviors impact performance and create a trajectory for success. Utilizing growth-oriented mindsets and heightening awareness of the cultural-construction of ability over genetic disposition, paired with the ongoing reflective practice of examining expectations may assist educational practices in becoming more equitably sound.

This is the heart of why growth-oriented leadership must exist.

What is the Purpose of School Leadership?

I envision schools as living, pulsing organisms. Full of life, they take on the character of the individuals leading them, so it makes sense that the values, thoughts, and resulting actions of 
those individuals are important. What they value, the school and its classrooms will value. What they expect, so shall the school (Carlone et al, 2011). If you are reading this, you are somehow interested in the efficacy of education, so I will take the liberty of assuming we agree that within every school, every child has the right to learn and grow. But do they all learn and grow? All of them? If not, why? Which ones do? Could it have something to do with the causal commentary reflective of our expectations and beliefs about ability?

This writing should have helped school leaders understand how notions of ability are limiting and flawed, what they have to do with expectations, why those are important, and how to change attitudes and beliefs when they do not benefit learners. Sections one and two presented the position that notions of ability are constructed and they matter in terms of our expectations - first, in classrooms, and secondly, through systems. The logical question to consider next is: What is a school leader to do when confronted with misplaced notions of ability or a culture of low-expectations? This section will explore what kind of leadership can help change a school culture. When paired with an understanding of the sections on ability and expectations, an informed leader has a powerful opportunity to improve opportunities for all children.

Remember Mrs. Farable? We've been with her through her first job, her first evaluation, and now she's ready to move into a formal leadership role. Take a look.

Ten years after Mrs. Farable's meeting with Marilee, she assumes her first administrative position in a district far, far away. Armed with beliefs about high expectations for all and empowering teachers, she is shocked when the school she enters espouses similar beliefs but engages in practices that are not reflective of that ideology. As a first-year administrator, she is faced with some important decisions. Is this contradiction worth 
illuminating? If so, how? What role does she have in influencing the school culture? Should she tell people how she thinks things should be done? Should she lead by example? Write memos? Or should she just move in quietly and assimilate?

Leadership is different than change, and notions of ability are not as simply manipulated as lunch schedules. Because of this, today's school leader must be equipped with a variety of tools. Bolstered by some of the leading research in the field, this section seeks to find commonalities in leadership guidance, filtered through the lens of growth mindset in order to offer guidance in leading lasting change for the benefit of students. It is important to note, however, that each of these leadership and change theories are only ideas and guidelines until put into the context of an organization. "A book can introduce you to a new domain, but it is only by opening up your own experiences and those of others that new possibilities can be embraced and enacted" (Hargreaves \& Fullan, 2012). The people with whom you partner and the community you learn within will help make these ideas come to life.

When I first came to my current school, I have shared with you that I followed a very effective, strongly organized principal who had opened the school ten years prior. I had to learn the hidden rules of a culture in which I was a foreigner. I needed to get to know the people with whom I would be living, working, and growing. I could not simply sweep in with a change agenda, based solely on my ideas and reading. I wrote that as if it were a ludicrous notion, and according to my beliefs about leadership, it is. Yet don't many new leaders do just that? Equipped with a new title and a bag of background knowledge, maybe topped with a charge from their boss, they come in and proclaim change on day one.

Here is where I urge caution: If you try to change without fully understanding your context, you are making assumptions. Not only are you making assumptions about the learning 
community, but you are also making assumptions about the people. I believe a learning organization is made of systems and people. In order to lead effective change, you need to fully understand the systems, and you need to develop a relationship based on understanding with the people. The reason it's impossible to come in with an accurate change agenda on day one is because it is highly unlikely the depth of understanding necessary to articulate the appropriate growth targets is in place.

Now, did I come to my school with ideas about leadership? Absolutely. Did I come with ideas about what makes a school great? Certainly. I wouldn't be a candidate for school leadership if I didn't have background knowledge on what makes an effective school. Nor would I be ready to lead if I hadn't considered and articulated my personal vision for school leadership. But none of that matters a bit until you understand a context. Without a school home, ideas stay abstract. Research remains words on a page. How on Earth could I possibly know exactly what my school needed until I knew my school?

My Superintendent has often said, "Change occurs one conversation at a time" (Lilly, personal correspondence). It might be easy in the context of a book written about changing the culture of a school community to think the change he is talking about is external, that you should have conversations to change others. But I think that interpretation is too limited. Yes, of course, the conversations you have and ideas you share about ability and mindset will change people. But through the conversations necessary for developing a deep understanding of your context, your ideas about what the school community needs will also change. Your ideas of who you are leading will change. And you know what? That's awesome. It's awesome because it's meaningful growth. Change is a form of growth, and when it is authentic and shared, it is meaningful. 
With that in mind, the work of the scholars presented in this section is intended to give you a wide range of options. These are all amazingly brilliant writers, thinkers, and doers. Fill your toolbox with their notions so when you feel fully equipped with a solid understanding of your organization and people, you will know which option best fits your context. In some ways, we used a little of each, and a more in-depth table is presented at the end of the chapter to illustrate how. Figure 7 is intended to show which of the options best fit our context, once I had taken the time to fully understand the context.

Specifically, in Motion Leadership, Fullan (2010) describes the importance of peer interaction as well as learning as the work. In our context, a social media framework promoted ongoing interaction fused with collaborative learning about growth mindset and its application in our school. Understanding Hargreaves \& Fullan's frame of Professional Capital (2012) helped our leadership team emphasize the time and trust required for this type of shift. This project is now four years in the making, and each step has further solidified the trust necessary for avoiding contrived collegiality and fully knowing each other. Similarly, Hargreaves \& Shirley’s work in The Fourth Way (2009), specifically, their seven principles of sustainable leadership, were important in developing tenants of endurance. Each person in the school was eventually touched by the concentric circles, and that related to their notions of depth and breadth, all concepts that were gleaned from that work. Adaptive Leadership became increasingly important as we realized our learning was not just growth mindset, but how broadening our notions of ability allowed us to think adaptively about all the frames within a school touched by expanding ideas about growth. Therefore, clearly diagnosing the system, mobilizing the system, seeing ourselves as the system, and eventually deploying ourselves as agents of adaptive change pulled a thread of adaptability throughout our work (Heifetz, et al, 2009). Perhaps most instrumental in 
our unique model of leadership for change was Constructivist Leadership (Lambert, et al, 2002). Understanding constructivism is the primary basis of learning for children, adults, and organizations, and pairing that with learning as the work, we used our team to construct new meaning and understanding together as we read, discussed, applied, observed, reflected, surveyed, and listened. That work continues to adapt our model of leadership, but it is done through construction of meaning. It is also done in a distributed manner (Spillane, 2006). Distribution of leadership was the other largest contributor to our development of change agency. Specifically, the notion of leader-plus, articulating that leadership is more than what individuals in formal leadership positions do, is exactly how the work of our team was effective. Sharing learning created a natural desire to change and improve notions of ability. Each person involved in the learning became a leader, thereby naturally distributing the lift of shifting our school culture toward a growth mindset frame. The final element of Humble Inquiry was evident in practice, as we view mistakes as opportunities, we slow down and reflect, and we take time to ask questions that assist with understanding (Schein, 2013). This element was more practical, related to our approach, while many of the others were more guiding principles.

Again, this frame is intended to illustrate how many leadership theories and concepts can be used as influencers in the development of the model most relevant to your context. Figure 7 is an illustration of the contributions from many theorists, also outlined in Table 10. All of those ideas resulted in our own model, which is illustrated in Figure 1 on page 7, and named Distributed Growth Leadership. 
Figure 7. Guiding Principles of Leadership for Change

Motion Leadership

(Fullan, 2010)

Distributed Leadership
(Spillane, J. 2006)

Humble Inquiry

(Schein, 2013)

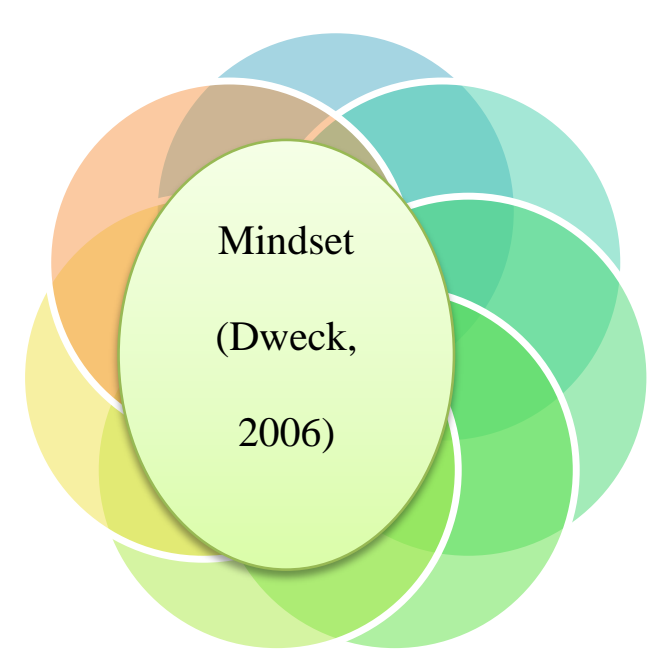

Professional Capital (Hargreaves\& Fullan, 2012)

The Fourth Way (Hargreaves \& Shirley, 2009)
Constructivist Leadership (Lambert, L. et al, 2002)
Adaptive Leadership (Heifeitz et al, 2009)

A leader with a fixed mindset will not enact much positive change. If Mrs. Farable entered her school, wrung her hands, and accepted the fate of the building as fixed, no improvement would be made. In an era of accountability and school improvement planning, it stands to reason that most school administrators understand business-as-usual is not an effective management style, nor is it an effective strategy for effectively serving students. Certainly, viewing the school as a complex system with many individuals, holding many differing levels of fixed or growth mindset would be an appropriate starting point for how much growth and change the school itself can endure. The first assessment, however, should be within the school leader, with the awareness that having a growth mindset alone is not enough. Only when paired with 
corresponding practices will growth mindset spread. What types of behaviors would a growthoriented leader demonstrate? Let me explain how these models contributed to the right combination.

It should come as no surprise that I think after successfully reflecting on the leader's personal capacity for growth and openness to change, the next most important step is building relationships and carefully listening to the humans who make the organization. Through "humble inquiry" and "seeking first to understand" the school leader gains a better understanding of current practices and beliefs, without making decisions based on assumptive thinking (Schein, 2013; Covey, 2004). Pursuing understanding is similar to the process of diagnosing the challenge accurately. As important as building relationships is the skill of carefully diagnosing the adaptive challenges and political landscapes in which the challenges exist. Analysis of the conversations and insights gained through humble inquiry may reveal the specific adaptive challenge the school is facing. Are there limiting beliefs about one type of student? From where do those beliefs originate? Are there low expectations for one group of students? Careful analysis of the historical and political landscape and the context of the challenge is also imperative before any action steps are discussed or collaboratively developed (Heifetz et al, 2009).

The diagnostic process should not be rushed in an effort to enact change for students; certainly, without taking the time to understand the actual challenge, the parts of the system, and the individuals who will be part of the movement, the change will not be clearly framed, nor will it occur successfully (Heifetz, et al, 2009). Carefully asking instead of telling will lead to greater understanding of an accurate, not assumptive starting point. It will also create a relationship of 
trust and "social glue", based on the leader's genuine desire to understand the team's members and the organization's fears (Fullan, 2010).

In their book, The Fourth Way, Hargreaves and Shirley describe an ongoing project called The Mindful Teacher (2009). Through the project, the teachers developed seven synergies of mindful teaching, including open mindedness, caring and loving, stopping (reflecting), professional expertise, authentic alignment of the teacher's pedagogy with his or her values, integration, and collective responsibilities. We encourage many of these synergies through our companion text, Glow and Grow: A Reflective Growth Journal (Hild, 2017). Reflecting on the leader's role in guiding those synergies into reality, paired with the understanding developed through humble inquiry, would give each organization its unique starting point. From that point, the leader must work with the organization to reflect on the fourth way: "...a democratic and professional path to improvement that builds from the bottom, steers from the top, and provides support and pressure from the sides...Here, teachers define and pursue high standards and shared targets, and improve by learning continuously through networks, from evidence, and from each other" (Hargreaves \& Shirley, 2009, p. 107). Pursing high standards and continuous learning are descriptors of actions within a growth mindset. The collaborative elements of the fourth way begin the development of the growth minded school community.

Once the starting point is identified, the leader can work to build leadership capacity in the organization. Investing in the professional capital of the educators in the organization through building capability, commitment, career, culture, an contexts or conditions of teaching will not only strengthen the school's overall effectiveness in serving students, it will also enhance the joy and efficacy teachers gain from their important work in the classroom and as part of a larger team (Hargreaves \& Fullan, 2012). When partnered with the topical chapters 
throughout this text - revealing beliefs, creating shared purposes for special education, reflecting on behavior management systems, and coaching through evaluation, the leader is building capacity in others in an organic, sustainable manner. These conversations become systemic change agents when they occur simultaneously, and the actionable, tangible change of procedures and tools are natural outcomes of the ongoing learning.

Sustainable change cannot be enacted on an organization the way a new schedule can be implemented. "Successful and sustainable improvement can...never be done to or even for teachers. It can only ever be achieved by and with them" (Hargreaves \& Fullen, 2012, p. 45). The type of change associated with beliefs about ability and the associated expectations must be explored through learning and reflecting, and it must be done together, especially since the type of change discussed in this work is not really change, but more of a "movement" (Hargreaves \& Fullen, 2012, p. 150). Confronting personal beliefs and values, examining entrenched practices and challenging them, and continuously renewing one's commitment to personal reflection in order to catch mindset triggers requires commitment and passion toward this movement. Rosenberg (2011) suggests the best way to change human behavior is through a type of positive peer pressure, in which teachers would gain the respect of the people they care most about through the work. As such, this work will be guided by the Professional Capital Framework for district and school leaders, but anchored by a commitment to collegial collaboration and celebration, including “pushing and pulling one's peers" (Hargreaves \& Fullan, 2012, p. 163; Rosenberg, 2011). How? The specific strategy we used was a Professional Learning Community that was a committee in the context of our building. We met in person, every month, for the duration of this work and continue up through the time of publication. In addition, the positive 
peer pressure and constant pushing and pulling continued online, through a private Facebook group we created in order to facilitate convenient, but never-ending, conversations.

In order to infuse Rosenberg's (2011) work on peer pressure and Heifetz et al's (2009) imperatives to be "on the dance floor" for the implementation and support of the change initiatives, as well as the ability to "get on the balcony" to view and assess the progress of the work, our team utilized the power of social media through the previously mentioned private Facebook page. In a very interesting way, the page allowed for ongoing commentary, the examination of artifacts and documents, as well as discourse analysis (Miles, Huberman, \& Saldana, 2014).

So much has been written on change and educational leadership. It can be interesting to cross-reference what authors believe to be most important, and it is definitely overwhelming. There are so many great ideas. There are so many excellent books. There are so many models, diagrams, steps. Where should someone begin? If you are a school leader interested in growth mindset, I would start by getting to know your context. The school community you have been hired to lead and the people who comprise it will show you want type of leadership they need. The following guiding questions may assist:

Think About It: How is my context showing me the type of leadership we need?

$\checkmark$ If you are new to your context, describe your predecessor's leadership style. If you have been in your building more than a year, describe your leadership style. This may be more challenging, because we are often blind to our own fallibility. It may be beneficial to enlist a trusted colleague to assist you with this exercise. 
- What strengths does the previous leadership style create in your school community? The following prompts should help you create a picture of context as it currently exists.

- Think carefully about the culture and climate of your building.

- Think about power structures that were intentionally or unintentionally created.

- Think about which groups of people feel most empowered, least.

- Think about how the leader spent his or her time.

- Think about what topics were most frequently discussed.

- From that picture, consider your current personal views on school community and culture. What stands to be improved? The following prompts should help you formulate a picture of improvement possibilities.

- Think about key partners and relationships.

- Think about emotions embedded within philosophies.

- Think about what you have read regarding ability.

$\checkmark$ Now, take some time to clarify what you want your leadership to mean.

$\circ \quad$ Who am I leading?

$\circ \quad$ What am I leading?

Why am I leading?

- How do I want to lead?

$\checkmark$ Finally, clarify your understanding of who you are serving.

- Who are the people in my school? In my community?

- What is important to them? 
- What long-standing values and beliefs help construct their identities?

- Who do I know well?

- Who do I need to work with to cultivate a relationship?

- What are the communication practices in my school community?

- How do we communicate with each other?

- What are the embedded expectations about communication?

- What do I like/dislike about the status quo?

- Where do I see our communication growing?

The answers to all of those questions act as funnels. If you drop all of the literature on change leadership and all of the literature on educational leadership into the top of the funnel, slowly, the answers to your questions filter out the models that do not match. Now, you may not need a model. There is nothing proclaimed anywhere that dictates school leaders use a published theory of leadership, or a copyrighted model for change. It might make it easier, though. Models are used to frame your thinking. They help in setting up a structure for what can be an overwhelming process, full of complexities. That's not to say you will follow any model perfectly, because you are leading a human organization. You must lead based on the cues your school community gives you.

With all of that considered, Table 10 is intended to show you a range of models that were helpful in guiding my thinking up to this point in our growth-mindset journey, as well as how they connected to the work we were doing as a school community. I most definitely did not use all of these models, but I did learn something and grew somehow from each. Use this table as a starting point. When you read something that intrigues you, go to the source. They will explain it better than I ever could! 
Table 10

Leadership Frames and Applications

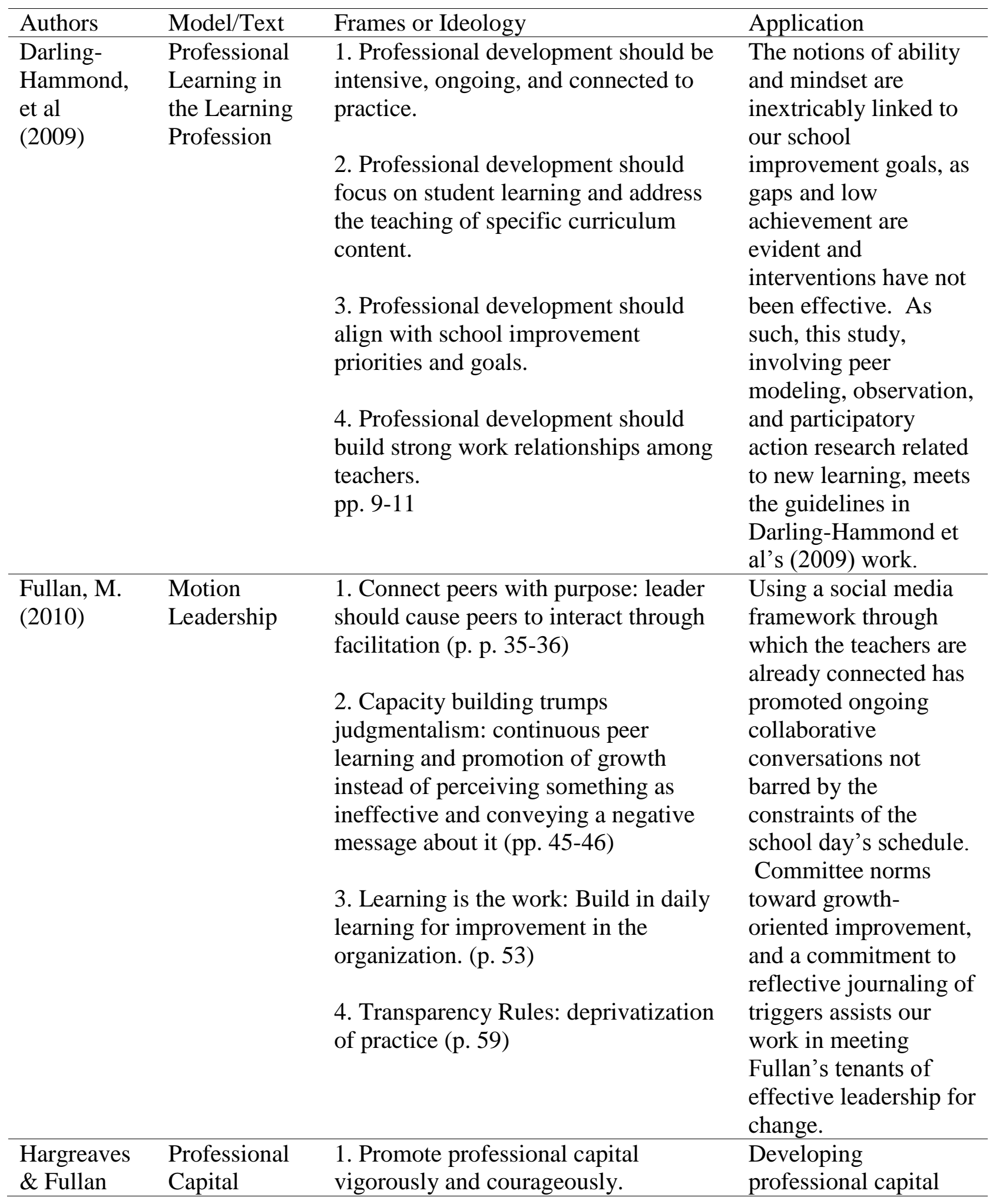

(Table Continues) 


\begin{tabular}{|c|c|c|c|}
\hline \multirow{2}{*}{$\begin{array}{l}\text { Authors } \\
(2012)\end{array}$} & Model/Text & Frames or Ideology & Application \\
\hline & & $\begin{array}{l}\text { 2. Know your people: understand their } \\
\text { culture. } \\
\text { 3. Secure leadership stability and } \\
\text { sustainability. } \\
\text { 4. Beware of contrived collegiality. } \\
\text { 5. Reach out beyond your borders. } \\
\text { 6. Be evidence-informed, not data- } \\
\text { driven. } \\
\text { (pp. } 163-172 \text { ) }\end{array}$ & $\begin{array}{l}\text { takes time and trust. } \\
\text { With that foundation, } \\
\text { this project is two } \\
\text { years in the making, } \\
\text { with the first year's } \\
\text { teachers acting as } \\
\text { mentors with the new } \\
\text { team of } 12 \text { teachers. } \\
\text { The work of both } \\
\text { teams has been } \\
\text { collaborative learning } \\
\text { about mindset and } \\
\text { evidences that speak to } \\
\text { the team as most } \\
\text { noteworthy examples } \\
\text { of fixed versus growth. }\end{array}$ \\
\hline $\begin{array}{l}\text { Hargreaves } \\
\text { \& Shirley } \\
\text { (2009) }\end{array}$ & $\begin{array}{l}\text { The Fourth } \\
\text { Way } \\
\text { (Specifically, } \\
\text { seven } \\
\text { principles of } \\
\text { sustainable } \\
\text { leadership) }\end{array}$ & $\begin{array}{l}\text { 1. Depth } \\
\text { 2. Breadth } \\
\text { 3. Endurance } \\
\text { 4. Justice } \\
\text { 5. Resourcefulness } \\
\text { 6. Conservation } \\
\text { 7. Diversity } \\
\text { (pp.97-98) }\end{array}$ & $\begin{array}{l}\text { The design of the } \\
\text { committee permits } \\
\text { endurance, as the } \\
\text { learning and work is } \\
\text { owned by our } \\
\text { collective staff, not by } \\
\text { one person. It is } \\
\text { deeply connected to } \\
\text { student outcomes that } \\
\text { matter, and those } \\
\text { outcomes relate to } \\
\text { each person in our } \\
\text { school as a } \\
\text { culminating effect of } \\
\text { our combined efforts. } \\
\text { Of primary focus is } \\
\text { our work to close } \\
\text { achievement gaps and } \\
\text { equitably serve all } \\
\text { students with the } \\
\text { shared resources and } \\
\text { ideas we have within. }\end{array}$ \\
\hline $\begin{array}{l}\text { Heifetz, et al } \\
(2009)\end{array}$ & $\begin{array}{l}\text { Adaptive } \\
\text { Leadership }\end{array}$ & $\begin{array}{l}\text { 1. Diagnose the system. (pp. 49-101) } \\
\text { 2. Mobilize the system. (pp. 113-164) } \\
\text { 3. See yourself as a system. (pp. } 181- \\
\text { 231) } \\
\text { 4. Deploy yourself. (pp. 233-298) }\end{array}$ & $\begin{array}{l}\text { The diagnostic portion } \\
\text { of adaptive leadership } \\
\text { is ongoing. While we } \\
\text { mobilize the portions } \\
\text { of the adaptive } \\
\text { challenge that bring us } \\
\text { closer together, we }\end{array}$ \\
\hline
\end{tabular}

(Table Continues) 


\begin{tabular}{|c|c|c|c|}
\hline Authors & Model/Text & Frames or Ideology & Application \\
\hline & & & $\begin{array}{l}\text { still examine deeply- } \\
\text { seated beliefs and } \\
\text { political risks guiding } \\
\text { some behaviors. } \\
\text { Effective conflicts } \\
\text { have occurred and the } \\
\text { work is better as a } \\
\text { result. We will } \\
\text { continue to monitor } \\
\text { our progress from the } \\
\text { balcony and on the } \\
\text { dance floor as we } \\
\text { move through the } \\
\text { processes of } \\
\text { observation, } \\
\text { interpretation, and } \\
\text { intervention. }\end{array}$ \\
\hline $\begin{array}{l}\text { James, E.A., } \\
\text { et al (2008) }\end{array}$ & $\begin{array}{l}\text { Participatory } \\
\text { Action } \\
\text { Research for } \\
\text { Educational } \\
\text { Leadership }\end{array}$ & $\begin{array}{l}\text { 1. Diagnose factors that contribute to } \\
\text { the status quo. } \\
\text { 2. Act with the intent of moving status } \\
\text { quo to an increased level of } \\
\text { effectiveness. } \\
\text { 3. Measure the results of actions taken } \\
\text { - work to achieve student level } \\
\text { outcomes. } \\
\text { 4. Reflect on the process and } \\
\text { brainstorm situation and additional } \\
\text { steps with others. } \\
\text { (p. } 16 \text { ) }\end{array}$ & $\begin{array}{l}\text { Although not } \\
\text { technically a } \\
\text { leadership or change } \\
\text { theory, the model of } \\
\text { participatory action } \\
\text { research propelled the } \\
\text { early shared work of } \\
\text { the organization and } \\
\text { brought together many } \\
\text { of the tenants } \\
\text { highlighted with other } \\
\text { researchers' work on } \\
\text { leadership for change. } \\
\text { We used something } \\
\text { similar when we used } \\
\text { the Brainology } \\
\text { Curriculum and } \\
\text { monitored mindset } \\
\text { beliefs and behaviors. }\end{array}$ \\
\hline $\begin{array}{l}\text { Jansen, J. } \\
\text { (2009) }\end{array}$ & $\begin{array}{l}\text { Educational } \\
\text { change in } \\
\text { radically } \\
\text { divided } \\
\text { communities. }\end{array}$ & $\begin{array}{l}\text { 1. Recognize the politics of emotions } \\
\text { that energize behaviors. } \\
\text { 2. The change strategy cannot create } \\
\text { victims. } \\
\text { 3. The problem must be named and } \\
\text { confronted. }\end{array}$ & $\begin{array}{l}\text { When discussing less- } \\
\text { than-desirable results } \\
\text { related to student } \\
\text { achievement, it is } \\
\text { necessary to } \\
\text { acknowledge the } \\
\text { corresponding } \\
\text { emotions. We do this } \\
\text { through journaling and }\end{array}$ \\
\hline
\end{tabular}

(Table Continues) 


\begin{tabular}{|c|c|c|c|}
\hline Authors & Model/Text & Frames or Ideology & Application \\
\hline & & $\begin{array}{l}\text { 4. Leaders must exemplify the expected } \\
\text { standards of behavior. } \\
\text { 5. We must engage emotionally with } \\
\text { students in their world. } \\
\text { 6. Teachers and principals themselves } \\
\text { are sometimes actors. } \\
\text { 7. The environment must accommodate } \\
\text { risk. } \\
\text { (p. } 189) \text {. }\end{array}$ & $\begin{array}{l}\text { our Facebook page, } \\
\text { and we also agree to } \\
\text { focus not on fault, but } \\
\text { on solutions. The } \\
\text { team is committed to } \\
\text { understanding } \\
\text { students' passions and } \\
\text { connecting content } \\
\text { with them to engage } \\
\text { emotionally and } \\
\text { encourage grit. } \\
\text { Finally, we are all } \\
\text { taking risks and } \\
\text { abiding by "Failure is } \\
\text { only failure if we stop } \\
\text { reflecting and } \\
\text { adjusting for } \\
\text { improvement." }\end{array}$ \\
\hline $\begin{array}{l}\text { Lambert, L. } \\
\text { et al } \\
\text { (2002) }\end{array}$ & $\begin{array}{l}\text { Constructivist } \\
\text { Leadership }\end{array}$ & $\begin{array}{l}\text { 1. The lives of children and adults are } \\
\text { inextricably intertwined. } \\
\text { 2. Constructivism is the primary basis } \\
\text { of learning for children, adults, and } \\
\text { organizations. } \\
\text { 3. Communities that encourage the } \\
\text { growth of human potential are based on } \\
\text { the principles of ecology. } \\
\text { 4. Patterns of relationship form the } \\
\text { primary bases for human growth and } \\
\text { development. } \\
\text { 5. Diversity provides complexity, } \\
\text { depth, multiple perspectives, and equity } \\
\text { to relationships, thereby extending } \\
\text { human and societal possibilities. } \\
\text { 6. Leadership as critical social and } \\
\text { intellectual transformation is achieved } \\
\text { through reciprocal, purposeful learning } \\
\text { in community. } \\
\text { pp. xvi-xvii }\end{array}$ & $\begin{array}{l}\text { This model is the heart } \\
\text { of our work. We are } \\
\text { constructing new } \\
\text { meaning and } \\
\text { understanding together } \\
\text { as we read, discuss, } \\
\text { apply, observe, reflect, } \\
\text { survey, listen, and } \\
\text { learn. An intentional } \\
\text { Devil's Advocate } \\
\text { pushes our thinking, } \\
\text { and the acknowledged } \\
\text { power role in the } \\
\text { principal's position is } \\
\text { attempted to be } \\
\text { lessened by the } \\
\text { encouragement to } \\
\text { challenge } \\
\text { presuppositions and } \\
\text { suggestions. }\end{array}$ \\
\hline $\begin{array}{l}\text { Rost, J.C. } \\
\text { (1991) }\end{array}$ & $\begin{array}{l}\text { Essential } \\
\text { Elements of } \\
\text { Leadership }\end{array}$ & $\begin{array}{l}\text { 1. The relationship is based on } \\
\text { influence. } \\
\text { 2. Leaders and followers are in the } \\
\text { relationship. } \\
\text { 3. Leaders and followers intend real } \\
\text { change. } \\
\text { 4. Leaders and followers develop }\end{array}$ & $\begin{array}{l}\text { Participants } \\
\text { acknowledge that our } \\
\text { ideas and thoughts will } \\
\text { influence one another, } \\
\text { just as our work } \\
\text { influences children. } \\
\text { We intend to utilize }\end{array}$ \\
\hline
\end{tabular}

(Table Continues) 


\begin{tabular}{|c|c|c|c|}
\hline Authors & Model/Text & Frames or Ideology & Application \\
\hline & & $\begin{array}{l}\text { mutual purposes. } \\
\text { (pp. 102-103) }\end{array}$ & $\begin{array}{l}\text { our learning and } \\
\text { thinking as a catalyst } \\
\text { for change in our } \\
\text { classrooms and } \\
\text { through our school } \\
\text { culture. }\end{array}$ \\
\hline $\begin{array}{l}\text { Schein } \\
(2013)\end{array}$ & $\begin{array}{l}\text { Humble } \\
\text { Inquiry } \\
\text { (Specifically, } \\
\text { decrease } \\
\text { learning } \\
\text { anxiety) }\end{array}$ & $\begin{array}{l}\text { 1. Slow down and vary the pace. } \\
\text { 2. Reflect more and ask yourself } \\
\text { humble inquiry questions. } \\
\text { 3. Become more mindful. } \\
\text { 4. Try innovating and engage the artist } \\
\text { within you. } \\
\text { 5. Review and reflect on your own } \\
\text { behavior after an event. } \\
\text { 6. Become sensitive to coordination } \\
\text { needs in your work. } \\
\text { 7. As a leader, build relationships with } \\
\text { your team members. } \\
\text { 8. Build cultural islands. }\end{array}$ & $\begin{array}{l}\text { The team has a general } \\
\text { outline for work to } \\
\text { accomplish; however, } \\
\text { this work will ebb and } \\
\text { flow as dictated by the } \\
\text { progress we make. In } \\
\text { an ongoing way, we } \\
\text { are humbly reflecting } \\
\text { through our journals, } \\
\text { we are incorporating } \\
\text { art through Beautiful } \\
\text { Oops and visual } \\
\text { documentation of } \\
\text { "smartness", and we } \\
\text { are meeting socially as } \\
\text { well as professionally. } \\
\text { Most importantly, we } \\
\text { are asking questions to } \\
\text { understand. }\end{array}$ \\
\hline $\begin{array}{l}\text { Spillane, } \\
\text { J.P. (2006) }\end{array}$ & $\begin{array}{l}\text { Distributed } \\
\text { Leadership }\end{array}$ & $\begin{array}{l}\text { - Leader-Plus: Leadership is more } \\
\text { than what individuals in formal } \\
\text { leadership positions do, whether } \\
\text { through assignment or personal } \\
\text { initiative. } \\
\text { - Leadership Practice: analysis of } \\
\text { interactions of leaders, followers, } \\
\text { and situations over a period of time. } \\
\text { pp. } 12 \text { - } 14\end{array}$ & $\begin{array}{l}\text { The team structure } \\
\text { assists the distribution } \\
\text { of leadership, and as } \\
\text { we add new } \\
\text { mentor/mentee teams } \\
\text { each year, the leader- } \\
\text { plus component will } \\
\text { continue to grow. } \\
\text { Additionally, as more } \\
\text { individuals are added } \\
\text { and participate, the } \\
\text { ongoing interactions } \\
\text { between staff and } \\
\text { situations will be } \\
\text { influenced by the } \\
\text { learning. }\end{array}$ \\
\hline $\begin{array}{l}\text { Senge, et al } \\
(2000)\end{array}$ & $\begin{array}{l}\text { The Fifth } \\
\text { Discipline }\end{array}$ & $\begin{array}{l}\text { - Personal Mastery: articulating a } \\
\text { personal mission in comparison } \\
\text { with current reality. } \\
\text { - } \quad \text { Mental Models: reflection and }\end{array}$ & $\begin{array}{l}\text { Growth mindset } \\
\text { begins with an } \\
\text { understanding of your } \\
\text { patterns of behaviors }\end{array}$ \\
\hline
\end{tabular}

(Table Continues) 


\begin{tabular}{|c|c|c|c|}
\hline Authors & Model/Text & Frames or Ideology & Application \\
\hline & & $\begin{array}{l}\text { inquiry to discover current } \\
\text { attitudes and beliefs of the people } \\
\text { around you. } \\
\text { - Shared Vision: Establishment of a } \\
\text { shared purpose } \\
\text { - Team Learning: Through dialogue } \\
\text { and discussion, small groups } \\
\text { transform their thinking through } \\
\text { learning that is greater than it } \\
\text { would be individually. } \\
\text { - Systems Thinking: developing an } \\
\text { understanding of interdependency } \\
\text { and how actions impact others } \\
\text { (pp. 7-8) }\end{array}$ & $\begin{array}{l}\text { and acknowledging } \\
\text { where you would like } \\
\text { to grow. From there, } \\
\text { the team will develop } \\
\text { shared vision about } \\
\text { our school, develop } \\
\text { trust so mental models } \\
\text { and barriers can be } \\
\text { authentically } \\
\text { discussed, and harness } \\
\text { the power of personal } \\
\text { and electronic } \\
\text { discussion to propel } \\
\text { our learning and } \\
\text { understanding of our } \\
\text { interconnectedness } \\
\text { and the ways our } \\
\text { shared practices } \\
\text { impact the school } \\
\text { system and its } \\
\text { students. }\end{array}$ \\
\hline $\begin{array}{l}\text { Rosenberg } \\
\text { (2011) }\end{array}$ & $\begin{array}{l}\text { Join the Club: } \\
\text { How Peer } \\
\text { Pressure Can } \\
\text { Transform the } \\
\text { World }\end{array}$ & $\begin{array}{l}\text { "The need for individuals to belong to } \\
\text { something greater than themselves and } \\
\text { to do something that would transform } \\
\text { society for the better." (in Hargreaves } \\
\text { \& Fullan, 2012, p. 8) }\end{array}$ & $\begin{array}{l}\text { In } 2014 \text {, this started } \\
\text { with a small team of } \\
\text { individuals. In 2015- } \\
\text { 2016, fourteen } \\
\text { additional members } \\
\text { participated. } \\
\text { (Table Continues) } \\
\text { In 2016-2017, twelve } \\
\text { additional staff } \\
\text { members participated. } \\
\text { In } 2017-2018 \text {, eight } \\
\text { more joined our } \\
\text { learning. As our } \\
\text { shared understanding } \\
\text { grows, the need for } \\
\text { others to participate } \\
\text { and join an important } \\
\text { movement for } \\
\text { assisting student } \\
\text { growth will also grow. }\end{array}$ \\
\hline
\end{tabular}




\section{CHAPTER IX: CHRONOLOGY}

Are you a list person? I am. I make a list to start each day, and at the end of the day, I write myself a quick reflection note in the Glow and Grow Reflective Growth Journal. I don't begin to know the psychology behind list-making, but for whatever reason, it feels good for me to visually see what I've accomplished and to check things off. I also enjoy going back in my journal to see progress and remember the small things that make up life but are so quickly forgotten if not recorded. This chapter is written for those of you who may have some of those same tendencies. Listing, charting, organizing, visually displaying - it's all wrapped up in a nice, chronological package for you. But before we dive into this list, I need to ask you to please use it carefully. I am not suggesting you attempt to implement this timeline. If you read the leadership chapter, you know that won't work. This timeline's purpose is not to dictate your specific course of action, but rather to guide your thinking and offer a suggested path that you can improve upon, tailor for your context, and perfect for your needs.

Within this three-year scope, many paradigms have shifted. Many relationships have strengthened. Many kids have been impacted. I am proud of our school because I am proud of the people in it. Even when it is hard, when we are challenging deeply-held beliefs and longstanding traditions, the people in our school community are committed to doing what is best for kids. Through the growing pains associated with shifting mindsets, we have celebrated successes, laughed and shared joyful stories, and cried tears of happiness when kids rise even beyond incredibly high expectations. We have work to do still, certainly. But we know that growth is in the work, we know we can do it together, and we know our community benefits. 
Table 11

Chronology of Shift

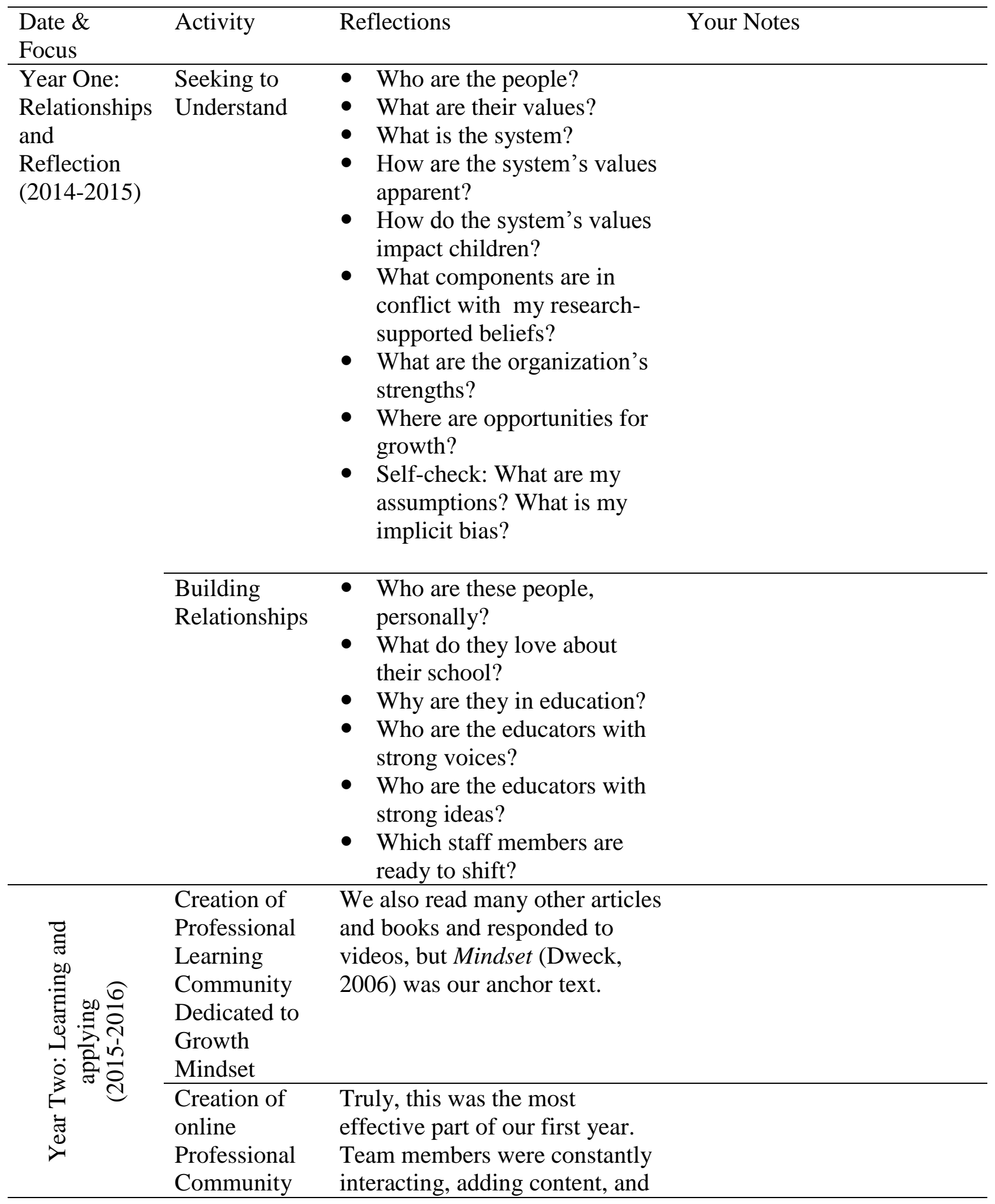

(Table Continues) 


\begin{tabular}{|c|c|c|}
\hline $\begin{array}{l}\text { Date \& } \\
\text { Focus }\end{array}$ & Activity & Reflections \\
\hline & & $\begin{array}{l}\text { conversing around notions of } \\
\text { ability. }\end{array}$ \\
\hline & $\begin{array}{l}\text { Share learning } \\
\text { experiences }\end{array}$ & $\begin{array}{l}\text { Self-check: My ideas needed to } \\
\text { change along with the people I } \\
\text { was leading. }\end{array}$ \\
\hline & $\begin{array}{l}\text { Revision of } \\
\text { Mission and } \\
\text { vision } \\
\text { statements }\end{array}$ & $\begin{array}{l}\text { At the end of the year, we used } \\
\text { our learning to guide the } \\
\text { development of a new mission } \\
\text { and vision inclusive of expanded } \\
\text { notions of ability and the } \\
\text { importance of growth. }\end{array}$ \\
\hline & $\begin{array}{l}\text { Application of } \\
\text { growth } \\
\text { mindset and } \\
\text { notions of } \\
\text { ability to } \\
\text { academic } \\
\text { interventions }\end{array}$ & $\begin{array}{l}\text { Progress monitoring took on a } \\
\text { new meaning and purpose. }\end{array}$ \\
\hline & $\begin{array}{l}\text { Visual } \\
\text { Messaging } \\
\text { Audit }\end{array}$ & $\begin{array}{l}\text { Team members and students } \\
\text { took pictures of things that sent } \\
\text { a message about our beliefs, and } \\
\text { the team made recommendations } \\
\text { for a shift. This began a visual } \\
\text { messaging project that focused } \\
\text { on students engaged in joyful } \\
\text { growth. }\end{array}$ \\
\hline & $\begin{array}{l}\text { Application to } \\
\text { teacher } \\
\text { evaluation } \\
\text { processes, } \\
\text { forms, and } \\
\text { approaches }\end{array}$ & $\begin{array}{l}\text { Some of this was a lucky } \\
\text { alignment with a change in state } \\
\text { law to include student data in the } \\
\text { teacher evaluation process. Our } \\
\text { work with Mindset (Dweck, } \\
\text { 2006) impacted our team's plan } \\
\text { to focus on individualized } \\
\text { student growth targets, and our } \\
\text { work on ability also impacted } \\
\text { the exclusionary criteria } \\
\text { discussion. }\end{array}$ \\
\hline \multirow{2}{*}{ 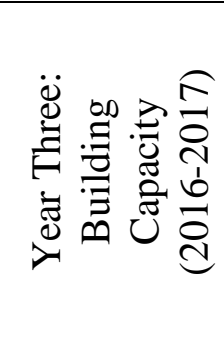 } & $\begin{array}{l}\text { Invite new } \\
\text { members into } \\
\text { the Mindset } \\
\text { PLC }\end{array}$ & \\
\hline & $\begin{array}{l}\text { Expanded } \\
\text { book studies }\end{array}$ & $\begin{array}{l}\text { We added trade books for } \\
\text { classroom use, in addition to } \\
\text { Mindset for the Classroom }\end{array}$ \\
\hline
\end{tabular}

(Table Continues) 


\begin{tabular}{|c|c|c|}
\hline $\begin{array}{l}\text { Date \& } \\
\text { Focus }\end{array}$ & Activity & Reflections \\
\hline & & $\begin{array}{l}\text { (Ricci, 2013) and The Growth } \\
\text { Mindset Coach (Brock \& } \\
\text { Hundley, 2016). }\end{array}$ \\
\hline & $\begin{array}{l}\text { Creation of a } \\
\text { student } \\
\text { leadership } \\
\text { team }\end{array}$ & $\begin{array}{l}5^{\text {th }} \text { Graders created lessons for } \\
\text { students in KDG }-4^{\text {th }} \text { grades } \\
\text { about the brain and growth } \\
\text { mindset. They presented at both } \\
\text { elementary schools. }\end{array}$ \\
\hline & $\begin{array}{l}\text { Inclusion of } \\
\text { Brainology } \\
\text { curriculum for } \\
\text { student } \\
\text { leaders }\end{array}$ & $\begin{array}{l}5^{\text {th }} \text { Grade leaders completed an } \\
\text { online Brainology course and } \\
\text { created materials to share with } \\
\text { families and students. }\end{array}$ \\
\hline & $\begin{array}{l}\text { Expansion of } \\
\text { message to } \\
\text { family nights }\end{array}$ & $\begin{array}{l}\text { At Open House, student leaders } \\
\text { disseminated literature they } \\
\text { created regarding growth } \\
\text { mindset. We also handed out } \\
\text { copies of the book. (Note: } \\
\text { Throughout the year, teachers } \\
\text { offered copies of the text to } \\
\text { parents, as well.) }\end{array}$ \\
\hline & $\begin{array}{l}\text { Application of } \\
\text { concepts to } \\
\text { grading } \\
\text { practices }\end{array}$ & $\begin{array}{l}\text { In a district-wide initiative } \\
\text { dedicated to the purpose of } \\
\text { grades, we discussed opening } \\
\text { gradebook deadlines for mastery } \\
\text { grading and separating academic } \\
\text { behaviors (effort, deadlines, etc.) } \\
\text { from academic content reports. } \\
\text { These processes are ongoing. }\end{array}$ \\
\hline \multirow{3}{*}{ 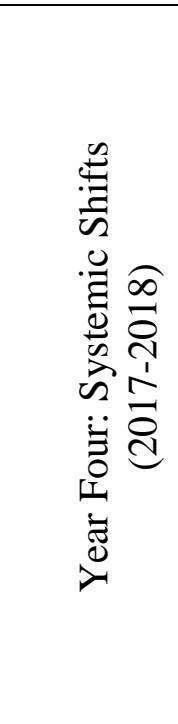 } & $\begin{array}{l}\text { Expansion of } \\
\text { Mindset study } \\
\text { with new } \\
\text { members }\end{array}$ & $\begin{array}{l}\text { The Facebook group now } \\
\text { includes all prior and new } \\
\text { members of the team. }\end{array}$ \\
\hline & $\begin{array}{l}\text { New hires are } \\
\text { given a } \\
\text { reading guide } \\
\text { for Mindset }\end{array}$ & $\begin{array}{l}\text { Along with a welcome packet, } \\
\text { the text is included as an } \\
\text { optional read. We invite new } \\
\text { staff members to participate on } \\
\text { the leadership team after getting } \\
\text { accustomed to the building in } \\
\text { year one, reflective of the } \\
\text { leadership model of } \\
\text { relationships and reflections } \\
\text { coming before content change. }\end{array}$ \\
\hline & Shift in & We expanded our options for \\
\hline
\end{tabular}

(Table Continues) 


\begin{tabular}{|c|c|c|c|}
\hline $\begin{array}{l}\text { Date \& } \\
\text { Focus }\end{array}$ & Activity & Reflections & Your Notes \\
\hline & $\begin{array}{l}\text { special } \\
\text { education } \\
\text { service } \\
\text { delivery } \\
\text { model }\end{array}$ & $\begin{array}{l}\text { students requiring specialized } \\
\text { instruction. The self-contained } \\
\text { classrooms could be available } \\
\text { for students whose goals } \\
\text { indicate separate placement, but } \\
\text { we increased the range of time } \\
\text { available for alternative } \\
\text { classrooms instead of having it } \\
\text { as an either all-day, or only } \\
\text { resource. This shift was } \\
\text { designed and proposed by } \\
\text { teachers who were part of the } \\
\text { Mindset PLC. }\end{array}$ & \\
\hline & $\begin{array}{l}\text { Paradigm } \\
\text { shift related to } \\
\text { purpose of } \\
\text { interventions }\end{array}$ & $\begin{array}{l}\text { This was easier with academics } \\
\text { than it was behaviors. The } \\
\text { conversations were led by our } \\
\text { school psychologist and school } \\
\text { social worker, both of whom had } \\
\text { served on the Mindset team. } \\
\text { This influence stretched beyond } \\
\text { the walls of our school and } \\
\text { started important systemic } \\
\text { conversations district-wide. }\end{array}$ & \\
\hline
\end{tabular}

What has been the effect of this work? What tangible changes have occurred? How does our school look different now than it did in 2014? To begin with, the idea of growth mindset has become part of who we are. It isn't as topical, but more infused. For example, rather than referencing Mindset, we now ask students to reflect on their mindset. Because orientation materials and procedures have been impacted by the thinking, learning, and growth, parents and students accept that the expectation here is growth. That may seem like a subtle change, but it is truly the foundational change that impacts all of the details.

Additionally, I see a change in teachers' perceptions of their leadership roles. In 2014, teachers wanted me to tell and direct. In 2018, teachers are sharing articles to push each other's thinking. Most recently, at a discipline committee meeting, a teacher asked about strategies for 
confronting implicit bias. That conversation would have never happened prior to this systemic shift, grounded in shared learning and growth experiences. In weekly collaboration, I observe educators encouraging each other to monitor and provide feedback on growth - both for students and themselves. Systems and structures are being developed by collaborative groups instead of The Principal, and what is being created is student-focused with the purpose for growth. I have had a front row seat to watch leadership distribute, and the ideas of many are much better and more powerful than the ideas of one.

Our work is ongoing. In 2018-2019, I anticipate our student leadership continuing to grow, along with including the last few staff members in the Mindset study group. In 20192020, my role in the district will shift to the Director of Student Services. I love my school and the people in it. I am deeply invested in the work we have done and will continue to do. I also believe through the deep relationships a principal fosters with students, staff, and family members, significant, important, and lasting change can occur. Being a principal is an important honor, it is humbling, hard, and so incredibly rewarding. So my heart breaks at the thought of leaving. On the flip side, in a district capacity, I can have the opportunity to expand this learning to more leaders, teachers, families, and students. When I think about my mission as an educator, it truly is to help expand notions of ability so all children have an opportunity to succeed without limits. In a district role, I can more widely cast that net, and for that, I am extremely grateful and excited.

This seems like an appropriate time to roll credits, but the interesting thing about growth is that there is never an end. This story will continue as long as educators committed to the growth of their students are fortunate enough to serve the education community. As long as 
educators like you are committed to challenging notions of ability, expanding traditionally valued traits, and leading with heart, there is no such thing as The End. 


\section{CHAPTER X: CONCLUSION}

Notions of ability are cultural constructions that can have real effects on opportunities and outcomes for students. Setting aside the need for labeling, sorting, and classifying children, and instead focusing on growth and improvement from whatever the starting point can harness the power of effective teaching and learning. An awareness of our beliefs and behaviors related to mindsets, whether naturally fixed- or growth-oriented, can not only assist improved student outcomes, but also enrich our lives as adult learners, educators, and people.

Perhaps most powerful is the learning organization who commits to challenging traditional notions of ability and a culture of low expectations to take the journey of growth together. Leadership for sustained, meaningful, student-centered change on a systemic level can have large, important, and lasting effects on student lives.

Reflecting on the leader's role in cultivating a growth-mindset school community, your work really boils down to three questions that should guide your conversations and decisions:

1) How do we think about ability in schools?

2) Why are these beliefs, or expectations, important?; and

3) How does an organization created a shared culture of high, growth-oriented expectations for all?

Use the work in this text. Let it help you guide a careful examination of hearts and minds to reveal beliefs about ability, to facilitate intentional decisions about actions related to expectations, and then to collaboratively improve opportunities for all children within your learning community. 


\section{End Note}

Fern Arable is a young girl in E.B. White's Charlotte Web. When faced with the fact her father intended to kill the runt of a new pig litter because of his size, she stood up to the injustice of such a large decision based on the one defining characteristic of the piglet: His size. Fern saw more than the "runt" of the litter; she saw more than his size. Fern saw possibility. She saw life and the potential for greatness, even though Wilbur didn't meet the entrance expectations of her father's farm.

You see, in a way, size was the farm's ability grouping, its IQ test, or its entrance exam simply a cultural construction in the context of the farm, and widely accepted by most farmers. It was a notion of ability, a lens through which most farmers viewed capacity. But Fern chose not to use that lens. She was divergent from the cultural discourse of the farm. Because she, Ms. Farable, questioned traditionally-accepted notions, Wilbur didn't create a self-identity of smallness. Rather, he became met Zuckerman's Famous Pig. Not only that, but his life allowed Charlotte created her magnum opis, and even the rat, Templeton, rose to serve others. How many lives are impacted when we see only what culture allows us to see? Fern saw more in Wilbur, and because of that, he was more.

So who is Ms. Farable? Or, rather, Ms. F.Arable?

Farable is you. She is me. She is any one of us who is willing to step away from culturally-constructed notions of ability in order to focus instead on the possibility of growth.

Principal Farable greets a new teacher who has just entered the school ready to set up her new classroom. Eager to get started and to do her absolute best, the teacher asks Mrs. Farable her input on the students listed on the roster the secretary just handed her. Mrs. Farable smiles. Then she says, "I don't need to see the list to tell you a thing or two about the students in your 
class. I can tell you their potential will only be limited by expectations that limit them. I can tell you their experiences will define their learning. I can tell you that how much they achieve-and really, how much you achieve - will be defined by the way you handle successes and adversities together this year, all of which are opportunities for growth. So my advice? Take risks. Have high expectations. Provide empathetic coaching. Connect to their passions. And monitor yourself to avoid the pitfalls of fixed thinking.

"I want you to focus on getting to know those amazing individuals on your roster. I want you to push them to see the greatness inside themselves they cannot yet see. I want you to make them great, and make them grow. For when they succeed, so do we." 


\section{REFERENCES}

Aronson, J., Fried, C.B. \& Good, C. (2002) Reducing the effects of stereotype threat on African American college students by shaping theories of intelligence. Journal of Experimental Social Psychology, 38(2), 113-125.

Artiles, A. (2011) Toward an interdisciplinary understanding of educational equity and difference: The case of the racialization of ability. Educational Researcher, 40(9), 431 445.

Babad, Inbar, \& Rosenthal. (1982). Pygmalion, Galatea, and the Golem: Investigations of biased and unbiased teachers. Journal of Educational Psychology, 74, 59-474.

Binet, A. (1916). New methods for the diagnosis of the intellectual level of subnormals. The development of intelligence in children: The Binet-Simon Scale.

Bishop, J. (2012). She's always been the smart one. I've always been the dumb one. Identities in the mathematics classroom. Journal for Research in Mathematics, 43(1), 34-74.

Blackwell, L.S., Trzensiewski, K.H., Dweck, C. (2007) Implicit theories of intelligence predict achievement across an adolescent transition: a longitudinal study and an intervention. Child Development, 78(1), 246-263.

Boaler, J. (2013). Ability and mathematics: The mindset revolution that is reshaping education. Forum, 55(1), 143-151.

Bobbitt, F. (1913). Some general principles of management applied to the problems of cityschool systems. In Bobbitt, F. The supervision of city schools. Twelfth yearbook of the national society for the study of education (pp. 7-96). Bloomington III: Public School Publishing Company. 
Bornstein, J. (2017). Entanglements of discipline, behavioral intervention, race, and disability. Journal of Cases in Educational Leadership, 20(2), 131-144.

Brookhart, S. (2011). Starting the conversation about grading. Educational Leadership, 69(3), p. $10-15$.

Carlone, H. B., Haun-Frank, J., \& Webb, A. (2011). Assessing equity beyond knowledge- and skills-based outcomes: A comparative ethnography of two fourth-grade reform-based science classrooms. Journal of Research in Science Teaching, 48(5), 459-485.

Costa, A.L. \& Kallick, B. (1995). Assessment in the learning organization: Shifting the paradigm. Alexandria, VA: ASCD.

Costello, B., Wachtel, J., and Watchel, T. (2009). The restorative practices handbook: For teachers, disciplinarians, and administrators, building a culture of community in schools. Bethlehem, PA: International Institute for Restorative Practices.

Covey, S. (1989). The seven habits of highly effective people: Powerful lessons in personal change. New York: Simon and Schuster.

Crano, W., \& Mellon, P. (1978). Causal influences of teacher's expectations on children's academic performance: A cross-lagged panel analysis. Journal of Educational Psychology, 70(1), 39-49.

Darling-Hammond, L., Wei, R., Andree, A., Richardson, N., \& Orphanos, S. (2009). Professional learning in the learning profession: A status report on teacher development in the United States and abroad. Dallas, TX: National Staff Development Council.

Darling-Hammond, L. (2010). The flat world and education: How America's commitment to equity will determine our future. New York: Teachers College Press. 
Deci, E. L. \& Ryan, R. R., eds. (2002). Handbook of self-determination research. Rochester, NY: The University of Rochester Press.

Duckworth, A. (2016). Grit: The power of passion and perseverance. New York: Scribner.

Dweck, C. (2000). Self-theories: Their role in motivation, personality, and development. Essays in Social Psychology. New York: Psychology Press.

Dweck, C. (2006). Mindset: The new psychology of success. New York: Ballantine.

Dweck, C. (2007). The perils and promise of praise. Educational Leadership, 65(2), 35-39.

Alexandria, VA: Association for Supervision and Curriculum Development.

Dweck, C. (2008). Brainology transforming students' motivation to learn. Independent School, 67(2), 100-118.

Dweck, C. (2009). Can we make our students smarter? Education Canada, 49(4), 56-61. Toronto, Ontario: Canadian Education Association.

Dweck, C. (2010a). Even geniuses work hard. Educational Leadership, 68(1), 16-20.

Alexandria, VA: Association for Supervision and Curriculum Development.

Dweck, C. (2010b). Mind-sets and equitable education. Principal Leadership, 10(5), 26-29.

Reston, VA: National Association of Secondary School Principals.

Dweck, C. (2014). The power of believing that you can improve. Retrieved from http://www/ted/talks/carol_dweck_the_power_of_believing_that_you_can_improve?lang uage $=$ en

Dweck, C. (2015, September 23). Growth mindset, revisited. Education Week, 35(5), 20-24.

Dweck, C. \& Leggett, E. (1988). A social-cognitive approach to motivation and personality. Psychological Review, 95(2), 256-273. 
Eden, D. (1990) Pygmalion in management: Productivity as a self-fulfilling prophecy. Toronto: Lexington Books.

Elashoff, J. D. \& Snow, R. E. (1971). Pygmalion reconsidered: A Case Study in Statistical Inference: Reconsideration of the Rosenthal-Jacobson Data on Teacher Expectancy. Worthington, Ohio: C.A. Jones Pub. Co.

Forget, M. (2011, July). MAX Teaching with reading and writing. Presentation at Mattoon Community Unit District 2 Train the Trainers Session in Mattoon, Illinois.

Fuchs, D., Fuchs, L.S., Mathes, P. G., Lipsey, M. W., \& Roberts, P. (2002). Is “learning disabilities" just a fancy term for low achievement? A meta-analysis of reading differences between low achievers with and without the label. In R. Bradley, L. Danielson \& D. P. Hallahan (Eds.) Identification of learning disabilities: Research to practice. The LEA series on special education and disability. (p. 737-762). Mahwah, NJ: Lawrence Erlbaum Associates.

Fullan, M. (2010). Motion leadership: The skinny on becoming change savvy. Thousand Oaks, CA: Corwin.

Garcia, S. B. \& Guerra, P. L. Deconstructing deficit thinking: Working with educators to create more equitable learning environments. Education and Urban Society, 36(2), 150-168.

Gardner, H. (2006). Multiple intelligences: New horizons. New York: Basic Books. Retrieved from http://reader.eblib.com.libproxy.lib.ilstu.edu/(S(zy2hnxood2nalcwodmcdhodo))/Reader.a spx?p=903035\&o=863\&u=eWzc\%2bvOw6zw\%3d\&t=1465846673\&h=9AACBEAB72 CD091C939374D05C34B25D8A6EB89C\&s=46063199\&ut=2787\&pg=1\&r=img\&c=$1 \& \mathrm{pat}=\mathrm{n} \& \mathrm{cms}=-1 \& \mathrm{sd}=2 \#$ 
Gladwell, M. (2013). David and Goliath: Underdogs, misfits, and the art of battling giants. New York: Back Bay Books.

Gonzales, K. (2017). An honest look at a real problem: Keeping our kids in school. Restorative Schools Vision Project. Retrieved from http://restorativeschoolsproject.org/wpcontent/uploads/2014/12/SNR_RSVPpgxx_060316r6.pdf

Good, C., Aronson, J., \& Inzlich, M. (2003) Improving adolescents'standardized test performance: an intervention to reduce the effects of stereotype threat. Applied Developmental Psychology, 24, 645-662.

Gottfredson, L. (2003). Dissecting practical intelligence theory: Its claims and its evidence. Intelligence, 31, 343-397.

Gottfredson, L.S. (2005). "Suppressing intelligence research: Hurting those we intend to help.". In Wright, R.H. and Cummings, N.A (Eds.) (PDF). Destructive trends in mental health: The well-intentioned path to harm. New York: Taylor and Francis. pp. 155-186. ISBN 0415-95086-4.

http://www.udel.edu/educ/gottfredson/reprints/2005suppressingintelligence.pdf.

Gould, S.J. (1996). The Mismeasure of Man. Revised and expanded edition. New York: W.W. Norton.

Greenstein, L. M. (2018). Restorative assessment: Strength-based practices that support all learners. Thousand Oaks, CA: Corwin.

Guskey, T. (2011). Five obstacles to grading reform. Educational Leadership, 69(3), p. 16-21.

Guskey, T. (2015). On your mark: Challenging the conventions of grading and reporting. Bloomington, IN: Solution Tree Press. 
Haberman, M. (1995). Star teachers of children in poverty. Indianapolis, IN: Kappa Delta Pi. Hargreaves, A. \& Fullan, M. (2012). Professional capital: Transforming teaching in every school. New York: Teachers College Press \& Toronto: Ontario Principals Council.

Hargreaves, A. \& Shirley, D. (2009). The fourth way: The inspiring future for educational change. Thousand Oaks, CA: Corwin

Harry, B. \& Klingner, J. (2014). Why are so many minority students in special education? Understanding race \& disability in schools. $2^{\text {nd }}$ ed. New York, NY: Teachers College Press.

Hart, B. \& Risley, T. R. (1995). Meaningful differences in the everyday experience of young American children. Baltimore, MD, US: Paul H Brookes Publishing.

Hatt, B. (2007). Street smarts vs. book smarts: The figured world of smartness in the lives of marginalized, urban youth. The Urban Review, 39(2), 145 - 166.

Hatt, B. (2012). Smartness as a cultural practice in schools. American Educational Research Journal, 49(3), 438-460.

Hattie, J. (2011). Visible learning: A synthesis of over 800 meta-analyses relating to achievement. New York: Routledge.

Heflebower, T., Hoegh, J.K., \& Warrick, P. (2014). A school leader's guide to standards-based grading. Bloomington, IN: Marzano Research.

Heifetz, R., Grashow, A., Linsky, M. (2009). Adaptive leadership: Tools and tactics for changing your organization and the world. Boston, MA: Harvard Business Review Publishing. 
Hochanadel, A., \& Finamore, D. (2015). Fixed and growth mindset in education and how grit helps students persist in the face of adversity. Journal of International Education Research, 11(1), 47-50.

Holland, D., Lachicotte, W., Skinner, D., \& Cain, C. (Eds.) (1998). Identity and agency in cultural worlds. Cambridge, MA: Harvard University Press.

Hu, W. (2009, June 14). No longer letting scores separate pupils. The New York Times, p. A15. Illinois State Board of Education. (2018). Innovation and ideas: Competency pilot. Retrieved from https://www.isbe.net/competency.

James, A. E., Milenkiewicz, M. T., Bucknam, A. (2008). Participatory action research for educational leadership: Using data-driven decision making to improve schools. Thousand Oaks, CA: Sage.

Jansen, J. (2009). When politics and emotion meet: Educational change in radically divided communities. In A. Hargreaves \& M. Fullan (Eds.), Change wars (pp. 185-200). Bloomington, IN: Solution Tree.

Jungbluth, P. (1994). Teacher expectations and ethnicity: The education and opportunities of adolescent migrants in the Netherlands. Zeitschrift fur Padagogik, 40 (1), p. 113-125.

Jussim, L. \& Fleming, C. (1996). Self-fulfilling prophecies and the maintenance of social stereotypes: the role of dyadic interactions and social forces. In Stereotypes and Stereotyping, by C. Neil Macrae, Charles Stangor, Miles Hewstone, Eds.

Knight, J. (2007). Instructional coaching: A partnership approach to improving instruction. Thousand Oaks, CA: Corwin Press. 
Knight, J., Elford, M. Hock, M., Dunekack, D., Bradley, B., Deschler, D., and Knight, D. (2015). Three steps to great coaching: A simple but powerful instructional coaching cycle nets results. $J S D, 36(1), 10-18$.

Kozol, J. (1991). Savage inequalities: Children in America's schools. New York: Crown Publishers.

Kuypers, L. (2011). The zones of regulation. Santa Clara, CA: Think Social Publishing. Lambert, L., Walker, D., Zimmerman, D.P., Cooper, J.E., Lambert, M.D., Gardner, M.E., \& Szabo, M. (2002). The constructivist leader, $2^{\text {nd }}$ ed. New York: Teachers College Press.

Lawrence, E. \& Hinds, T. (2016) From punish and discipline to repair and restore: Promoting restorative justice in the early childhood classroom. Principal, November/December 2016, p. $20-23$.

Livingston, J.S. (2009). Pygmalion in management. Boston, MA: Harvard Business School Publishing.

Lombardo, S., trans. (2010). Ovid's Metamorphes. Indianapolis, Indiana: Hackett Publishing Company.

Mackintosh, N. J. (1998). IQ and Human Intelligence. Oxford: Oxford University Press. p. 15. ISBN 978-0-19-852367-3. Lay summary (9 August 2010).

Marzano, R. (2003). What works in schools: Translating research into action. Alexandria, VA: Association for Supervision and Curriculum Development.

Marzano, R. (2011). Relative to students: It's what you do that counts. Educational Leadership, $68(6), 82-83$

Mastery Transcript Consortium. (2018). A new model. Retrieved from http://mastery.org/. 
McDermott, R., Goldman, S., \& Varenne, H. (2006). The cultural work of learning disabilities. Educational Researcher, 35(6), 12-17.

Miller, J.H. (1990). Versions of Pygmalion. Cambridge, MA: Harvard University Press.

Mraz, K. \& Hertz, C. A Mindset for learning: Teaching the traits of joyful, independent growth. Portsmouth, NH: Heinemann.

Newkirk, T. (2017). Embarrassment and the emotional underlife of learning. Portsmouth, NH: Heinemann.

Nieto, S. (1996). Affirming diversity: The sociopolitical context of multicultural education. White Plains, NY: Longman.

O’Connor, Ken (2018). How to grade for learning: Linking grades to standards, $4^{\text {th }} \mathrm{ed}$. Thousand Oaks, CA: Corwin.

O’Neil, J. (1992). On tracking and individual differences: A conversation with Jeannie Oakes. Educational Leadership, 50(2): 18-21.

Oakes, J. (1985). Keeping track: How schools structure inequality. New Haven: Yale University Press.

Oakes, J. (2005). Keeping track, $2^{\text {nd }}$ ed. New Haven, CT: Yale University Press.

Oakes, J., Ormseth, T., Bell, R., \& Camp, P. (1990). Multiplying inequalities: The effects of race, social class, and tracking on opportunities to learn mathematics and science. Santa Monica, CA: Rand.

Peters, T., \& Waterman, R. (1982). In search of excellence. New York: Harper Collins.

Raudenbush, S. W. (1984). Magnitude of teacher expectancy effects on pupil IQ as a function of the credibility of expectancy induction: A synthesis of findings from 18 experiments. Journal of Educational Psychology, 76(1), 85-97. 
Reynolds, D. (2007). Restraining Golem and harnessing Pygmalion in the classroom: A laboratory study of managerial expectations and task design. Academy of Management Learning \& Education, 6(4), 475-483.

Ricci, M.C. (2013). Mindsets in the classroom: Building a culture of success and student achievement in schools. Waco, TX: Prufrock Press.

Robbins, T. (2016). The pain of changing yourself. Retrieved from https://www.youtube.com/watch?v=ZrxMk7_YRs4

Rosenthal, R. (1991). Teacher expectancy effects: A brief update 25 years after the Pygmalion experiment. Journal of Research in Education, 1(1), 3-12.

Rosenthal, R.; Jacobson, L. (1992). Pygmalion in the classroom (Expanded ed.). New York: Irvington.

Rosenthal, R., \& Jacobson, L. (1968). Teacher expectations for the disadvantaged. Scientific American, 218, 16-23.

Rosenthal, R. \& Rubin, D. B. (1978). Interpersonal expectancy effects: The first 345 studies. Behavioral and Brain Sciences, 1(3), 377-415.

Rosenberg, T. (2011). Join the club: How peer pressure can transform the world. New York: W. W. Norton.

Rost, J. C. (1991). Leadership for the twenty-first century. Westport, CT: Praeger Publishers.

Rowe, W. G. \& O', Brien, J. (2002). The role of Golem, Pygmalion, and Galatea effects on opportunistic behavior in the classroom. Journal of Management Education, 26(6), 612628. 
Rubie-Davies, C., Hattie, J. A. C., \& Hamilton, R. (2006). Expecting the best for students: Teacher expectations and academic outcomes. British Journal of Educational Psychology, 76, 429-444.

Rubie-Davies, C. M. (2006). Teacher expectations and student self-perceptions: Exploring relationships. Psychology in the Schools, 43(5), 537-552.

Rubie-Davies, C. M. (2006). Classroom interactions: Exploring the practices of high- and lowexpectation teachers. British Journal of Educational Psychology, 77, 289-306.

Ryan, W. (1971) Blaming the victim. New York: Random House.

Sakya, B. R. (1979). Teacher expectation biases as affected by hereditary social structures in Nepal. Dissertation research, University of Southern California.

Schein, E. H. (2013). Humble inquiry: The gentle art of asking instead of telling. Oakland, CA: Berrett-Koehler.

Schmidt, M. F. H., \& Sommerville, Ja. A. (2011). Fairness expectations and altruistic sharing in 15-month-old human infants. PLoS One, 6(10).

Scholfield, J. W. (1995). Review of research on school desegregation's impact on elementary and secondary school students. In C. Darling-Hammond's The flat world and education (p. 35). New York: Teachers College Press.

Scott, K. (2017) Radical candor: How to be a kick-ass boss without losing your humanity. New York: St. Martin's Press.

Scott, K. (2016) How to get feedback from others. Available at https://www.radicalcandor.com/blog/get-feedback/ 
Senge, P., Cambron-McCabe, N., Lucas, T., Smith, B., Dutton, J. \& Kleiner, A. (2000). Schools that learn: A fifth discipline fieldbook for educators, parents, and everyone who cares about education. New York: Doubleday.

Shanker, A. (1993). Public vs. private schools. National Forum. Phi Kappa Phi Journal, 73(4), $14-17$.

Smith, Fisher, \& Frey. (2015). Better than carrots or sticks: restorative practices for positive classroom management. Alexandria, VA: Association for Supervision and Curriculum Development.

Spillane, J. P. (2006). Distributed leadership. San Francisco, CA: Jossey-Bass.

St. George, A. (1983). Teacher expectations and perceptions of Polynesian and Pakeha pupils and the relationship to classroom behavior and achievement. British Journal of Educational Psychology, 53 (1), 48-59.

Sternberg, R. J. (1985). Beyond IQ: A Triarchic Theory of Intelligence. Cambridge: Cambridge University Press.

Sternberg, R. J. (1997). A Triarchic View of Giftedness: Theory and Practice. In N. Coleangelo \& G. A. Davis (Eds.), Handbook of Gifted Education (pp. 43-53). Boston, MA: Allyn and Bacon.

Sternberg, R. (2007). Who are the bright children? The cultural context of being and acting intelligent. Educational Researcher, 36(3). 148-155.

Sun, K. L. (2014, July 9). Math can-do. USA Today. Retrieved from http://usat.ly/1mh2rKR

Sun, K. L. (2015). There's no limit: Mathematics teaching for a growth mindset (Doctoral dissertation). Retrieved from https://searchworks.stanford.edu/view/11059824 
Suttie, J. (2016, October). Four ways teachers can reduce implicit bias. Greater Good Magazine. Retrieved from https://greatergood.berkeley.edu/article/item/four_ways_teachers_can_reduce_implicit_bi as

Tauber, R. (1997). Self-fulfilling prophecy: A practical guide to its use in education. London: Praeger.

1872 March 21, Cedar Rapids Times, Religious, Quote Page 1, Column 6, Cedar Rapids, Iowa. (Newspaper Archive) (The digital image shows "Sow and act" which is likely a misprint for the common version: "Sow an act")

U.S. Department of Education Office for Civil Rights. (2014). Civil rights data collection: Data snapshot: School discipline. Available: https://www2.ed.gov/about/offices/list/ocr/docs/crdc-discipline-snapshot.pdf

Valian, V. (1998). Who so slow? The advancement of women. Cambridge, MA: The MIT Press. Valencia, R. R. (2010). Dismantling contemporary deficit thinking: Educational thought and practice. New York: Routledge.

Varlas, L. (2016). Mindset 20/20. ASCD Education Update, 58(3), 3-5.

Vatterott, C. (2009). Rethinking homework: Best practices that support diverse needs. Alexandria, VA: ASCD.

Vaughn, G. M. (1963). Racial issues in New Zealand. Auckland, New Zealand: Akarana Press. Weinstein, R.S. (2002). Reaching higher: The power of expectations in schooling. Cambridge, MA: Harvard University Press.

Weinstein, C.S., Tomlinson-Clark, S., \& Curran, M. (2004). Toward a conception of culturally responsive classroom management. Journal of Teacher Education, 55(1), 25-38. 
Weis, L. (2004). Class reunion: The remaking of the American White working class. New York, NY: Routledge.

White, E.B. (1952). Charlotte's Web. New York: Harper Collins.

Wiesel, E. (1983). The Golem: The story of a legend. New York: Summit.

Wineburg, S. S. (1987). The self-fulfillment of the self-fulfilling prophecy. Educational Researcher, 16 (9), 28-37.

Wormeli, R. (2006). Fair isn't always equal: Assessing and grading in the differentiated classroom. Portland, ME: Stenhouse Publishers.

Wormeli, R. (2011). Redos and retakes done right. Educational Leadership, 69(3), p. 22 - 27.

Yeager, D.S. \& Dweck, C.S. (2012). Mindsets that promote resilience: When students believe that personal characteristics can be developed. Educational Psychologist, 47(4), 302-314. 
APPENDIX A: ASPIRING ADMINSTRATOR BELIEFS \& VALUES ASSESSMENT

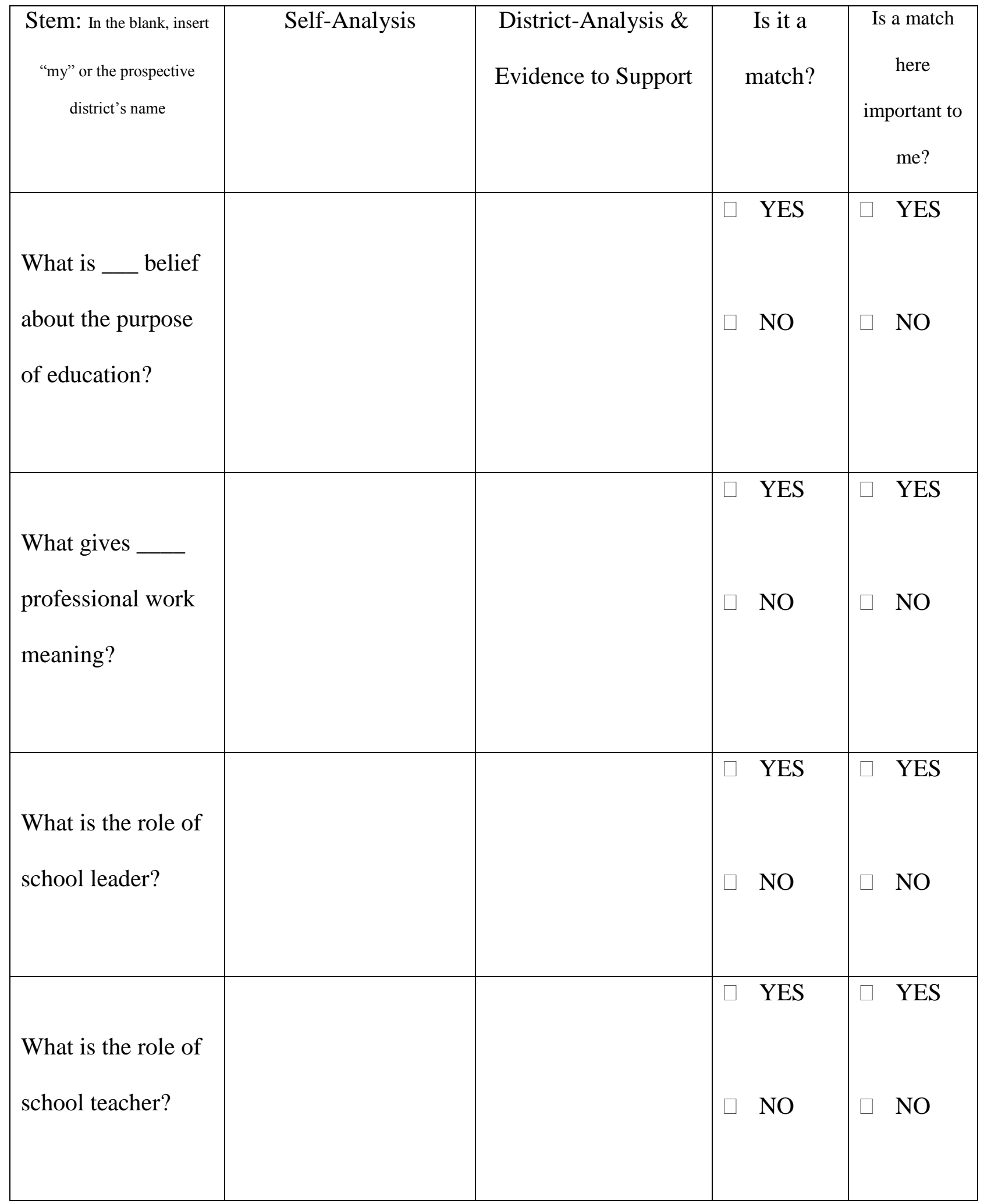




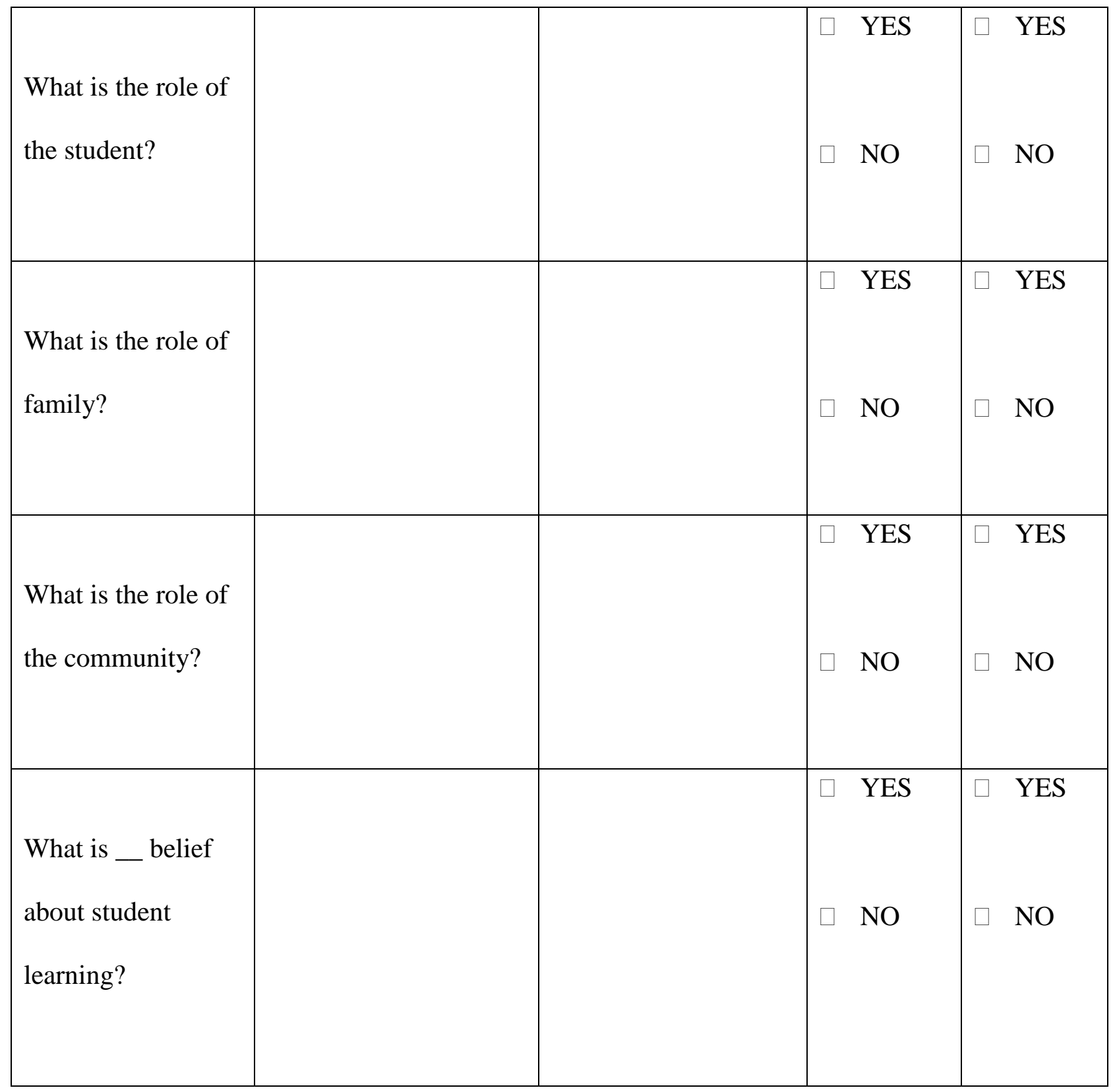

\section{THINK ABOUT IT:}

If you accept a position in this district, how will you reconcile areas that do not match?

If you accept a position in this district, how do your strengths match their needs? 


\section{APPENDIX B: ACADEMIC BEHAVIORS CHECKLIST}

This checklist was developed by a team of leaders in our school district.

\begin{tabular}{|c|c|c|c|}
\hline Work Habits & Responsibility & Respect & Notes \\
\hline $\begin{array}{l}\text { Managing Time } \\
\text { Wisely } \\
\text { K-12 When prompted, } \\
\text { the student uses time } \\
\text { given to meet } \\
\text { classroom } \\
\text { objectives/expectations }\end{array}$ & $\begin{array}{l}\text { Following Directions } \\
\text { K-12 When given } \\
\text { class expectations } \\
\text { (written and oral), the } \\
\text { student follows } \\
\text { directions. }\end{array}$ & $\begin{array}{l}\text { Respecting Others } \\
\text { K-12 Student respects } \\
\text { the rights of others to } \\
\text { learn, teach, and grow }\end{array}$ & \\
\hline $\begin{array}{l}\text { Giving Effort } \\
\text { K-12 When given a } \\
\text { task or assignment, the } \\
\text { student puts forth } \\
\text { effort to follow } \\
\text { directions, work } \\
\text { neatly, and work to the } \\
\text { best of their ability. }\end{array}$ & $\begin{array}{l}\text { Completing Tasks on } \\
\text { Time } \\
\text { K-12 When provided } \\
\text { a task or assignment, } \\
\text { the student completes } \\
\text { work on time }\end{array}$ & $\begin{array}{l}\text { Managing Behaviors } \\
\text { and Emotions } \\
\text { K-12 Student } \\
\text { identifies and } \\
\text { manages behaviors } \\
\text { and emotions }\end{array}$ & \\
\hline \multirow{2}{*}{$\begin{array}{l}\text { Perseverance } \\
\text { K-12 The student } \\
\text { utilizes their strengths } \\
\text { as a part of his/her } \\
\text { effort to overcome } \\
\text { obstacles and improve } \\
\text { upon areas of needed } \\
\text { growth by using } \\
\text { strategies that may } \\
\text { include, but not limited } \\
\text { to: making corrections, } \\
\text { retakes, or seeking out } \\
\text { external supports. }\end{array}$} & $\begin{array}{l}\text { Supplies } \\
\text { K-12 Student brings } \\
\text { necessary materials to } \\
\text { class and utilizes them } \\
\text { appropriately while } \\
\text { keeping their work } \\
\text { area neat and } \\
\text { organized }\end{array}$ & & \\
\hline & $\begin{array}{l}\text { In Attendance } \\
\text { K-12 Student } \\
\text { regularly attends class } \\
\text { for the duration }\end{array}$ & & \\
\hline \multicolumn{4}{|c|}{ Ratings for Each Indicator } \\
\hline Consistently & Sometimes & Not Yet & \\
\hline
\end{tabular}




\section{APPENDIX C: GROWTH NOTE}

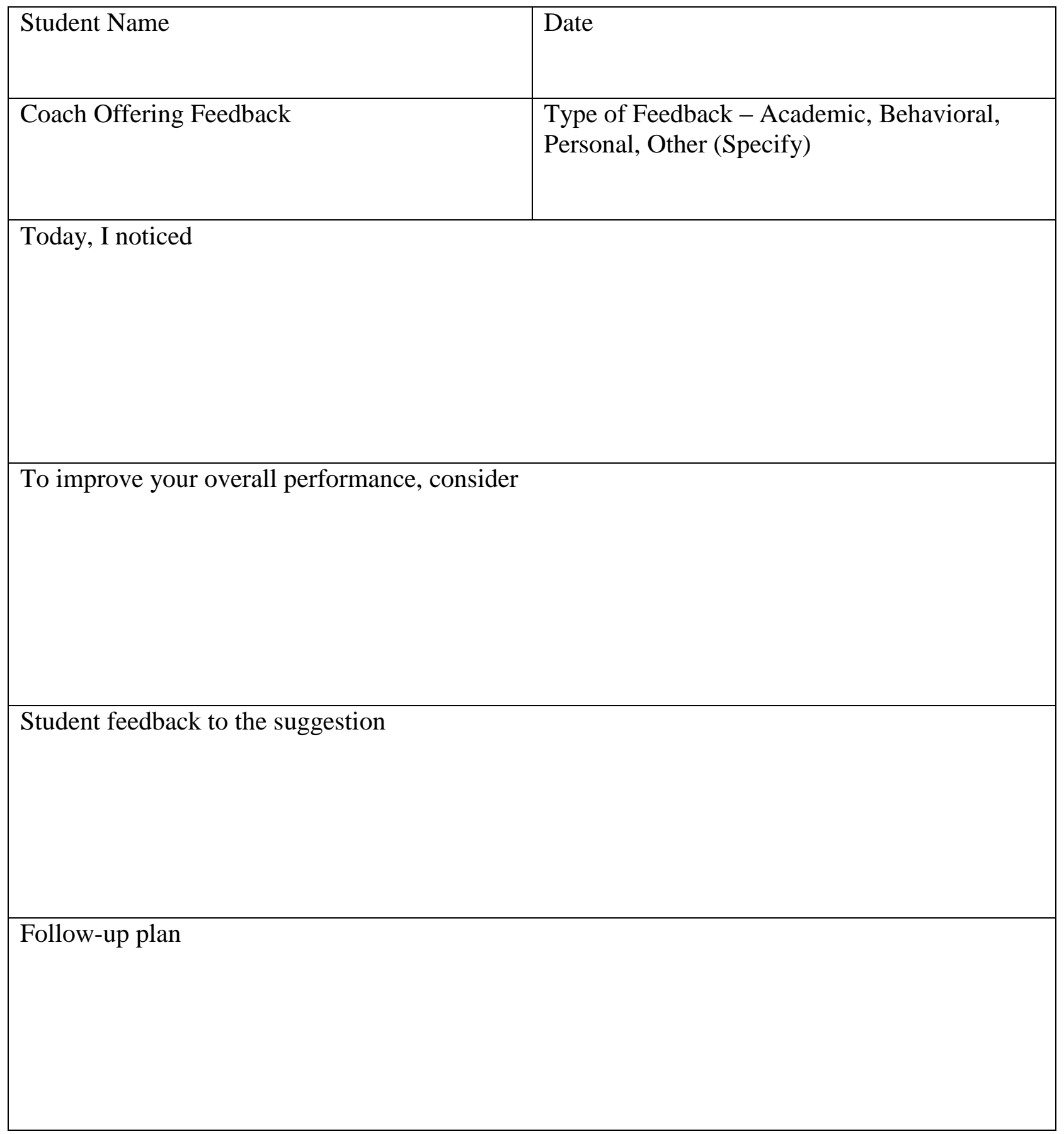




\section{APPENDIX D: DISCIPLINE REFLECTION FORMS}

PRIMARY (K-2) DOCUMENT:

Name:

Date:

1. Summarize the Event: Why are you in re-teaching today?

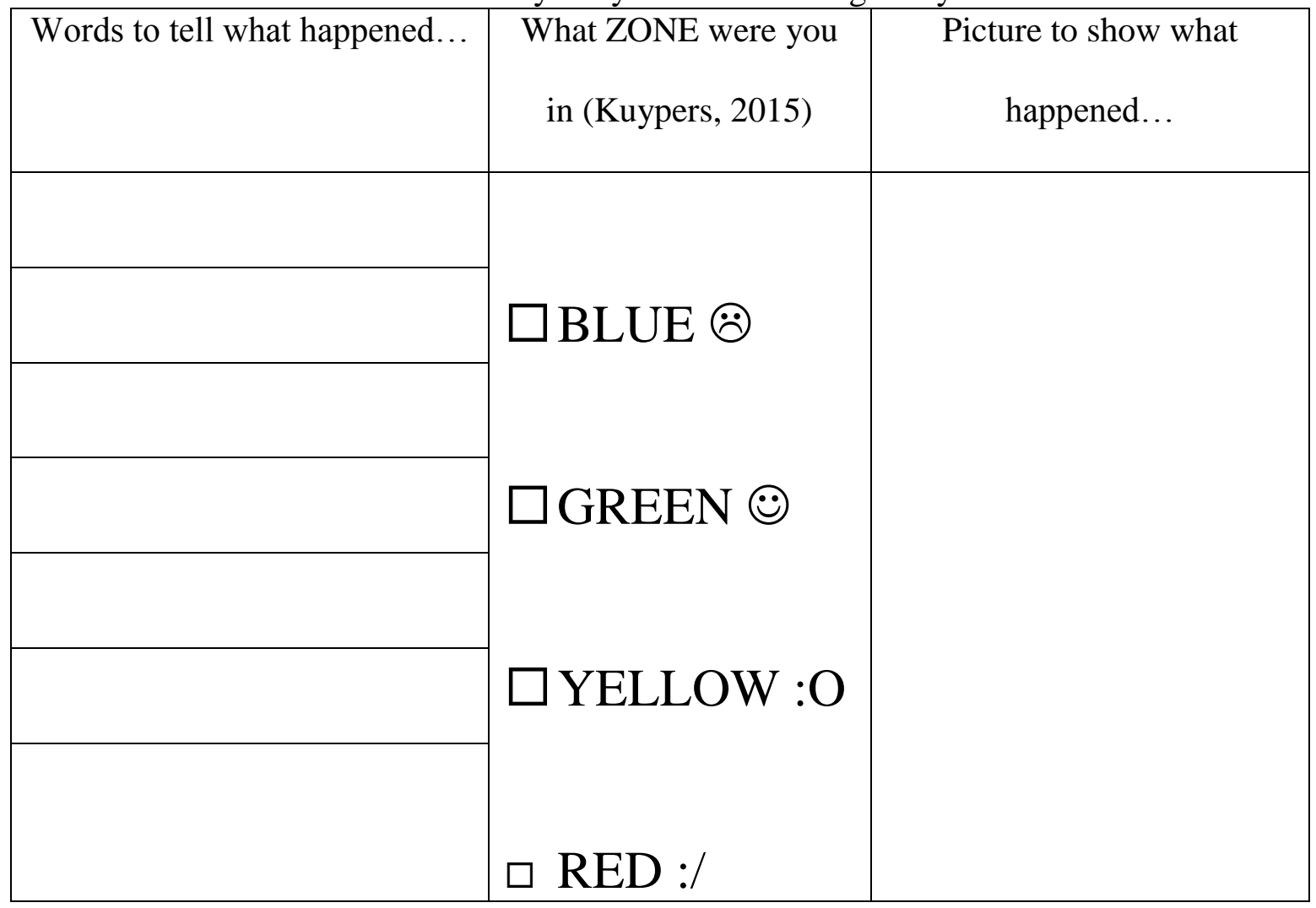

2. Revise the Ending: What would have been a better choice?

\begin{tabular}{|l|l|}
\hline Words to tell & \\
\hline & \\
\hline & \\
\hline & \\
\hline & \\
\hline & \\
\hline & \\
& \\
\hline
\end{tabular}


Write a Sequel: I can grow from this! Next time, I will:

\begin{tabular}{|l|l|}
\hline Words to tell & \\
\hline & \\
\hline & \\
\hline & \\
\hline & \\
\hline
\end{tabular}

Predict the Future: Are you ready?

\begin{tabular}{|l|l|}
\hline What ZONE are you in now? & Picture to show my plan for the rest of the \\
day: \\
$\square$ BLUE $\odot:$ & \\
$\square$ GREEN $\odot:$ & \\
$\square$ YELLOW :O & \\
$\square$ RED :/ & \\
\hline
\end{tabular}


INTERMEDIATE (3-5) DOCUMENT

Name:

Date:

Directions: Please take some time to reflect about what occurred so you are able to grow from this experience. Please use good sentence structure to put your thoughts and ideas into this reflection writing. Once your writing is completed effectively and you conference with your coach, you may join your friends and apply what you learned.

Why were you assigned a pink slip?

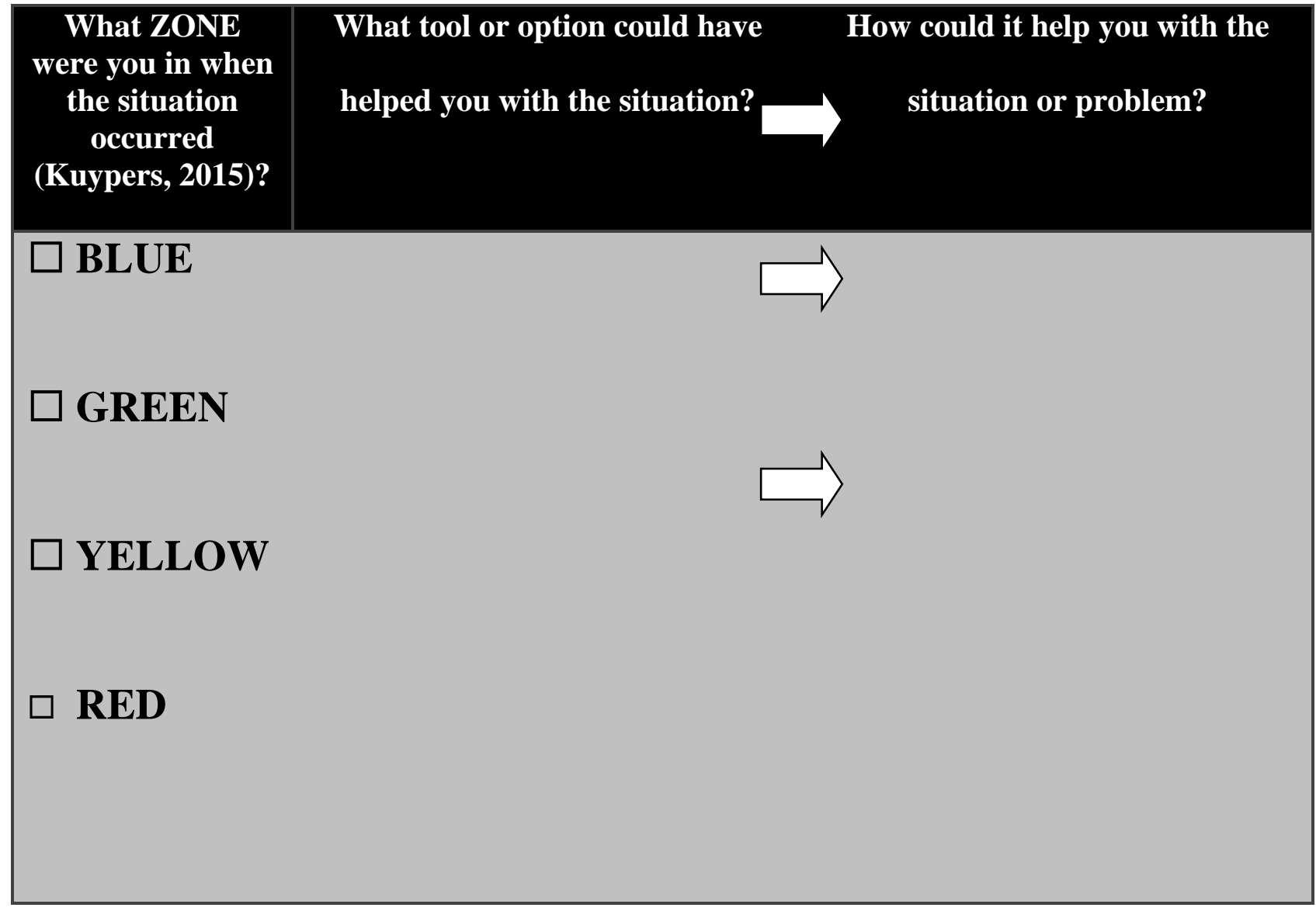


Now is your chance to make a plan to resolve and grow from this situation. Please describe your plan of action. Think about who you have affected and how you could avoid this next time.

Use signal words like first, second, and then to help your reader follow your plan.

\begin{tabular}{|l|}
\hline \\
\hline \\
\hline 2
\end{tabular}

Are you ready? What ZONE are you in, and how do you know? 


\section{APPENDIX E: RESTORATIVE QUESTIONS}

How My Choices Affect Others - Classroom Version

Today, while my teacher, , was trying to teach and my friends were trying to learn, I

The reason I did that was:

I know my choice affected others. Here is how it affected:

The other student

I bet he felt:

My teacher

I bet he/she felt: 
The rest of the students in my class

I bet they were thinking:

\section{I can learn from this and fix it.}

In order to restore my relationship with my teacher, I need to

In order to restore my relationship with the other student, I need to

In order to restore my place in our classroom community, I need to

I have grown from this experience. Here is how: 
APPENDIX F: GROWTH-ORIENTED FUNCTIONAL BEHAVIOR ASSESSMENT

\begin{tabular}{lll}
\hline Student Name & School & Teacher
\end{tabular}

Team Members Participating

\begin{tabular}{|c|c|c|c|c|c|c|c|}
\hline \multicolumn{2}{|c|}{ Environment } & \multicolumn{6}{|c|}{ Behavior } \\
\hline $\begin{array}{l}\text { Antecedent } \\
\text { What event or } \\
\text { setting takes } \\
\text { place prior to } \\
\text { the target } \\
\text { behavior? } \\
\text { What is the } \\
\text { student getting } \\
\text { from that? }\end{array}$ & $\begin{array}{l}\text { Antecedent } \\
\text { Manipulation } \\
\text { What } \\
\text { settings/context } \\
\text { s/antecedents } \\
\text { can you modify } \\
\text { to make } \\
\text { proactive } \\
\text { changes in the } \\
\text { environment to } \\
\text { make the target } \\
\text { behavior } \\
\text { unnecessary? }\end{array}$ & $\begin{array}{l}\text { Targeted } \\
\text { Behavior: } \\
\text { What } \\
\text { behavior do } \\
\text { you want to } \\
\text { improve? }\end{array}$ & $\begin{array}{l}\text { Targeted } \\
\text { Behavior } \\
\text { Benefit: } \\
\text { What adult or } \\
\text { peer behaviors } \\
\text { may be } \\
\text { encouraging } \\
\text { or reinforcing } \\
\text { this behavior? } \\
\text { Positive and } \\
\text { negative } \\
\text { consequences } \\
\text { should be } \\
\text { included. }\end{array}$ & $\begin{array}{l}\text { Replacement } \\
\text { Behavior: } \\
\text { What new } \\
\text { behaviors } \\
\text { might you } \\
\text { teach to } \\
\text { replace the } \\
\text { targeted } \\
\text { behavior? }\end{array}$ & $\begin{array}{l}\text { Replacement } \\
\text { Behavior } \\
\text { Benefit: } \\
\text { How might you } \\
\text { change the } \\
\text { adult behavior } \\
\text { regarding the } \\
\text { original } \\
\text { targeted } \\
\text { behavior and } \\
\text { the new } \\
\text { replacement } \\
\text { behavior? }\end{array}$ & $\begin{array}{l}\text { Goal } \\
\text { Behavior: } \\
\text { What do you } \\
\text { want the } \\
\text { student to do } \\
\text { instead? }\end{array}$ & $\begin{array}{l}\text { Goal } \\
\text { Behavior } \\
\text { Benefit: } \\
\text { What adult or } \\
\text { peer responses } \\
\text { or behaviors } \\
\text { will encourage } \\
\text { the goal } \\
\text { behavior? } \\
\text { What is the } \\
\text { benefit to the } \\
\text { student, and } \\
\text { how will the } \\
\text { student know? }\end{array}$ \\
\hline
\end{tabular}

Talk with the student. Does the child believe improvement is possible? What is the motivation for growth?

How will this plan be monitored?

By whom?

Start Date:

Data Review Date: 


\begin{tabular}{|lll|}
\hline Trigger Consideration & $\begin{array}{l}\text { Before Feedback: } \\
\text { What do I need to } \\
\text { think about before this } \\
\text { feedback conference? }\end{array}$ & $\begin{array}{l}\text { After Feedback: How } \\
\text { might this trigger be } \\
\text { interfering with a growth } \\
\text { message I need to hear? }\end{array}$ \\
\hline $\begin{array}{l}\text { 1. What "truth triggers" may I be } \\
\text { disposed to with my evaluator? }\end{array}$ & & \\
\hline $\begin{array}{l}\text { 2. What relationship triggers might } \\
\text { taint my openness to this person's } \\
\text { feedback? }\end{array}$ & & \\
\hline $\begin{array}{l}\text { 3. How do I identity myself as a } \\
\text { teacher? If I receive feedback in } \\
\text { conflict with that identity, how can I } \\
\text { look for truth? }\end{array}$ & & \\
\hline $\begin{array}{l}\text { Feedback Filter } \\
\text { Before Feedback }\end{array}$ & $\begin{array}{l}\text { After Feedback Conference: } \\
\text { Conference: what do I } \\
\text { need to consider in } \\
\text { relation to this strategy } \\
\text { before my feedback } \\
\text { conference? }\end{array}$ & $\begin{array}{l}\text { How did I respond in the } \\
\text { conference, and/or how can }\end{array}$ \\
\hline
\end{tabular}

1. PATTERN: How do I typically respond to feedback? (Defensively, argumentatively, passively, emotionally)

2. RELATIONSHIP: How can I sort out the "what" from the "who"? What do I need to set aside about the person who will be giving me feedback so I can listen for growth-opportunities?

3. SORT: How do I typically listen to feedback - as judgement or coaching?

4. UNPACK: Ask for specifics instead of politely nodding. What specific action should I take to improve that area?

5. REQUEST: Instead of waiting for your evaluation for the lone source of feedback, seek it frequently in small doses from many people. How can you, or have you, incorporated feedback into your general practice?

6. EXPERIMENT: What small steps can you take to improve, based on previous or current feedback? 